\title{
Nicotine Modifies Corticostriatal Plasticity and Amphetamine Rewarding Behaviors in Mice ${ }^{1,2,3}$
}

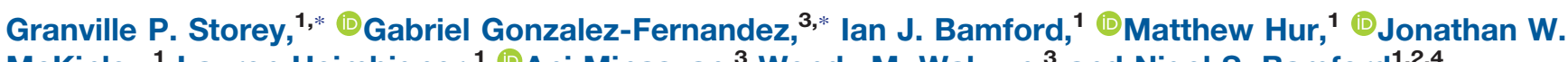
McKinley, ${ }^{1}$ Lauren Heimbigner, ${ }^{1}{ }^{\circledR}$ Ani Minasyan, ${ }^{3}$ Wendy M. Walwyn, ${ }^{3}$ and Nigel S. Bamford ${ }^{1,2,4}$

DOI:http://dx.doi.org/10.1523/ENEURO.0095-15.2015

${ }^{1}$ Department of Neurology, The Graduate Program in Neurobiology and Behavior, and Center on Human Development and Disability, University of Washington and Seattle Children's Hospital, Seattle, Washington 98105, ${ }^{2}$ Departments of Pediatrics and Psychology, the Graduate Program in Neurobiology and Behavior, and Center on Human Development and Disability, University of Washington and Seattle Children's Hospital, Seattle, Washington 98105, ${ }^{3}$ Department of Psychiatry and Biobehavioral Sciences, David Geffen School of Medicine, University of California Los Angeles, Los Angeles, California 90095, and ${ }^{4}$ Departments of Pediatrics and Neurology, Yale School of Medicine, New Haven, Connecticut 06520

\begin{abstract}
Corticostriatal signaling participates in sensitized responses to drugs of abuse, where short-term increases in dopamine availability provoke persistent, yet reversible, changes in glutamate release. Prior studies in mice show that amphetamine withdrawal promotes a chronic presynaptic depression in glutamate release, whereas an amphetamine challenge reverses this depression by potentiating corticostriatal activity in direct pathway medium spiny neurons. This synaptic plasticity promotes corticostriatal activity and locomotor sensitization through upstream changes in the activity of tonically active cholinergic interneurons (Chls). We used a model of operant drug-taking behaviors, in which mice self-administered amphetamine through an in-dwelling catheter. Mice acquired amphetamine self-administration under fixed and increasing schedules of reinforcement. Following a period of abstinence, we determined whether nicotinic acetylcholine receptors modified drug-seeking behavior and associated alterations in Chl firing and corticostriatal activity. Mice responding to conditioned reinforcement showed reduced $\mathrm{Chl}$ and corticostriatal activity ex vivo, which paradoxically increased following an amphetamine challenge. Nicotine, in a concentration that increases $\mathrm{Ca}^{2+}$ influx and desensitizes $\alpha 4 \beta 2 *$-type nicotinic receptors, reduced amphetamine-seeking behaviors following abstinence and amphetamine-induced locomotor sensitization. Nicotine blocked the depression of Chl firing and corticostriatal activity and the potentiating response to an amphetamine challenge. Together, these results demonstrate that nicotine reduces reward-associated behaviors following repeated amphetamine and modifies the changes in Chls firing and corticostriatal activity. By returning glutamatergic activity in amphetamine self-administering mice to a more stable and normalized state, nicotine limits the depression of striatal activity in withdrawal and the increase in activity following abstinence and a subsequent drug challenge.
\end{abstract}

Key words: acetylcholine; addiction; amphetamine; self-administration; sensitization; striatum; nicotine

\section{Significance Statement}

Chls exert a strong influence on striatal function, and in combination with medium spiny neurons, are key mediators of cue and drug responses to psychostimulants, such as cocaine. As Chls and corticostriatal terminals express nicotinic receptors, we used a new model of chronic psychostimulant use, amphetamine self-administration in mice, to examine the role of these receptors in modulating striatal responses to drug exposure. Nicotine activation of these receptors normalized many of the cellular and behavioral adaptations to chronic amphetamine, suggesting a novel target to offset the effects of chronic psychostimulants. 


\section{Introduction}

Psychostimulants, including amphetamine and cocaine, have a high potential for abuse as they acutely increase brain dopamine (DA) levels (Sulzer, 2011). Psychostimulants trigger long-lasting and parallel adaptations in striatal glutamate (Pierce et al., 1996; McFarland et al., 2003; Bamford et al., 2004a; Wang et al., 2013a) and acetylcholine (ACh; Bickerdike and Abercrombie, 1997, 1999), which contribute to the motor and neuropsychological symptoms of drug dependence (Kalivas, 2009).

Chronic psychostimulant use alters corticostriatal signaling (Kalivas 2009). Withdrawal induces a further adaptation by promoting a chronic presynaptic depression (CPD) in glutamate release from cortical projections within the dorsal striatum that disrupts normal DA filtering of corticostriatal activity (Bamford et al., 2008; Wang et al., 2013a). A drug challenge reverses CPD by increasing glutamate availability through a process called paradoxical presynaptic potentiation (PPP), when DA exerts an excitatory, rather than an inhibitory, effect on the corticostriatal pathway. By normalizing corticostriatal activity in withdrawal, PPP may provide a mechanism by which drug re-administration promotes physiological and behavioral stability, a feature supported in models of addiction (Ahmed and Koob, 2005).

The dorsal striatum is a key mediator of many of the reward-related behaviors. This structure is associated with the formation of compulsive drug-seeking habits (Yin et al., 2004; Everitt and Robbins, 2005, 2015), locomotor sensitization (Bamford et al., 2008), cue-dependent and reversal learning, cognitive flexibility (Quintana et al., 2012; Bertran-Gonzalez et al., 2013; Bradfield et al., 2013; Wang et al., 2013a), and sensorimotor conditioning (Aosaki et al., 1994). The changes in synaptic glutamate that occur during amphetamine withdrawal are analogous to measurements of extrasynaptic glutamate in the nucleus accumbens (NAc) that follow repeated cocaine (Pierce et al., 1996; McFarland et al., 2003). However, withdrawal from cocaine, but not amphetamine, modifies glutamater-

Received August 23, 2015; accepted December 28, 2015; First published January 13, 2016

${ }^{1}$ The authors declare no competing financial interests.

${ }^{2}$ Contributions: G.P.S., G.G.-F., M.H., J.W.M., A.M., W.M.W., and N.S.B. designed research; G.P.S., G.G.-F., A.M., W.M.W., and N.S.B. performed research; G.P.S., I.J.B., M.H., J.W.M., L.H., W.M.W., and N.S.B. analyzed data; I.J.B., W.M.W., and N.S.B. wrote the paper.

${ }^{3}$ This work was supported by HHS NIH National Institute of Neurological Diseases and Stroke (NS060803 to N.S.B.), University of Washington Alcohol and Drug Abuse Institute (ADAI-0312-4; G.P.S., N.S.B.), HHS NIH, National Institute of Child Health and Human Development (U54 HD083091 to N.S.B.), and NIDA (DA005010 to W.M.W.), and the Shirley and Stefan Hatos Foundation (W.M.W., G.F.G., A.M.). We thank Eliahu B. Bouganim and Joshua K. Hakimian for preparing the cartoon.

${ }^{*}$ G.P.S. and G.G.-F. contributed equally to this work.

Correspondence should be addressed to Dr Nigel S. Bamford, 15 York Street, PO Box 208018, New Haven, CT 06520-8064. E-Mail: nigel.bamford@yale.edu.

DOI:http://dx.doi.org/10.1523/ENEURO.0095-15.2015

Copyright @ 2016 Storey et al.

This is an open-access article distributed under the terms of the Creative Commons Attribution 4.0 International, which permits unrestricted use, distribution and reproduction in any medium provided that the original work is properly attributed. gic signaling in the ventral and dorsal striatum by upregulating postsynaptic AMPA and NMDA receptor surface expression (Nelson et al., 2009). This suggests that contributions from upstream circuitry differentially regulate corticostriatal activity following cocaine or amphetamine withdrawal.

Within the dorsal striatum, Chls play a critical role in these behaviors and contribute toward CPD and PPP (Bamford et al., 2008; Wang et al., 2013a). Through an extensive arborization network, Chls exert a strong influence on striatal information processing (Wilson et al., 1990). Although morphologically similar across striatal regions in the rodent brain (Gonzales and Smith, 2015), Chls show distinct region-specific responses to cocaine (Benhamou et al., 2014). Such heterogeneity may be a result of restricted DA and glutamate cotransmission (Chuhma et al., 2004). For example, in the dorsolateral striatum DA induces a pause in Chl firing followed by a rebound in activity. DA increases Chl activity in the NAc shell, but reduces $\mathrm{Chl}$ firing in the NAc core. A single exposure to amphetamine increases this heterogeneity across regions (Chuhma et al., 2014), suggesting that local DA release induces region-specific striatal responses.

ACh acts at nicotinic and muscarinic receptors in the striatum to regulate DA (Zhang and Sulzer, 2004), glutamate (McGehee et al., 1995), and ACh availability in a region-specific manner (Zhou et al., 2001; Threlfell and Cragg, 2011). Nicotinic receptors, through their profile of activation and desensitization, modulate the probability of DA and glutamate release to affect psychostimulantinduced reward behaviors (Hansen and Mark, 2007; Bamford et al., 2008; Wang et al., 2013a; Li et al., 2014). We propose that the Chls in the dorsolateral striatum, and their repertoire of nicotinic receptors, are a key mediator of the striatal response to amphetamine-induced DA and glutamatergic plasticity.

Using a model of contingent amphetamine exposure in mice, we have examined striatal adaptations induced by amphetamine. This model pairs single or multiple lever press with a drug infusion through an indwelling jugular catheter to generate a behavioral profile of amphetamine use. We then examined the electrophysiological profile of the effects of chronic amphetamine on the Chls in the dorsolateral striatum, an important hub of habitual drugseeking behaviors. Finally, we probed the involvement of the $\alpha 4 \beta 2 *$ - and $\alpha 7 *$-type nicotinic acetylcholine receptor subtypes in blocking the presynaptic corticostriatal plasticity induced by amphetamine.

\section{Methods}

\section{Animals}

All animal procedures were performed in accordance with the authors' university animal care committee's regulations. Experiments started when male and female C57BL/6J mice (Jackson Laboratories) were 2-3 months old and completed by 6 months. Mice were housed together in a modified specific pathogen free vivarium with a $12 \mathrm{~h}$ light/dark cycle with ad libitum access to food and water. For some mice, a catheter $(0.2 \mathrm{~mm}$ inner diameter, 
$0.4 \mathrm{~mm}$ outer diameter; Camcaths) was implanted in the right jugular vein; the mice were housed singly thereafter. The catheters were maintained by flushing daily with heparinized $0.9 \%$ saline (Thomsen and Caine, 2005; Cui et al., 2014) with Timentin $(120 \mathrm{mg} / \mathrm{ml})$ added for the first $7 \mathrm{~d}$. We anesthetized mice with Beuthanasia $(320 \mathrm{mg} / \mathrm{kg}$, i.p.) or with ketamine $(650 \mathrm{mg} / \mathrm{kg}$, i.p.) and xylazine $(44 \mathrm{mg} / \mathrm{kg}$, i.p.) prior to euthanasia.

\section{Operant intravenous amphetamine self- administration}

Stage 1: sucrose pretraining. After $2 \mathrm{~d}$ of a graded food restriction protocol with unrestricted access to water, all mice obtained and maintained a $10 \%$ reduction in body weight. A further $2 \mathrm{~d}$ of food restriction followed but with a $20 \%$ sucrose solution provided for $8 \mathrm{~h}$ each day. The mice habituated to the testing room containing the operant chambers during on these days (Med Associates). Over the following $5 \mathrm{~d}$, they were trained to enter the magazine (2d) and then press either of two operant levers (3 d) to obtain a $20 \%$ sucrose reward (delivered to the magazine) to a maximum of 30 reinforcers per session.

Stage 2: amphetamine self-administration. Food and water were provided ad libitum after the last sucrose training session and for the remainder of the experiment. Intravenous jugular catheters were implanted the day after the last sucrose session.

A: acquisition. Following $3 \mathrm{~d}$ of recovery, the mice were returned to the operant boxes for intravenous amphetamine $(0.05 \mathrm{mg} / \mathrm{kg})$ self-administration. The preferred lever during sucrose pretraining was designated as the active lever for amphetamine self-administration. A response on the designated active lever resulted in an amphetamine reinforcer ( $0.67 \mu \mathrm{l} / \mathrm{g}$ body weight) and a cue (house light extinguished for $30 \mathrm{~s}$ ), during which no further drug could be obtained. A maximum of 50 reinforcers was allowed during the $2 \mathrm{~h}$ session and the session concluded when either parameter was obtained. Mice underwent a minimum of $10 \mathrm{~d}$ of acquisition training at a fixed ratio of 1 (FR1), during which one lever press resulted in one reinforcer. Mice with $\leq 20 \%$ variation and a minimum of 20 earned reinforcers over the preceding $3 \mathrm{~d}$ were advanced to the next stage, FR2, where two lever presses resulted in one reinforcer. Mice trained at this level for a minimum of $3 \mathrm{~d}$ until they obtained stable rates of reinforcers. Thereafter, they proceeded to FR5 for a minimum of $3 \mathrm{~d}$, where five presses resulted in one reinforcer. Mice with $\leq 20 \%$ variation in earned reinforcers then progressed to the next phase. We tested catheter patency by infusing $1 \%$ propofol $(20 \mu \mathrm{l})$ after FR1 and again after FR3 and FR5. We removed mice from the study if they failed to become transiently limp during the patency test.

B: amphetamine challenge following incubation. As the measured presynaptic adaptations are stable for $140 \mathrm{~d}$ following amphetamine injections (Bamford et al., 2008) and maintaining catheter patency in mice is technically challenging, a within-subject design was used to assess the effect of nicotine on amphetamine reward-seeking behaviors following 7 or $14 \mathrm{~d}$ of abstinence. Mice were randomly assigned to either an amphetamine group or an amphetamine with nicotine group, received a noncontingent amphetamine injection alone (1 mg/kg, i.p.) or amphetamine ( $1 \mathrm{mg} / \mathrm{kg}$, i.p.) with nicotine $(0.25 \mathrm{mg} / \mathrm{kg}$, i.p.), and were then placed immediately in the same operant chamber as used during acquisition. Under an FR1 schedule of reinforcement, the number of active lever presses, inactive lever presses, and reinforcers (or cue presentations) were recorded for $30 \mathrm{~min}$. After $7 \mathrm{~d}$, these same reward-seeking behaviors were recorded in mice receiving the alternative treatment. Electrophysiology experiments were conducted within $30 \mathrm{~d}$ of the final FR5 session.

\section{Locomotor sensitization}

Locomotor responses were measured using animal activity monitor cages (San Diego Instruments). Computer monitoring of four infrared beams, separated by $8.8 \mathrm{~cm}$ that cross the width of each chamber, recorded the number of times mice broke each beam. We measured locomotor activity in ambulations (2 consecutive beam interruptions) summated over 5 min intervals. On each test day, animals acclimated to individual activity chambers for 90 min to allow the animal to become accustomed to its behavioral cage before subsequent injections of either amphetamine (2 mg/kg, i.p.) or saline $(10 \mu \mathrm{l} / \mathrm{g}$, i.p.). Following each injection, the mice were placed back into their respective activity chamber and their ambulations were recorded for $90 \mathrm{~min}$. To separate the effects of novelty from the pharmacological effects of the drug, animals were acclimated to the locomotor chambers and injected with saline on experiment days 1 and 2 .

\section{Electrophysiology}

Data were obtained from three to four mice per experiment using standard techniques to prepare slices for electrophysiology. Experiments in the dorsal striatum were performed using 250- $\mu$ m-thick coronal sections containing the motor cortex and dorsal striatum, second to fourth frontal slice of caudate putamen [bregma, +1.54 to $+0.62 \mathrm{~mm}$ ]. To measure evoked EPSCs (eEPSCs) in medium spiny neurons (MSNs), experiments were performed on thicker $300 \mu \mathrm{m}$ sagittal sections, obtained at an interaural distance range from 0.72 to $1.44 \mathrm{~mm}$ from midline. Brains were dissected and immediately submerged in ice-cold, carbogenated $\left(95 \% \mathrm{O}_{2}, 5 \% \mathrm{CO}_{2}\right)$ artificial cerebrospinal fluid solution (ACSF) containing the following (in $\mathrm{mM}$ ): $124 \mathrm{NaCl}, 5 \mathrm{KCl}, 26 \mathrm{NaHCO}_{3}, 1.25$ $\mathrm{NaH}_{2} \mathrm{PO}_{4}, 2 \mathrm{MgCl}_{2}, 2 \mathrm{CaCl}_{2}$, and 10 glucose, $\mathrm{pH}$ 7.2-7.4, 290-310 mOsm. Slices $(300 \mu \mathrm{m})$ were prepared on a vibratome then transferred to an incubating chamber containing carbogenated NMDG-recovery solution, containing the following (in $\mathrm{mM}$ ): $100 \mathrm{~N}$-methyl D-glucamine, 2.5 $\mathrm{KCl}, 1.2 \mathrm{NaH}_{2} \mathrm{PO}_{4}, 30 \mathrm{NaHCO}_{3}, 20$ HEPES, $10 \mathrm{MgSO}_{4}, 0.5$ $\mathrm{CaCL}_{2}$, and 25 glucose at $35^{\circ} \mathrm{C}, \mathrm{pH} 7.3-7.4,300-310$ mOsm. After $5 \mathrm{~min}$, the slices were transferred to carbogenated ACSF (vehicle; $3 \mathrm{ml} / \mathrm{min}$ ) warmed to $35^{\circ} \mathrm{C}$ and performed electrophysiology experiments on upright Zeiss Axioskop FS or an Olympus BX51WI microscope.

Cell-attached recordings from Chls and whole-cell recordings from MSNs in the dorsal striatum were obtained in voltage-clamp mode. MSNs were clamped at $-70 \mathrm{mV}$. 
Cells were visualized in slices with the aid of infrared videomicroscopy coupled with differential interference contrast optics. Chls were identified by size $(\sim 18-25 \mu \mathrm{m})$ and repetitive firing in gap-free mode. Cell identification was confirmed by measuring passive and active membrane properties in whole-cell configuration (Wang et al., 2013a) and by labelling with $1 \%$ biocytin, according to published protocols (Joshi et al., 2009). The pipette internal solution contained the following (in $\mathrm{mM}$ ): $119 \mathrm{KMeSO}_{4}$, $1 \mathrm{MgCl}_{2}, 0.1 \mathrm{CaCl}_{2}, 10 \mathrm{HEPES}, 1$ EGTA, 12 phosphocreatine, $2 \mathrm{Na}_{2} \mathrm{ATP}$, and $0.7 \mathrm{Na}_{2} \mathrm{GTP}, \mathrm{pH} 7.2,280-300$ mOsm/L (Bennett and Wilson, 1999; Maurice et al., 2004). Currents were Bessel filtered at $2 \mathrm{kHz}$ and were allowed to stabilize for $5 \mathrm{~min}$ after achieving a seal resistance $>1 \mathrm{G} \Omega$. Cells were removed from analysis if the seal resistance fell $<1 \mathrm{G} \Omega$ or if the firing rate was $<0.3 \mathrm{~Hz}$ or changed by $>20 \%$ during the baseline (Bennett and Wilson, 1999).

Whole-cell recordings in acute striatal slices were used to measure miniature EPSCs (mEPSCs) in MSNs from salinetreated mice, amphetamine self-administering mice, and nonresponding mice. MSNs were identified by somatic size $(\sim 8-12 \mu \mathrm{m})$ and typical passive basic membrane properties. There were no differences in passive membrane properties of MSNs from saline-treated, amphetamine selfadministering, and nonresponding mice (membrane resistance: 118 $\pm 19, \quad 95 \pm 12, \quad 107 \pm 20 \quad M \Omega ; \quad$ membrane capacitance: $80 \pm 8,87 \pm 8,80 \pm 14 \mathrm{pF}$; series resistance: $11 \pm 1, \quad 11 \pm 2, \quad 9 \pm 3 \mathrm{M} \Omega$; holding current: $-150 \pm 16$, $-131 \pm 28,-159 \pm 39 \mathrm{pA}$; time constant: $0.9 \pm 0.1,1 \pm 0.2$, $0.8 \pm 0.3 \mathrm{~ms}$, respectively).

The electrophysiological properties were monitored throughout the recording and cells were removed from further analysis if the series resistance changed by $>20 \%$. The patch pipette (4-7 M $\Omega$ ) contained the following internal solution (in $\mathrm{mm}$ ): $125 \mathrm{Cs}$-methanesulfonate, 3 $\mathrm{KCl}, 4 \mathrm{NaCl}, 1 \mathrm{MgCl}_{2}$, $5 \mathrm{MgATP}, 5$ EGTA, 8 HEPES, 1 Tris-GTP, 10 di-sodium phosphocreatine, 0.1 leupeptin, and $4 \mathrm{~N}$-(2,6-dimethylphenylcarbamoylmethyl)triethylammonium bromide (QX-314), $\mathrm{pH}$ 7.2-7.3, 270-280 mOsm).

EPSCs were evoked by electrical stimulation of the deep cortical layers of the motor cortex using a twisted tungsten bipolar electrode at stimulation strengths adjusted to $1.5 \times$ threshold $(0.6 \pm 0.2 \mathrm{~mA})$. Paired current pulses of $200 \mu$ s in duration were delivered at $20 \mathrm{~Hz}$ every $30 \mathrm{~s}$. eEPSC currents were Bessel filtered at $1 \mathrm{kHz}$. The paired-pulse ratio (PPR) was calculated by dividing the amplitude of the second pulse by that of the first pulse and then multiplying by 100 . Cells demonstrating eEPSCs with variable latencies or prolonged durations suggesting polysynaptic responses were rejected. mEPSCs were Bessel filtered at $4 \mathrm{kHz}$ and recorded in gap free mode. The $\mathrm{Na}^{+}$channel antagonist tetrodotoxin $(1 \mu \mathrm{M})$ was added to block spontaneous cortically-derived action potentials and isolate presynaptic terminal activity. Currents were digitized at $50 \mu \mathrm{s}$ using Digidata $1440 \mathrm{~A}$ data acquisition and pClamp10.2 software (Molecular Devices). Cell activity was analyzed with Clampfit (Molecular Devices) and Mini Analysis (Synaptosoft). Chemicals and ligands were obtained from Sigma-Aldrich.

\section{Spike analysis}

The power spectra for recorded spike trains were calculated as the magnitude-squared of the Fourier transform (St-Pierre et al., 2014) using custom software designed in MATLAB (MathWorks). The nonuniform sampling rate of spike time data required a method for resampling at a uniform sampling rate. The time of each spike was rounded to the nearest thousandth to guarantee an equivalent time in a resampled train at $1000 \mathrm{~Hz}(\Delta t=0.001$ s) in which corresponding time instances were set to 1 in the new train and all others to 0 . A sampling rate of 1000 $\mathrm{Hz}$ provided a high Nyquist frequency at $500 \mathrm{~Hz}$, while limiting aliasing contribution for frequency bins $<200 \mathrm{~Hz}$ (Bair et al., 1994).

Frequency spectra were computed by a Fast Fourier transform (FFT) according to Welch's method using a division of 15 windows with $50 \%$ overlap (Table 1; Welch, 1967). A Hanning window was used to improve frequency accuracy and to reduce spectral leakage (Wickramarachi, 2003). Window overlap preserved spikes located near the tapered ends of the Hanning windows. The spectrum of each window was squared then normalized to its average power to preserve the relative peaks and dips at the lower frequencies of interest when averaging (Bair et al., 1994). We applied these processing operations at the Welch window level to improve spectral accuracy for each cell. Averaging a large number of windows decreased spectral variance at the expense of frequency resolution (Jokinen et al., 2000), which was compensated by greater window length of overlapping windows than that of non-overlapping windows. To reduce the direct current spike, we subtracted windows by their means to create a zeromean spike train. Peak frequencies were the center of the bin with the maximum integral (Table 2). Bins started at each calculated frequency and extended out for a total of 10 points in each window. The peak frequencies of each cell were normalized to their corresponding power, which roughly approximated the peaks seen in the frequency spectrum. Frequency distributions were determined by creating a probability distribution of the $1 /$ interspike interval (ISI) frequencies (Table 3). We averaged the distributions for each spike train in an experimental group to create an average distribution of that group and then calculated the peak frequencies using the same method used for the frequency spectra.

We used the Robust Gaussian Surprise (RGS; Ko et al., 2012) methods to analyze the burst and pause firing patterns in Chls. The RGS method can accurately detect small bursts, small pauses, and strings of pause activity in individual Chls (Tables 4 and 5). Unlike the Poisson Surprise method, which is limited by its assumption of a Poisson process (Legéndy and Salcman, 1985), and the Rank Surprise method, which does not accurately detect small bursts, the RGS method exhibits a robust adaptability to varying firing rates (Ko et al., 2012). It also provides many facets for statistical significance including both burst and pause information. A $p$ value of 0.05 was used in the calculation of the central location of all ISI distributions and in the Bonferroni correction of the results. This method's robustness is due to its normalization 


\section{Table 1. MATLAB code for power spectrum computation}

function [f, spec] $=$ welchfft(Spikes, dt, numBins, pOverlap, Padding) $\% \%$ WELCHFFT $\%$

$\%$ Calculates power spectrum by averaging Fast Fourier Transforms of

$\%$ overlapping window divisions

$\%$

$\%$ INPUTS:

$\%$ Spikes (s): Times of spikes

$\%$ dt: Sampling rate for new sampled train

$\%$ numBins: Number of window divisions

$\%$ pOverlap: Percent overlap between windows

$\%$ Padding (optional): Number of zeros to zero-pad signal (increases frequency

$\%$ resolution)

$\%$ NOTE: Can change window type manually in the code (SEE LINE 69).

$\%$ OUTPUTS:

$\% \mathrm{f}$ : Column vector of frequencies

$\%$ spec: Column vector of normalized spectrum values

$\%$ EXAMPLE values used in this paper:

$\%$ Spikes $=($ Spike times go here)

$\% \mathrm{dt}=0.001$

$\%$ numBins $=15$;

$\%$ pOverlap $=50$

$\%$ Padding $=50$;

$\%$ [f, spec] = welchfft(Spikes, dt, numBins, pOverlap, Padding);

$\% \operatorname{plot}(f, s p e c)$;

$\%$ Reference: Welch (1967) The use of fast Fourier transform for the

$\%$ estimation of power spectra: a method based on time averaging over

$\%$ short, modified periodograms. IEEE Trans Audio Electroacoust 15:70-73.

$\% \%$

if nargin $==4$

Padding $=0$;

end

nTime $=($ Spikes(1):dt:Spikes(end) $+\mathrm{dt}) ; \%$ New uniformly sampled times

nTime(2,:) = 0; \%Initialize spike train

\%Find equivalent times and set value at that time to 1

nTime $(2$, ismember(round(nTime(1,:).*(1/dt)).*dt, round(Spikes.*(1/dt)).*dt)) . .

$=1$;

\%Spike train equals binary train $(1,0)$

spikeTrain $=$ nTime(2,:);

$\mathrm{N}=$ length(spikeTrain); \%Length of spike train

fs $=1 / \mathrm{dt} ; \%$ Sampling rate of new spike train

$\mathrm{L}=$ floor(N/(numBins-pOverlap/100 $\times$ numBins + pOverlap/100)); \%Number of points in \%length of window

Overlap_N = floor $(\mathrm{L} \times$ pOverlap/100); \%Number of points in each overlapping section

$\%$ Set endpoints of the windows

windowEndpoints $=[$ linspace $(1,1+($ L-Overlap_N $) \times($ numBins-1), numBins $) ; \ldots$

L:L-Overlap_N:length(spikeTrain)+(L-Overlap_N)/2];

\%Fix error from floor due to percent input

spikeTrain $=$ [spikeTrain zeros(1, windowEndpoints(2,end)-length(spikeTrain))];

\%Initalize windows

windows $=$ zeros(numBins, 1 )

$\%$ Compute fft for all windows

for $\mathrm{i}=1$ :numBins

\%Take current window from the spike train

currTrain $=[$ spikeTrain $($ windowEndpoints $(1, \mathrm{i})$ :windowEndpoints $(2, \mathrm{i})) \ldots$

zeros(1,Padding)];

$\%$ Can change window here by replacing line 71 with

\%options below:

windowed $=$ hanning(length(currTrain) $)^{\prime} \cdot *($ currTrain);

$\%$ windowed = blackman(length(currTrain) $)^{\prime} . *($ currTrain);

$\%$ windowed $=$ flattopwin(length(currTrain))'.*(currTrain);

$\%$ windowed $=$ hamming(length(currTrain))'.*(currTrain);

\%Take zero-mean, $\mathrm{ft}$, and magnitude-squared

windows(i,1:length(windowed)) = abs(fft(windowed-mean(windowed))).^2;

$\%$ Normalize to the mean

windows $(\mathrm{i},:)=$ windows $(\mathrm{i},.) \cdot /$ mean $($ windows $(\mathrm{i},)$.$) ;$

end

$\%$ Frequencies up to the nyquist

$f=$ linspace $(0, f s / 2$, floor(length(windows $) / 2)$ )'

$\%$ Average results of windows of corresponding spectra values

spec $=$ mean $($ windows $(:, 1:$ floor(length(windows $) / 2)))^{\prime}$;

end
Table 2. MATLAB code for determining peak frequencies

function [peak,dist] $=$ peakdetect(A, B, binsize $)$

$\% \%$ PEAKDETECT help

$\%$

$\%$ Determines the peak value of a distribution.

$\%$

$\%$ INPUTS:

$\%$ A: $x$ values of distribution.

$\%$ B: distribution values.

$\%$ binsize: Number of points to be included in a bin.

$\%$ OUTPUTS:

$\%$ peak: center of bin with the maximum distribution value.

$\%$ dist: highest average distribution value for a bin.

$\%$

$\%$ EXAMPLE:

$\% \mathrm{~A}=(x$ values go here $)$

$\% \mathrm{~B}=$ (distribution values go here)

$\%$ binsize $=10$

$\%[$ peak, dist $]=$ peakdetect $(A, B$, binsize $)$;

$\%$

$\% \%$ PEAKDETECT

$\%$ The number of points to extend forward or backward

$\%$ Step size of the distribution

$\mathrm{dx}=\mathrm{A}(2)-\mathrm{A}(1)$

\%Initialize integral array

integral $=$ zeros(length(B)-binsize $+1,1)$

$\%$ Calculate the integrals

for $\mathrm{i}=1$ :length(B)- binsize +1

\%Take the sum of the $x$ values multiplied by $y$ values in the bin

integral $(i)=\operatorname{sum}(d x \times B(i: i+$ binsize -1$))$;

end

\%Find the index of the center of the bin with the max integral

$\mathrm{j}=$ find(integral $==\max ($ integral) $)+$ round(binsize/2);

\%Find the value of the max integral

peak $=A(j)$;

\%Return the average dist around the max distribution value dist $=$ mean(B(j-round(binsize/2):j+round(binsize/2)));

end

algorithm, which takes the base 10 logarithm of all the ISIs and locates the central location through the median and median absolute deviation of the distribution of a standard window length around each logarithmic ISI. Then, each central location was subtracted from its corresponding logarithmic ISI to form a normalized $\log _{10}$ ISI train. The median and median average deviation of the distribution of normalized ISIs were used to generate a cumulative Gaussian probability distribution, which was then used to determine surprise values for burst and pause seeds. Burst seeds were set as normalized $\log _{10}$ ISIs less than -2.58 times the median average deviation, whereas pause seeds were set as normalized $\log _{10}$ ISIs $>+2.58$ times the median average deviation. Normalized $\log _{10}$ ISIs $(>0.05 \mathrm{~s})$ in front or behind of the seeds were added if they decreased the likelihood, assuming a Gaussian distribution with mean and SD taken from the normalized $\log _{10}$ ISI distribution, of the occurrence of the burst or pause string according to the cumulative probability distribution. This method's precise selection of spikes in each burst or pause string event by only including spikes that decrease the probability of the occurrence of the event, as well as the normalization that prevents the stringing of multiple small bursts in regions contribute to 
Table 3. MATLAB code for ISI frequency distribution

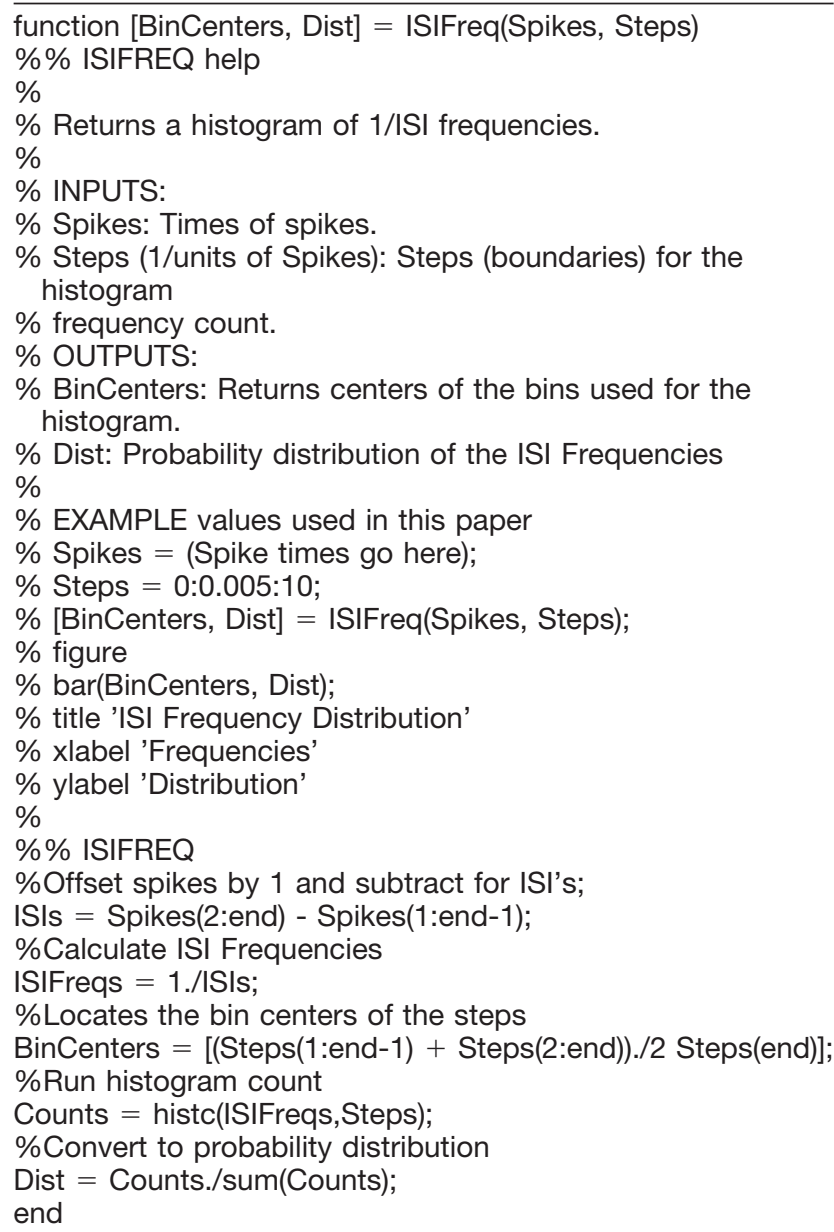

its accurate and robust performance. Patterns in bursts and pauses were determined using variable thresholds to connect these events (Table 6). All algorithms were implemented in MATLAB.

\section{Statistics}

Values given in the text and in the figures are indicated as mean \pm SE. For the behavioral experiments, differences between groups across training days were analyzed using a linear mixed model, which can be used to maintain test validity by directly modeling unequal covariance across repeated measures (training day), which is intrinsic to a learning experiment, where responding starts off low and increases in variance (and mean) as days progress. These models included fixed effects for day and their interaction, along with an unstructured residual covariance matrix. For tests where equal variance and covariance could be assumed, as determined by Mauchley's test of sphericity (because learning had already occurred, for example, stable responding in FR2 and progressive ratio data), two-way ANOVA (day and genotype) with repeated measures and factorial analysis were used. We compared locomotor ambulations using two-way ANOVA (day and genotype) with repeated measures. Differences in the electrophysiological tests were assessed with Student's,
Table 4. MATLAB code for RGS burst and pause detection

function [Bursts, Pauses] = RGSDetect(Spikes, N_min, Steps, p, alpha)

$\% \%$ RGSDETECT help

$\%$

\% Determines burst and pause interspike interval (ISI) thresholds and

$\%$ identifies burst and pause strings based on the Robust Gaussian Surprise

$\%$ (RGS) method.

$\%$

$\%$ INPUTS:

$\%$ Spikes (s): Times of spikes in seconds.

\% N_min: Minimum number of spikes to be considered a burst/pause

$\%$ string.

\% Steps (log10(s)): Bin edges for histogram count (histc) of the

$\%$ log ISIs.

$\% \mathrm{p}$ : Bottom and top $\mathrm{p} \%$ used as outliers to calculate central

$\%$ location; keep $\mathrm{p}$ in range [0.05, 0.30] (default 0.05).

$\%$ alpha: Value used in Bonferroni correction; lower value of

$\%$ alpha to filter out false positives (default 0.05).

$\%$ NOTE: Requires MATLAB statistics toolbox.

$\%$

$\%$ OUTPUTS:

$\%$ Bursts: Structure containing burst information.

\% Bursts.BurstingSpikes (s): Column of times of all spike times

$\%$ included in a burst.

\% Bursts.IBF $(\mathrm{Hz})$ : Column of intraburst frequency (IBF) of each

$\%$ burst.

\% Bursts.NumSpikes: Column of number of spikes in each burst.

\% Bursts.Windows (s): 2 Columns of start and end times of each

$\%$ burst.

\% Pauses: Structure containing pause information.

$\%$ Pauses.AllSpikes (s): Start times of all ISIs that satisfy

$\%$ pause threshold.

$\%$ Pauses.AllLengths (s): Lengths of all ISIs that satisfy pause $\%$ threshold.

\% Pauses.PausingSpikes (s): Column of all spike times

$\%$ included in a pause string.

\% Pauses.IPF (Hz): Column of intrapause frequency (IPF) of each

$\%$ pause string.

\% Pauses.NumSpikes: Column of number of spikes in each pause

$\%$ string.

$\%$ Pauses.Windows (s): 2 Columns of start and end times of each

$\%$ pause string.

\% NOTE: Rows of structure elements correspond to the same burst or

$\%$ pause.

\% NOTE: Normalized Log ISI Distribution (NLISI) plot is used confirm

$\%$ central distribution is centered on 0 . If distribution is not $\%$ centered on 0 , change $\mathrm{p}$ until it is. Use steps to adjust the $\% x$-axis.

$\%$

$\%$ EXAMPLE values used in this paper:

$\%$ Spikes $=$ (Spike times go here); 
$\% \mathrm{~N} \_\min =2$;

$\%$ Steps $=-3: 0.005: 1.5$

$\% p=0.05$

$\%$ alpha $=0.05$

$\%$ [Bursts, Pauses] = RGSDetect(Spikes, N_min, Steps, $\mathrm{p}$, alpha);

$\%$

\% REFERENCE: Ko et al. (2012)

$\%$ Detection of bursts and pauses in spike trains

\% J Neurosci Methods 211:145-158

$\%$

$\% \% \%$ NORMALIZED LOG ISI DISTRIBUTION

ISIs = Spikes(2:end)-Spikes(1:end-1); \%Offset spikes by 1 and subtract

\%for ISI's

LogISIs = log10(ISIs); \%Take the log10 of ISI's

$\mathrm{N}=$ length(LogISIs); \% $\mathrm{N}=$ number of ISIs

$\mathrm{Q}=\max ([20$,floor $(0.2 \times N)]) ; \%$ Set window length as max of 20 and $20 \%$ of $\mathrm{N}$

NLISITrain = zeros(1,length(LogISIs))'; \%Initialize Normalized Log ISI Train

\%Central Location of first $2 \times Q+1$ ISIs

CentralLoc1 $=$ ComputeCL(LogISIs $(1: 2 \times Q+1)$, Steps, $p)$;

\%Subtract Central Location (Normalize)

NLISITrain(1:Q) = LogISIs(1:Q) - CentralLoc1;

$\%$ Central Location of last $2 \times Q+1$ ISIs

CentralLoc2 = ComputeCL(LogISIs $(N-2 \times Q: N)$, Steps, p);

$\%$ Subtract Central Location (Normalize)

NLISITrain(N-Q+1:end) = LogISIs(N-Q+1:end) - CentralLoc2;

$\%$ For the middle portion

for $\mathrm{i}=\mathrm{Q}+1: \mathrm{N}-\mathrm{Q}$

$\%$ Compute central location for portion of index $+/-Q$ and subtract

NLISITrain(i) = LogISIs(i) - ComputeCL(LogISIs(i-Q:i+Q), Steps, p);

end

\%Get statistics of the NLISI train

med = median(NLISITrain);

pool $M A D=\operatorname{mad}($ NLISITrain);

CentralDistBounds $=$ [med - pool_MAD $\times 2.58$ med + pool_MAD $\times 2.58]$;

$\mathrm{mu}=$ median(NLISITrain);

sigma $=\operatorname{mad}($ NLISITrain);

\%Plot the NLISI Distribution

figure

hold on

\%Run a smoothing pdf kernel.

NLISIpdf = pdf(fitdist(NLISITrain,'Kernel'), Steps);

NLISIpdf = NLISIpdf./sum(NLISIpdf);

plot(Steps, NLISIpdf,'g')

\%Plot treshold lines

plot([CentralDistBounds(1) CentralDistBounds(1)], [0 $\max ($ NLISIpdf)], '-r')

plot([CentralDistBounds(2) CentralDistBounds(2)], [0 $\max ($ NLISIpdf)], '-b')

xlabel 'Normalized Log ISIs'

ylabel 'Probability'

title 'Normalized Log ISI Distribution'

$\% \%$ BURST AND PAUSE STRING DETECTION

$\%$ Get index and ISI lengths of all ISIs that satisfy burst threshold

Burst_Thresh $=$ CentralDistBounds(1);

BurstINDXS = 1:length(NLISITrain);

BurstINDXS(NLISITrain > = Burst_Thresh) $=$ [; \% \% Delete all indexes greater than \%the burst threshold

if $\sim$ isempty(BurstINDXS)

\%Matrix of all potential burst ISIs and their indexes

BurstsM = [NLISITrain(NLISITrain <

Burst_Thresh)';BurstINDXS];

$[\sim, c]=\operatorname{size}($ BurstsM);

Burst_Seed $=$ mat2cell(BurstsM,2,ones $(1, \mathrm{c}, 1))$;

else

Burst_Seed $=\{\}$

Bursts $=$ Burst Seed;

end

\%Loop through each potential burst ISI (Burst Seed)

for $\mathrm{i}=1$ :length(Burst_Seed);

$\%$ Go forward and backward from the current burst until both conditions

$\%$ are unsatisfied

forward = 1;

backward $=1$;

while forward $\|$ backward

currBurst $=$ cell2mat(Burst_Seed(i));

$\%$ Go forward 1 ISI

if forward

\%Set current ISI as end of the current burst

currSpike = currBurst(:,end);

if currSpike(2) = length(NLISITrain)

$\% q$ is number of spikes

$[\sim, q]=$ size(currBurst);

$\% \mathrm{P} 1$ is probability burst will occur assuming Gaussian

\%distribution with mean, mu $\times \mathrm{q}$, and std, sqrt(q) $\times$ sigma

$\mathrm{P} 1=\operatorname{normcdf}(\operatorname{sum}(\operatorname{currBurst}(1,:))$, mu $\times \mathrm{q}$, sqrt(q). $\times$ sigma);

testBurst $=$ [currBurst [NLISITrain(currSpike(2)+1);. . .

currSpike(2)+1]];

$\% \mathrm{P} 2$ is the same probability with the next ISI added to the $\%$ burst

P2 = normcdf(sum(testBurst $(1,:)), \operatorname{mu} \times(q+1), \ldots$

$\operatorname{sqrt}(q+1) . \times$ sigma);

\%If the next ISI increased the probability of the burst

\%occurring

if $\mathrm{P} 2>=\mathrm{P} 1$

$\%$ Stop going forward

forward $=0$;

else

$\%$ Otherwise, set the current burst seed to the tested

\%burst

Burst_Seed $\{i\}=$ testBurst;

end

else

\%Stop going forward if at the end of the ISI train

forward =0;

end

end

currBurst $=$ cell2mat(Burst_Seed(i));

$\%$ Go backward 1 ISI

if backward

\%Set current ISI as end of the current burst

currSpike = currBurst(:,1);

if currSpike(2) $\sim=1$

$\% \mathrm{q}$ is number of spikes

$[\sim, \mathrm{q}]=$ size(currBurst);

$\% \mathrm{P} 1$ is probability burst will occur assuming Gaussian \%distribution with mean, mu $\times \mathrm{q}$, and std, sqrt(q) $\times$ sigma P1 = normcdf(sum(currBurst(1,:)), mu $\times q$, sqrt(q). $\times$ sigma); testBurst $=[[$ NLISITrain(currSpike(2)-1); currSpike(2)-1] . . . currBurst];

$\% \mathrm{P} 2$ is the same probability with the next ISI added to the 


\section{\%burst}

P2 $=$ normcdf(sum(testBurst $(1,:)), \operatorname{mu} *(q+1), \ldots$

$\operatorname{sqrt}(q+1) . * \operatorname{sigma})$;

\%If the next ISI increased the probability of the burst

\%occurring

if $\mathrm{P} 2>=\mathrm{P} 1$

\%Stop going backward

backward =0;

else

$\%$ Otherwise, set the current burst seed to the tested

\%burst

Burst_Seed $\{i\}=$ testBurst;

end

else

\%Stop going backward if at the end of the ISI train

backward = 0;

end

end

end

end

if isempty(Burst_Seed)

\%Initialize Burstinfo

Burstlnfo = zeros(length(Burst_Seed),3);

$\%$ Get start index of each burst

BurstInfo(:,1) = cellfun(@(x) x(2,1),Burst_Seed);

$\%$ Get end index of each burst

Burstlnfo(:,2) = cellfun(@(x) x(2,end),Burst_Seed);

$\%$ Get P-value of each burst (probability of occurence assuming Gaussian

\%distribution)

Burstlnfo(:,3) = cellfun(@(x) normcdf(sum(x(1,:)), mu*length(x),

...

sqrt(length(x)).×sigma),Burst_Seed);

$\%$ Filter out bursts less than minimum number of spikes specified by N_min

BurstInfo(Burstlnfo(:,2)-BurstInfo(:,1)+2 < N_min,:) = ];

\%Filter out overlapping bursts

no_overlap $=0$;

$\mathrm{i}=1$;

if $\sim$ isempty(Burstlnfo)

$[r, \sim]=$ size(Burstlnfo);

if $r \sim=1$

while $\sim$ no_overlap

\%If the indexes of the burst ISIs don't intersect

if isempty(intersect(BurstInfo(i,1):BurstInfo(i,2),... .

Burstinfo(i+1,1):Burstlnfo(i+1,2)))

$\%$ move to the next burst

$\mathrm{i}=\mathrm{i}+1$.

else

\%If the intersect, choose the burst with the lower P

$\%$ value

if BurstInfo(i,3) $<=$ Burstlnfo( $i+1,3)$

BurstInfo(i+1,:) = [;

else

BurstInfo(i,::) = ];

end

end

$\%$ When the end is reached, stop

$[r, \sim]=\operatorname{size}$ (BurstInfo);

if $\mathrm{i}==\mathrm{r}$

no_overlap $=1$

end

end

end

$\% r$ is the number of rows or the number of bursts $[r, \sim]=\operatorname{size}($ Burstinfo);

Bursts.BurstingSpikes = ];

\%for each burst, append the burst spikes

for $i=1: r$

Bursts.BurstingSpikes $=$ [Bursts.BurstingSpikes; . .

Spikes(BurstInfo(i,1):Burstlnfo(i,2)+1)]

end

end

\%Bonferroni correction for false positives

$\mathrm{KB}=$ length(find(Burstlnfo(:,3) < alpha));

Burstinfo(BurstInfo(:,3) $\times \mathrm{KB}>=$ alpha,:) $=[$;

$\%$ Use the indexes in burst info to find the burst windows

Bursts.Windows $=[$ Spikes(BurstInfo(:,1))

Spikes(BurstInfo(:,2)+1)];

\%Use the indexes to find the number of spikes in each burst

Bursts.NumSpikes = BurstInfo(:,2) - Burstlnfo(:,1) + 2;

$\%$ Use the number of spikes and windows to calculate the IBF

Bursts.IBF $=$ Bursts.NumSpikes./(Bursts.Windows(:,2) - . .

Bursts.Windows(:,1));

end

\%Get index and ISI lengths of all NLISIs that satisfy pause threshold

Pause Thresh $=$ CentralDistBounds(2);

PauselNDXS = 1:length(NLISITrain);

$\%$ Delete all indexes less than the pause threshold

PauseINDXS(NLISITrain $<=$ Pause_Thresh) $=$ ];

if isempty(PauselNDXS)

\%Matrix of all potential pause string NLISIs and their indexes

PausesM $=$ [NLISITrain(NLISITrain >

Pause_Thresh)';PauseINDXS];

$[\sim, c]=\operatorname{size}($ PausesM);

Pause_Seed $=$ mat2cell(PausesM,2,ones $(1, \mathrm{c}, 1))$;

else

Pause_Seed $=\{\}$;

Pauses = [;

end

\%Loop through each potential pause string NLISI (Pause Seed)

for $i=1$ :length(Pause_Seed);

$\%$ Go forward and backward from the current pause string until both conditions

\%are unsatisfied

forward $=1$;

backward $=1$;

while forward $\|$ backward

currPause $=$ cell2mat(Pause_Seed(i));

$\%$ Go forward 1 ISI

if forward

\%Set current ISI as end of the current pause string

currPauseind $=$ currPause(:,end);

if currPauseind(2) = length(NLISITrain)

$[\sim, q]=$ size(currPause);

$\% \mathrm{P} 1$ is probability pause string will occur assuming Gaussian \%distribution with mean, mu $\times \mathrm{q}$, and std, sqrt(q) $\times$ sigma

$\mathrm{P} 1=(1$-normcdf(sum(currPause $(1,:)), \operatorname{mu} \times \mathrm{q}$, sqrt(q). $\times$ sigma $)$ ); testPause $=$ [currPause [NLISITrain(currPauseind(2) +1$) ;.$. currPauseind(2)+1]];

$\% \mathrm{P} 2$ is the same probability with the next ISI added to the $\%$ pause string

P2 $=(1$-normcdf(sum(testPause(1,:)), $\operatorname{mu} \times(q+1), \ldots$

$\operatorname{sqrt}(q+1) \cdot \times \operatorname{sigma}))$;

\%If the next ISI increased the probability of the pause

$\%$ string occurring

if $\mathrm{P} 2>=\mathrm{P} 1$ 
\%Stop going forward

forward =0;

else

\%Otherwise, set the current pause seed to the tested

$\%$ pause string

Pause_Seed $\{\mathrm{i}\}=$ testPause;

end

else

forward $=0$;

end

end

currPause = cell2mat(Pause_Seed(i));

$\%$ Go backward 1 ISI

if backward

currPauseind = currPause(:,1);

if currPauseind(2) $\sim=1$

$[\sim, q]=$ size(currPause);

$\% \mathrm{P} 1$ is probability pause string will occur assuming Gaussian

$\%$ distribution with mean, mu $\times q$, and std, sqrt(q) $\times$ sigma

P1 = (1-normcdf(sum(currPause(1,:)), mu $\times q$, sqrt(q). $\times$ sigma));

testPause $=[[$ NLISITrain(currPauseind(2)-1);. . .

currPauseind(2)-1] currPause];

$\% \mathrm{P} 2$ is the same probability with the next ISI added to the

$\%$ pause string

P2 = (1-normcdf(sum(currPause(1,:)), mu $\times(q+1), \ldots$

$\operatorname{sqrt}(q+1) . \times \operatorname{sigma}))$;

\%If the next ISI increased the probability of the pause

\%string occurring

if $\mathrm{P} 2>=\mathrm{P} 1$

\%Stop going forward

backward =0;

else

$\%$ Otherwise, set the current pause seed to the tested

$\%$ pause string

Pause_Seed $\{i\}=$ testPause;

end

else

backward $=0$;

end

end

end

end

if $\sim$ isempty(Pause_Seed)

\%Initialize Pauselnfo variable

Pauselnfo = zeros(length(Pause_Seed),3);

$\%$ Starting indexes of pause strings

Pauselnfo(:,1) = cellfun(@(x) x(2,1),Pause_Seed);

$\%$ Ending indexes of pause strings

Pauselnfo(:,2) = cellfun(@(x) x(2,end),Pause_Seed);

$\% \mathrm{P}$-value of the pause strings

Pauselnfo(:,3) = cellfun(@(x) (1-normcdf(sum(x(1,:)), mu $\times$ length $(x), \ldots$

sqrt(length $(\mathrm{x})) . \times$ sigma)),Pause_Seed);

$\%$ Minimum number of spikes filter

Pauselnfo(Pauselnfo(:,2)-Pauselnfo(:,1) $+2<\mathrm{N} \_$min,:) $=$[;

\%Filter out overlaps

no_overlap $=0$;

$i=1$;

if isempty(Pauselnfo)

$\% r$ is number of current pause strings

$[r, \sim]=$ size(Pauselnfo);

if $r \sim=1$

while $\sim$ no_overlap

\%If the indexes of the burst ISIs don't intersect

if isempty(intersect(Pauselnfo(i,1):Pauselnfo(i,2),. . .

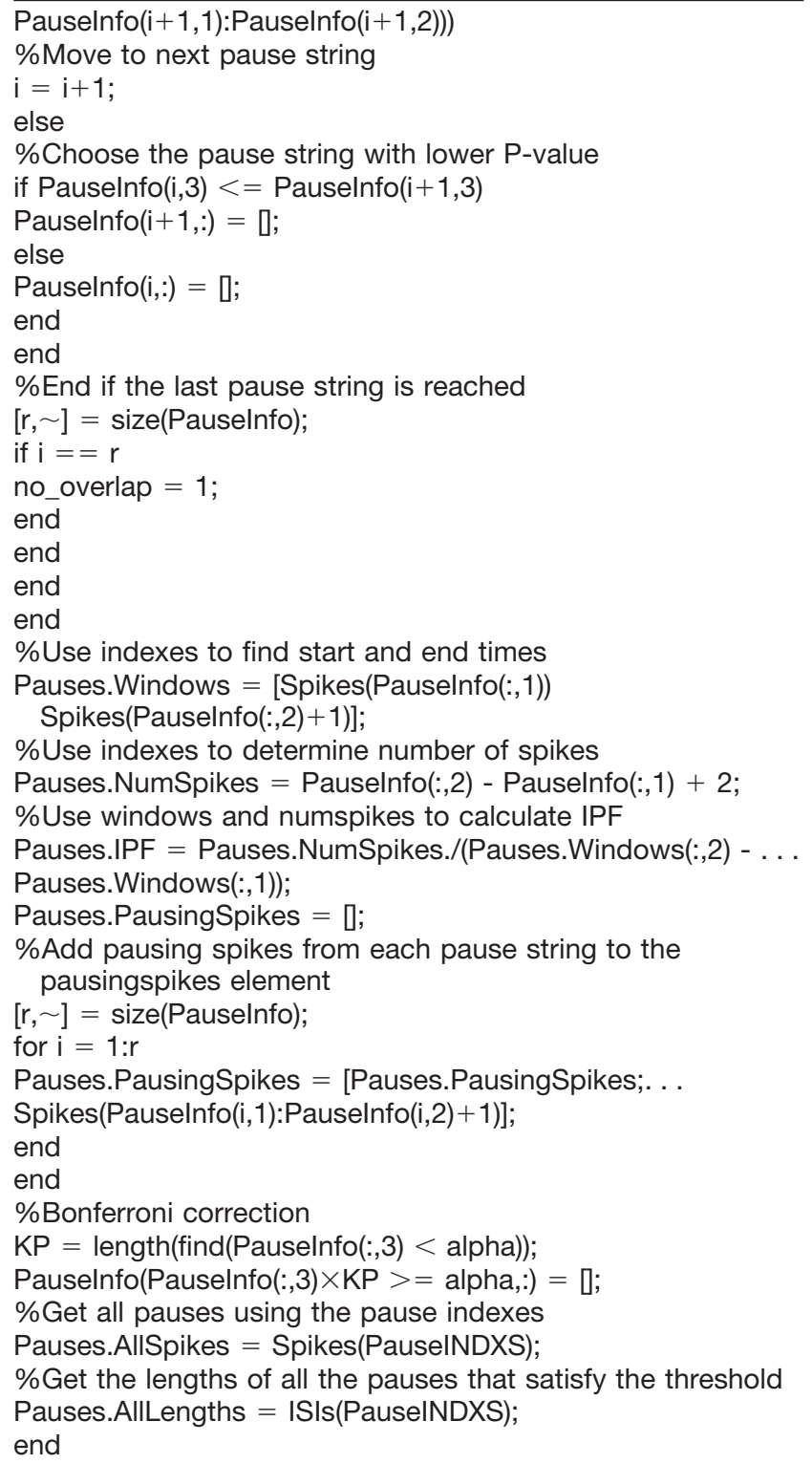

paired, or Bonferroni $t$ tests. Statistical analyses were performed with Statistica (StatSoft), or SPSS 21 (IBM) and differences were considered significant if $p<0.05$ (Table 7).

\section{Results}

\section{Mice acquire stable intravenous amphetamine self- administration}

Although amphetamine self-administration has been demonstrated in rats, there are no published examples of mice acquiring amphetamine self-administration. We used a multistage protocol to obtain amphetamine selfadministration through an indwelling jugular catheter (Fig. $1 A)$. After a period of habituation and sucrose exposure, we trained mice to obtain a $20 \%$ sucrose reward, delivered to the magazine, upon pressing either of two levers for 3 consecutive days (Table 8). We then implanted an intravenous catheter in a jugular vein, and after $3 \mathrm{~d}$ of 
Table 5. MATLAB code for computing central location used in RGS

function [CentralLocation] = ComputeCL(ISIs, Steps, p) $\% \%$ COMPUTECL help

$\%$

$\%$ Subroutine required for MATLAB code for RGS burst and pause detection

$\%$ (Table 4). This subroutine computes the central location given an ISI train

$\%$ using robust measures

$\%$ of the median absolute difference (MAD), median, and central set.

$\%$

$\%$ INPUTS:

$\%$ ISIs (s): Lengths of ISIs in seconds.

$\%$ Steps: Bin edges for histogram count (histc) of the ISIs.

$\% \mathrm{p}$ : Bottom and top $\mathrm{p} \%$ used as outliers to calculate central

$\%$ location; keep $p$ in range [0.05, 0.30] (default 0.05).

$\%$ NOTE: RGSDetect inputs log scale ISIs and Steps.

$\%$ OUTPUTS:

$\%$ CentralLocation: Central location of the ISI distribution $\%$

\% REFERENCE: Ko et al. (2012) Detection of bursts and

$\%$ pauses in spike trains. J Neurosci Methods 211:145-158 $\%$

$\% \%$ COMPUTECL

$\%$

\%Locates the bin centers of the steps on a linear scale

bincenters $=[($ Steps $(1:$ end- 1$)+$ Steps $(2:$ end $)) . / 2$

Steps(end)];

\%Histogram counts the ISIs using Steps

ISIhist = histc (ISIs,Steps) ';

\%Converts to probability distribution

normhist $=$ ISlhist./sum(ISIhist);

\%Creates cumulative probability distribution

cumprob = cumsum(normhist);

$\%$ Calculates thresholds for bottom and top $p$ quantiles

$[\sim$,burstquantid $]=\min ($ abs $($ cumprob-(p)));

$[\sim$, pausequantid $]=\min ($ abs $($ cumprob- $(1-p)))$;

burstquant $=$ bincenters(burstquantid);

pausequant $=$ bincenters(pausequantid);

\%Caclulates E-Center as average of 2 thresholds

$\mathrm{E} \_$Center $=$(burstquant + pausequant)/2;

\%Calculates central set using MAD

CentralSetBoundaries $=[$ E_Center $-1.64 \times \operatorname{mad}(I S I s, 1)$

E Center + ....

$1.64 \times \operatorname{mad}($ ISIs, 1$)]$;

CentralSet $=[$ bincenters $($ bincenters

$>=$ CentralSetBoundaries(1) \& . . .

bincenters $<=$ CentralSetBoundaries(2));

normhist(bincenters ...

$>=$ CentralSetBoundaries(1) \& bincenters

$<=$ CentralSetBoundaries(2))];

$\%$ Calculates median of central set

CentralDistCumProb =

cumsum(CentralSet(2,:)./sum(CentralSet(2,:)));

$[\sim$,CentralLocationid $]=\min ($ abs $($ CentralDistCumProb -

$0.5)$;

CentralLocation $=$ CentralSet(1,CentralLocationid); end

recovery, began amphetamine self-administration (0.05 $\mathrm{mg} / \mathrm{kg} /$ infusion per reinforcer) using fixed, increasing schedules of reinforcement. Within the group of 20 mice self-administering amphetamine with patent catheters, 10 mice obtained 50 reinforcers, the maximum number
Table 6. MATLAB code for finding burst-pause patterns using RGS output

function [BSPB, BDPB] =

BurstPausePatternDetector(Bursts,Pauses,dt)

$\% \%$ BURSTPAUSEPATTERNDETECTOR help

$\%$

$\%$ Identifies patterns in bursting and pausing using outputs from

$\%$ RGSDetect.

$\%$

$\%$ INPUTS:

\% Bursts: Structure containing burst information obtained from RGSDetect.

\% Pauses: Structure containing pause information obtained from RGSDetect.

$\% \mathrm{dt}$ : Minimum threshold connecting burst and pause events. Argument can

$\%$ take single threshold or vector of thresholds.

$\%$

$\%$ OUTPUTS:

\% NOTE: Each structure element of both outputs have $L$ cells containing

$\% \mathrm{NxM}$ matrices, where $\mathrm{L}$ is the length of vector $\mathrm{dt}, \mathrm{N}$ is the number

$\%$ of hits and $\mathrm{M}$ is the length of the pattern. Each element of the cell

$\%$ contains the results of its respective threshold in $\mathrm{dt}$.

$\%$ NOTE: Thresholds dynamically attenuated so they do not fall past

$\%$ more than one event.

$\%$

\% BSPB: Structure containing patterns associated with string pauses.

$\%$ BSPB.BSPHits (s): Cell of 2 column matrices. The matrices

$\%$ contain string pauses falling within the threshold past bursts.

\% Each row is one pattern where the first column contains burst

$\%$ start times, and the second column contains pause start times.

$\%$ BSPB.SPBHits (s): Cell of 2 column matrices. The matrices

$\%$ contain bursts falling within the threshold past string pauses.

$\%$ Each row is one pattern where the first column contains string

$\%$ pause start times, and the second column contains burst start times.

\% BSPB.BSPBHits (s): Cell of 3 column matrices. The matrices

$\%$ contain bursts falling within the threshold past string pauses.

$\%$ Each row is one pattern where the first column contains string

$\%$ pause start times, and the second column contains burst start times.

\% BDPB: Structure containing patterns associated with discrete

$\%$ pauses.

$\%$ BDPB.BDPHits (s): Cell of 2 column matrices. The matrices

$\%$ contain discrete pauses falling within the threshold past bursts.

\% Each row is one pattern where the first column contains burst

$\%$ start times, and the second column contains pause start times. 
\% BDPB.DPBHits (s): Cell of 2 column matrices. The matrices

$\%$ contain bursts falling within the threshold past discrete pauses.

$\%$ Each row is one pattern where the first column contains

$\%$ discrete pause start times, and the second column contains

$\%$ burst start times.

$\%$ BDPB.BDPBHits (s): Cell of 3 column matrices. The matrices

$\%$ contain bursts falling within the threshold past discrete pauses.

$\%$ Each row is one pattern where the first column contains

$\%$ discrete pause start times, and the second column contains

$\%$ burst start times.

$\%$

\% EXAMPLE values used in this paper:

$\%$ Spikes $=($ Spike times go here);

$\%$ N_min $=2$;

$\%$ Steps $=-3: 0.005: 1.5$

$\% \mathrm{p}=0.05$

$\%$ alpha $=0.05$

$\%$ [Bursts, Pauses] = RGSDetect(Spikes, N_min, Steps, $\mathrm{p}$, alpha);

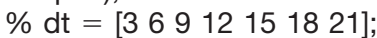

$\%$ [BSPB, BDPB] $=$

BurstPausePatternDetector(Bursts,Pauses, dt); $\%$

$\% \%$ Initialization

BWindows = Bursts. Windows;

BurstStarts = BWindows(:,1);

BurstEnds = BWindows(:,2);

PWindows $=$ Pauses. Windows;

PauseStarts = PWindows(:,1);

PauseEnds = PWindows(:,2);

DPStarts $=$ Pauses.AllSpikes;

DPEnds = Pauses.AllSpikes + Pauses.AllLengths;

$\% \% * *$ Burst-String Pause-Burst $* *$ Search

\%B-SP Sub-search

BSPHits = cell(length(dt),1);

for $\mathrm{i}=1$ :length(dt)

\%Add threshold to end of all burst events.

edges $=[\text { BurstEnds BurstEnds }+\mathrm{dt}(\mathrm{i}) / 60]^{\prime}$;

edges = edges(:)';

$\%$ Fix ranges that overlap.

edges $($ diff(edges) $<=0)=\operatorname{edges}($ logical $([0$ diff(edges $)<=0]))$ $10^{\wedge}(-8)$;

\%Histogram count the string pauses using ranges (edges).

$[\mathrm{N}, \sim$,bin $]=$ histcounts (PauseStarts,edges)

$\%$ Take only the first string pause after each burst.

bin(logical([0; diff(bin) $\left.\left.==0]^{\prime}\right)\right)=0$;

$\%$ Use the results from even bins.

$\operatorname{bin}(\bmod (\operatorname{bin}, 2)==0)=0$;

bin(bin $\sim=0)=1$;

$\mathrm{N}(2: 2$ :end $)=\square$;

\%Assign results to BSPHits.

BSPHits(i) $=\{[$ BurstStarts $(\mathrm{N} \sim=0)$ PauseStarts $($ logical(bin) $)]\}$;

end

BSPB.BSPHits = BSPHits;

\%SP-B Sub-search

SPBHits = cell(length(dt),1);

for $\mathrm{i}=1$ :length(dt)

edges $=[$ PauseEnds PauseEnds + dt(i)/60]';

edges $=$ edges(:)'; edges(diff(edges) $<=0$ ) = edges $($ logical $([0$ diff(edges $)<=0]))-$ $10^{\wedge}(-8)$;

$[\mathrm{N}, \sim$,bin $]=$ histcounts(BurstStarts,edges);

$\operatorname{bin}\left(\operatorname{logical}\left([0 ; \operatorname{diff}(\operatorname{bin})==0]^{\prime}\right)\right)=0$;

$\operatorname{bin}(\bmod (\operatorname{bin}, 2)==0)=0$;

$\operatorname{bin}($ bin $\sim=0)=1$;

$\mathrm{N}(2: 2:$ end $)=[]$

SPBHits(i) $=\{[$ PauseStarts $(\mathrm{N} \sim=0)$ BurstStarts(logical(bin) $)]\}$;

end

BSPB.SPBHits = SPBHits;

\%B-SP-B Concatenation

BSPBHits = cell(length(dt),1);

for $\mathrm{i}=1$ :length(dt)

\%Obtain results from BSP and SPB

BSPi = BSPHits $\{i\} ;$ SPBi = SPBHits $\{i\}$;

\%Find common start times of string pauses.

[hits,ia,ib] = intersect(BSPi(:,2),SPBi(:,1));

\%Concatenate the common BSP and SPB patterns into a 3 event pattern.

BSPBHits(i) $=\{[$ BSPi(ia,1) hits SPBi(ib,2)]\};

end

BSPB.BSPBHits = BSPBHits;

$\% \% * *$ Burst-Discrete Pause-Burst $* *$ Search

$\%$ B-DP Sub-search

BDPHits $=$ cell(length $(\mathrm{dt}), 1)$;

for $\mathrm{i}=1$ :length(dt)

edges $=$ [BurstEnds BurstEnds $+\mathrm{dt}(\mathrm{i}) / 60]^{\prime}$;

edges $=$ edges(:)';

edges(diff(edges) $<=0$ ) = edges(logical([0 diff(edges) $<=0]))$ $10^{\wedge}(-8)$;

$[\mathrm{N}, \sim$, bin $]=$ histcounts(DPStarts,edges);

$\operatorname{bin}\left(\right.$ logical $\left.\left([0 ; \operatorname{diff}(\text { bin })==0]^{\prime}\right)\right)=0$;

$\operatorname{bin}(\bmod (\operatorname{bin}, 2)==0)=0$;

bin $($ bin $\sim=0)=1$;

$\mathrm{N}(2: 2$ :end $)=[$;

BDPHits(i) $=\{[$ BurstStarts $(\mathrm{N} \sim=0)$ DPStarts $($ logical(bin) $)]\}$;

end

BDPB.BDPHits = BDPHits;

\%DP-B Sub-search

DPBHits = cell(length(dt),1);

for $i=1$ :length $(d t)$

edges $=[\text { DPEnds DPEnds }+\mathrm{dt}(\mathrm{i}) / 60]^{\prime}$;

edges $=$ edges $(:)^{\prime}$;

edges $($ diff(edges) $<=0)=\operatorname{edges}($ logical $([0$ diff(edges $)<=0]))$ $10^{\wedge}(-8)$;

$[\mathrm{N}, \sim$,bin $]=$ histcounts(BurstStarts,edges);

$\operatorname{bin}\left(\operatorname{logical}\left([0 ; \operatorname{diff}(\operatorname{bin})==0]^{\prime}\right)\right)=0$;

$\operatorname{bin}(\bmod (\operatorname{bin}, 2)==0)=0$;

$\operatorname{bin}($ bin $\sim=0)=1$;

$\mathrm{N}(2: 2$ :end $)=[$;

DPBHits(i) $=\{[$ DPStarts $(\mathrm{N} \sim=0)$ BurstStarts $($ logical(bin) $)]\}$;

end

BDPB.DPBHits = DPBHits;

\%B-DP-B Concatenation

BDPBHits = cell(length(dt), 1 );

for $\mathrm{i}=1$ :length $(\mathrm{dt})$

BDPi $=$ BDPHits $\{i\} ;$ DPBi $=$ DPBHits $\{i\}$;

[hits,ia,ib] = intersect(BDPi(:,2),DPBi(:,1));

BDPBHits(i) $=\{[\operatorname{BDPi}(i a, 1)$ hits DPBi(ib,2)]\};

end

BDPB.BDPBHits = BDPBHits;

end 
Table 7. Statistics

Dataset

Fig. 1B. Active lever presses (saline-treated vs self-administering mice)

Fig. 1D. Active vs total lever presses in saline-treated mice

Fig. 1E. Drug reinforcers (saline-treated vs self-administering mice)

Incubation effect of amphetamine challenge in self-administering mice

Fig. 1F. Active lever presses (self-administering mice without and with amphetamine and nicotine)

Fig. 1l. Cue reinforcers (self-administering mice without and with amphetamine and nicotine)

Fig. 1G. Number of inactive lever presses (self-administering mice treated with amphetamine vs self-administering mice treated with amphetamine and nicotine)

Fig. $1 \mathrm{H}$. Percentage ratio of active/total lever presses (self-administering mice treated with amphetamine vs self-administering mice treated with amphetamine and nicotine)

Fig. 2A. Baseline firing frequency (saline-treated vs self-administering mice)

Fig. 2B. Peak firing frequency power (saline-treated vs self-administering mice)

Fig. 2D. Peak firing frequency distribution (saline-treated vs self-administering mice)

Fig. 2E. Firing frequency in saline-treated mice (vehicle vs amphetamine)

Fig. 2F. Firing frequency in self-administering mice (vehicle vs amphetamine)

Fig. 2E. Firing frequency in saline-treated mice (vehicle vs amphetamine with nicotine)

Fig. 2E. Firing frequency in saline-treated mice (amphetamine vs amphetamine with nicotine)

Fig. 2F. Firing frequency in self-administering mice (vehicle vs amphetamine with nicotine)

Fig. 2F. Firing frequency in self-administering mice (amphetamine vs amphetamine with nicotine)

Fig. $2 \mathrm{H}$. Peak firing frequency distribution in saline-treated mice (vehicle vs amphetamine)

Fig. $2 \mathrm{H}$. Peak firing frequency distribution in saline-treated mice (vehicle vs amphetamine with nicotine)

Fig. $2 \mathrm{H}$. Peak firing frequency distribution in saline-treated mice (amphetamine vs amphetamine with nicotine)

Fig. 2l. Peak firing frequency distribution in self-administering mice (vehicle vs amphetamine)

Fig. 2l. Peak firing frequency distribution in self-administering mice (vehicle vs amphetamine with nicotine)

Fig. 2l. Peak firing frequency distribution in self-administering mice (amphetamine vs amphetamine with nicotine)

Fig. 2J. Peak firing frequency distribution (saline-treated vs self-administering mice)

Fig. 3C. Discrete bursting (saline-treated vs self-administering mice)

Fig. 3D. Intra-burst frequency (saline-treated vs self-administering mice)

Fig. 3D. Burst length in saline-treated mice (saline-treated vs self-administering mice)

Fig. 3D. Time bursting (saline-treated vs self-administering mice)

Fig. 3E. Discrete pausing (saline-treated vs self-administering mice)

Fig. 3F. Intra-pause frequency (saline-treated vs self-administering mice)

Fig. 3F. Pause string length (saline-treated vs self-administering mice)

Fig. 3F. Time pausing (saline-treated vs self-administering mice)

Fig. 3G. Rate of burst and pause pattern occurrence (saline-treated vs self-administering mice)

Fig. 3H. Rate of pause and burst pattern occurrence (saline-treated vs self-administering mice)

Fig. 3I. Rate of burst-pause-burst pattern occurrence (saline-treated vs self-administering mice)

Fig. 4A. Discrete bursting in saline-treated mice (vehicle vs amphetamine)

Fig. 4A. Discrete bursting in saline-treated mice (vehicle vs amphetamine with nicotine)

Fig. 4A. Discrete bursting in saline-treated mice (amphetamine vs amphetamine with nicotine)

Fig. 4B. Intra-burst frequency in saline-treated mice (vehicle vs amphetamine)

Fig. 4B. Intra-burst frequency in saline-treated mice (vehicle vs amphetamine with nicotine)

Fig. 4B. Intra-burst frequency in saline-treated mice (amphetamine vs amphetamine with nicotine)

Fig. 4B. Burst length in saline-treated mice (vehicle vs amphetamine)

Fig. 4B. Burst length in saline-treated mice (amphetamine vs amphetamine with nicotine)

Fig. 4B. Burst length in saline-treated mice (vehicle vs amphetamine with nicotine)

Fig. 4B. Time spent bursting in saline-treated mice (vehicle vs amphetamine)

Fig. 4B. Time spent bursting in saline-treated mice (amphetamine vs amphetamine with nicotine)

Fig. 4B. Time spent bursting in saline-treated mice (vehicle vs amphetamine with nicotine)

Fig. 4C. Discrete pausing in saline-treated mice (vehicle vs amphetamine)

Fig. 4C. Discrete pausing in saline-treated mice (vehicle vs amphetamine with nicotine)

Fig. 4C. Discrete pausing in saline-treated mice (amphetamine vs amphetamine with nicotine)

Fig. 4D. Intra-pause frequency in saline-treated mice (vehicle vs amphetamine)

Fig. 4D. Intra-pause frequency in saline-treated mice (vehicle vs amphetamine with nicotine)

Fig. 4D. Intra-pause frequency in saline-treated mice (amphetamine vs amphetamine with nicotine)

Fig. 4D. Pause string length in saline-treated mice (vehicle vs amphetamine)

Fig. 4D. Pause string length in saline-treated mice (vehicle vs amphetamine with nicotine)

Fig. 4D. Pause string length in saline-treated mice (amphetamine vs amphetamine with nicotine)

Fig. 4D. Time spent pausing in saline-treated mice (vehicle vs amphetamine)

Fig. 4D. Time spent pausing in saline-treated mice (amphetamine vs amphetamine with nicotine)

Fig. 4D. Time spent pausing in saline-treated mice (vehicle vs amphetamine with nicotine)

Fig. 4E. Discrete bursting in self-administering mice (vehicle vs amphetamine)

Fig. 4E. Discrete bursting in self-administering mice (vehicle vs amphetamine with nicotine)

Fig. 4E. Discrete bursting in self-administering mice (amphetamine vs amphetamine with nicotine)

Fig. 4F. Intra-burst frequency in self-administering mice (vehicle vs amphetamine)

Fig. 4F. Intra-burst frequency in self-administering mice (amphetamine vs amphetamine with nicotine)

Fig. 4F. Intra-burst frequency in self-administering mice (vehicle vs amphetamine with nicotine)

Fig. 4F. Burst length in self-administering mice (vehicle vs amphetamine)

Fig. 4F. Burst length in self-administering mice (amphetamine vs amphetamine with nicotine)

Fig. 4F. Burst length in self-administering mice (vehicle vs amphetamine with nicotine)

Fig. 4F. Time spent bursting in self-administering mice (vehicle vs amphetamine with nicotine)

Fig. 4F. Time spent bursting in self-administering mice (amphetamine vs amphetamine with nicotine)

Fig. 4F. Time spent bursting in self-administering mice (vehicle vs amphetamine with nicotine)

Fig. 4G. Discrete pausing in self-administering mice (vehicle vs amphetamine)

Fig. 4G. Discrete pausing in self-administering mice (amphetamine vs amphetamine with nicotine)

Fig. 4G. Discrete pausing in self-administering mice (vehicle vs amphetamine with nicotine)

Fig. $4 \mathrm{H}$. Intra-pause frequency in self-administering mice (vehicle vs amphetamine)
Data structure

Normal distribution

Normal distribution

Normal distribution

Normal distribution

Normal distribution

Normal distribution

Normal distribution

Normal distribution

Type of test

Two-way ANOVA

$p$ value

wo-way ANOVA

$<0.0001$

paired $t$ test

paired $t$ test

paired $t$ test

0.01

0.02

0.02

0.07

paired $t$ test

0.15

Normal distribution

Normal distribution

Normal distribution

Normal distribution

Normal distribution

Normal distribution

Normal distribution

Normal distribution

Normal distribution

Normal distribution

Normal distribution

Normal distribution

Normal distribution

Normal distribution

Normal distribution

Normal distribution

Normal distribution

Normal distribution

Normal distribution

Normal distribution

Normal distribution

Normal distribution

Normal distribution

Normal distribution

Normal distribution

Normal distribution

Normal distribution

Normal distribution

Normal distribution

Normal distribution

Normal distribution

Normal distribution

Normal distribution

Normal distribution

Normal distribution

Normal distribution

Normal distribution

Normal distribution

Normal distribution

Normal distribution

Normal distribution

Normal distribution

Normal distribution

Normal distribution

Normal distribution

Normal distribution

Normal distribution

Normal distribution

Normal distribution

Normal distribution

Normal distribution

Normal distribution

Normal distribution

Normal distribution

Normal distribution

Normal distribution

Normal distribution

Normal distribution

Normal distribution

Normal distribution

Normal distribution

Normal distribution

Normal distribution

Normal distribution

Normal distribution

Normal distribution

Normal distribution
Student's $t$ test

Student's $t$ test

Student's $t$ test

paired $t$ test

paired $t$ test

paired $t$ test

paired $t$ test

paired $t$ test

paired $t$ test

paired $t$ test

paired $t$ test

paired $t$ test

paired $t$ test

paired $t$ test

paired $t$ test

Student's $t$ test

Student's $t$ test

Student's $t$ test

Student's $t$ test

Student's $t$ test

Student's $t$ test

Student's $t$ test

Student's $t$ test

Student's $t$ test

Student's $t$ tes

Student's $t$ test

Student's $t$ tes

Paired $t$ test

Paired $t$ test

Paired $t$ test

Paired $t$ test

Paired $t$ test

Paired $t$ test

Paired $t$ test

Paired $t$ test

Paired $t$ test

Paired $t$ test

Paired $t$ tes

Paired $t$ test

Paired $t$ test

Paired $t$ test

Paired $t$ test

Paired $t$ test

Paired $t$ test

Paired $t$ test

Paired $t$ test

Paired $t$ test

Paired $t$ tes

Paired $t$ test

Paired $t$ test

Paired $t$ tes

Paired $t$ test

Paired $t$ test

Paired $t$ test

Paired $t$ test

Paired $t$ test

Paired $t$ test

Paired $t$ test

Paired $t$ test

Paired $t$ test

Paired $t$ tes

Paired $t$ test

Paired $t$ test

Paired $t$ test

Paired $t$ test

Paired $t$ test

Paired $t$ tes
0.03

0.02

0.02

0.006

0.04

0.3

0.04

0.3

0.08

0.03

0.1

0.008

0.09

0.04

0.09

0.7

0.03

0.009

0.5

0.2

0.8

0.4

0.2

0.02

0.03

0.02

0.5

0.2

0.1

0.3

0.1

0.2

0.09

0.4

0.7

0.5

0.2

0.3

0.1

0.6

0.2

0.06

0.2

0.1

0.2 


\section{Datase}

Fig. $4 \mathrm{H}$. Intra-pause frequency in self-administering mice (amphetamine vs amphetamine with nicotine) Fig. $4 \mathrm{H}$. Intra-pause frequency in self-administering mice (vehicle vs amphetamine with nicotine) Fig. $4 \mathrm{H}$. Pause string length in self-administering mice (vehicle vs amphetamine)

Fig. $4 \mathrm{H}$. Pause string length in self-administering mice (amphetamine vs amphetamine with nicotine)

Fig. $4 \mathrm{H}$. Pause string length in self-administering mice (vehicle vs amphetamine with nicotine)

Fig. $4 \mathrm{H}$. Time spent pausing in self-administering mice (vehicle vs amphetamine)

Fig. $4 \mathrm{H}$. Time spent pausing in self-administering mice (amphetamine vs amphetamine with nicotine)

Fig. $4 \mathrm{H}$. Time spent pausing in self-administering mice (vehicle vs amphetamine with nicotine)

Fig. 5A. Chl frequency (saline-treated vs self-administering mice)

Fig. 5A. Chl frequency in saline-treated mice (vehicle vs nicotine

Fig. 5A. Chl frequency in self-administering mice (vehicle vs nicotine)

Fig. 5C. Peak frequency in saline-treated mice (vehicle vs nicotine)

Fig. 5D. Peak frequency in saline-treated mice (vehicle vs nicotine)

Fig. 5E. Peak frequency in saline-treated mice (vehicle vs nicotine)

Fig. 5F. Discrete bursting in saline-treated mice (vehicle vs nicotine)

Fig. 5G. Intra-burst frequency in saline-treated mice (vehicle vs nicotine)

Fig. 5G. Burst length in saline-treated mice (vehicle vs nicotine)

Fig. 5G. Time bursting in saline-treated mice (vehicle vs nicotine)

ac Fig. $5 \mathrm{H}$. Discrete pausing in saline-treated mice (vehicle vs nicotine)

Fig. 5I. Intra-pause frequency in saline-treated mice (vehicle vs nicotine)

Fig. 5l. Pause length in saline-treated mice (vehicle vs nicotine)

Fig. 5l. Time pausing in saline-treated mice (vehicle vs nicotine)

ad Fig. 5J. Discrete bursting in self-administering mice (vehicle vs nicotine)

Fig. $5 \mathrm{~K}$. Intra-burst frequency in self-administering mice (vehicle vs nicotine)

Fig. 5K. Burst length in self-administering mice (vehicle vs nicotine)

ae $\quad$ Fig. 5K. Time bursting in self-administering mice (vehicle vs nicotine)

af Fig. 5L. Discrete pausing in self-administering mice (vehicle vs nicotine)

ag Fig. 5M. Intra-pause frequency in self-administering mice (vehicle vs nicotine)

ah Fig. 5M. Pause length in self-administering mice (vehicle vs nicotine)

Fig. 5M. Time pausing in saline-treated mice (vehicle vs nicotine)

Fig. 6A. mEPSC frequency (saline-treated mice vs self-administering mice)

Fig. 6A. mEPSC frequency (saline-treated mice vs nonresponding mice)

ak Fig. 6A. mEPSC frequency (self-administering mice vs nonresponding mice)

Fig. 6B. mEPSC frequency (saline-treated mice vs self-administering mice)

Fig. $6 \mathrm{~B}$. mEPSC frequency (saline-treated mice vs nonresponding mice)

Fig. 6C. Peak frequency of mEPSCs (saline-treated mice vs self-administering mice)

Fig. $6 C$. Peak frequency of mEPSCs (saline-treated mice vs nonresponding mice)

Fig. 6C. Peak frequency of mEPSCs (self-administering mice vs nonresponding mice)

Fig. 6D. mEPSC frequency in saline-treated mice (vehicle vs amphetamine)

an Fig. 6D. mEPSC frequency in saline-treated mice (vehicle vs amphetamine with nicotine)

am Fig. 6D. mEPSC frequency in saline-treated mice (amphetamine vs amphetamine with nicotine)

Fig. 6E. mEPSC frequency in saline-treated mice (vehicle vs amphetamine)

Fig. 6E. mEPSC frequency in saline-treated mice (vehicle vs amphetamine with nicotine)

Fig. 6E. mEPSC frequency in saline-treated mice (amphetamine vs amphetamine with nicotine)

Fig. 6F. Peak frequency of mEPSCs in saline-treated mice (vehicle vs amphetamine)

Fig. 6F. Peak frequency of mEPSCs in saline-treated mice (vehicle vs amphetamine with nicotine)

Fig. 6F. Peak frequency of mEPSCs in saline-treated mice (amphetamine vs amphetamine with nicotine)

Fig. 6G. mEPSC frequency in self-administering mice (vehicle vs amphetamine)

ap Fig. 6G. mEPSC frequency in self-administering mice (amphetamine vs amphetamine with nicotine)

Fig. $6 \mathrm{H}$. mEPSC frequency in self-administering mice (vehicle vs amphetamine)

Fig. $6 \mathrm{H}$. mEPSC frequency in self-administering mice (vehicle vs amphetamine with nicotine)

Fig. $6 \mathrm{H}$. mEPSC frequency in self-administering mice (amphetamine vs amphetamine with nicotine)

Fig. 6I. Peak frequency of mEPSCs in self-administering mice (vehicle vs amphetamine)

Fig. 6l. Peak frequency of mEPSCs in self-administering mice (vehicle vs amphetamine with nicotine)

Fig. 6l. Peak frequency of mEPSCs in self-administering mice (amphetamine vs amphetamine with nicotine)

Fig. 6J. Peak frequency of mEPSCs (saline-treated mice vs self-administering mice with nicotine)

Fig. 6K. mEPSC frequency in nonresponding mice (vehicle vs amphetamine)

ar Fig. 6K. mEPSC frequency in nonresponding mice (amphetamine vs amphetamine with nicotine)

Fig. 6L. mEPSC frequency in nonresponding mice (vehicle vs amphetamine)

Fig. 6L. mEPSC frequency in nonresponding mice (vehicle vs amphetamine with nicotine)

Fig. 6L. mEPSC frequency in nonresponding mice (amphetamine vs amphetamine with nicotine)

Fig. 6M. Peak frequency of mEPSCs in nonresponding mice (vehicle vs amphetamine)

Fig. 6M. Peak frequency of mEPSCs in nonresponding mice (vehicle vs amphetamine with nicotine)

Fig. 6M. Peak frequency of mEPSCs in nonresponding mice (amphetamine vs amphetamine with nicotine)

Fig. 7A. mEPSC frequency in saline-treated mice (vehicle vs nicotine)

Fig. 7B. mEPSC frequency in saline-treated mice (vehicle vs nicotine)

Fig. 7C. Peak frequency of mEPSCs in saline-treated mice (vehicle vs amphetamine)

at Fig. 7D. mEPSC frequency in self-administering mice (vehicle vs nicotine)

Fig. 7E. mEPSC frequency in self-administering mice (vehicle vs nicotine)

Fig. 7F. Peak frequency of mEPSCs in self-administering mice (vehicle vs amphetamine)

Fig. 7G. mEPSC frequency in saline-treated mice (vehicle vs nicotine)

au Fig. 7G. mEPSC frequency (saline-treated mice vs self-administering mice)

av Fig. 7G. mEPSC frequency in self-administering mice (vehicle vs nicotine)

Fig. $7 \mathrm{H}$. mEPSC frequency (saline-treated mice vs self-administering mice with nicotine)

Fig. 71. mEPSC frequency in saline-treated mice (vehicle vs nicotine with $\mathrm{DH} \beta \mathrm{E}$ )

Fig. 7J. mEPSC frequency in saline-treated mice (vehicle vs nicotine with $\mathrm{DH} \beta \mathrm{E}$ )

Fig. 7K. mEPSC frequency in saline-treated mice (vehicle vs nicotine with MLA)

Fig. 7L. mEPSC frequency in saline-treated mice (vehicle vs nicotine with MLA)

ay Fig. 8B. Ambulations of saline-treated mice vs amphetamine-treated mice

az Fig. 8C. Ambulations of saline-treated mice vs amphetamine-treated mice
Data structure

Normal distribution

Normal distribution

Normal distribution

Normal distribution

Normal distribution

Normal distribution

Normal distribution

Normal distribution

Normal distribution

Normal distribution

Normal distribution

Normal distribution

Normal distribution

Normal distribution

Normal distribution

Normal distribution

Normal distribution

Normal distribution

Normal distribution

Normal distribution

Normal distribution

Normal distribution

Normal distribution

Normal distribution

Normal distribution

Normal distribution

Normal distribution

Normal distribution

Normal distribution

Normal distribution

Normal distribution

Normal distribution

Normal distribution

Normal distribution

Normal distribution

Normal distribution

Normal distribution

Normal distribution

Normal distribution

Normal distribution

Normal distribution

Normal distribution

Normal distribution

Normal distribution

Normal distribution

Normal distribution

Normal distribution

Normal distribution

Normal distribution

Normal distribution

Normal distribution

Normal distribution

Normal distribution

Normal distribution

Normal distribution

Normal distribution

Normal distribution

Normal distribution

Normal distribution

Normal distribution

Normal distribution

Normal distribution

Normal distribution

Normal distribution

Normal distribution

Normal distribution

Normal distribution

Normal distribution

Normal distribution

Normal distribution

Normal distribution

Normal distribution

Normal distribution

Normal distribution

Normal distribution

Normal distribution

Normal distribution

Normal distribution

Normal distribution

Normal distribution
Type of test

Paired $t$ test

Paired $t$ test

Paired $t$ test

Paired $t$ test

Paired $t$ test

Paired $t$ test

Paired $t$ test

Paired $t$ test

Student's $t$ test

Paired $t$ test

Paired $t$ test

Paired $t$ test

Paired $t$ test

Student's $t$ test

Paired $t$ test

Paired $t$ test

Paired $t$ test

Paired $t$ test

Paired $t$ test

Paired $t$ test

Paired $t$ test

Paired $t$ test

Paired $t$ test

Paired $t$ test

Paired $t$ test

Paired $t$ test

Paired $t$ test

Paired $t$ test

Paired $t$ test

Paired $t$ test

Student's $t$ test

Student's $t$ test

Student's $t$ test

Bonferroni $t$ test

Bonferroni $t$ test

Student's $t$ test

Student's $t$ test

Student's $t$ test

Paired $t$ test

Paired $t$ test

Paired $t$ test

Bonferroni $t$ test

Bonferroni $t$ test

Bonferroni $t$ test

Paired $t$ test

Paired $t$ test

Paired $t$ test

Paired $t$ test

Paired $t$ test

Bonferroni $t$ test

Bonferroni $t$ test

Bonferroni $t$ test

Paired $t$ test

Paired $t$ test

Paired $t$ test

Student's $t$ test

Paired $t$ test

Paired $t$ test

Bonferroni $t$ test

Bonferroni $t$ test

Bonferroni $t$ test

Paired $t$ test

Paired $t$ test

Paired $t$ test

Paired $t$ test

Bonferroni $t$ test

Paired $t$ test

Paired $t$ test

Bonferroni $t$ test

Paired $t$ test

Paired $t$ test

Student's $t$ test

Paired $t$ test

Student's $t$ test

Paired $t$ test

Bonferroni $t$ test

Paired $t$ test

Bonferroni $t$ test

rm ANOVA

2-way rm-ANOVA

0.4

0.5

0.04

0.08

0.2

0.03

0.04

0.03

0.02

0.01

0.04

0.08

0.7

0.0008

0.4

0.5

0.01

0.02

0.02

0.02

0.1

0.04

0.003

0.0003

0.00003

0.002

0.009

0.006

0.0008

0.04

0.01

0.04

0.04

0.01

0.09

0.7 


\begin{tabular}{|c|c|c|c|c|}
\hline & Dataset & Data structure & Type of test & $p$ value \\
\hline ba & Fig. 8D. Ambulations of saline-treated mice (low-dose vs high-dose nicotine) & Normal distribution & 2-way rm-ANOVA & 0.9 \\
\hline $\mathrm{bb}$ & Fig. 8E. Ambulations of amphetamine-treated mice (amphetamine vs amphetamine with low-dose nicotine) & Normal distribution & 2-way rm-ANOVA & 1 \\
\hline bc & Fig. 8E. Ambulations of amphetamine-treated mice (amphetamine vs amphetamine with high-dose nicotine) & Normal distribution & 2-way rm-ANOVA & 0.01 \\
\hline bd & Fig. 8F. Ambulations of saline-treated mice (amphetamine vs amphetamine with high-dose nicotine) & Normal distribution & 2-way rm-ANOVA & 0.9 \\
\hline be & $\begin{array}{l}\text { Fig. } 8 \mathrm{G} \text {. Ambulations of saline-treated mice challenged with nicotine vs amphetamine-treated mice challenged } \\
\text { with nicotine }\end{array}$ & Normal distribution & 2-way rm-ANOVA & 0.9 \\
\hline bf & Fig. $8 \mathrm{H}$. eEPSC amplitude in saline-treated mice (vehicle vs nicotine) & Normal distribution & Paired $t$ test & 0.02 \\
\hline $\mathrm{bg}$ & Fig. $8 \mathrm{H}$. PPR in saline-treated mice (vehicle vs nicotine) & Normal distribution & Paired $t$ test & 0.009 \\
\hline bh & Fig. 8l. eEPSC amplitude in amphetamine-treated mice (vehicle vs nicotine) & Normal distribution & Paired $t$ test & 0.0008 \\
\hline bi & Fig. 8I. PPR in amphetamine-treated mice (vehicle vs nicotine) & Normal distribution & Paired $t$ test & 0.013 \\
\hline bj & Fig. 8H,I. eEPSC amplitude (saline-treated mice vs amphetamine-treated mice) & Normal distribution & Student's $t$ test & 0.02 \\
\hline bk & Fig. $8 \mathrm{H}$,I. eEPSC amplitude (saline-treated mice with nicotine vs amphetamine-treated mice with nicotine) & Normal distribution & Student's $t$ test & 0.2 \\
\hline
\end{tabular}

allowed, after $10 \mathrm{~d}$ at FR1, during which one lever press resulted in one reinforcer. We designated this group as amphetamine self-administering mice. Of the 10 remaining mice, five were removed due to occluded catheters. Five additional mice that had not obtained more than an average of 20 reinforcers during the last three sessions of FR1 were designated as nonresponding mice and excluded from the rest of the behavioral study. The 10 amphetamine self-administering mice progressed from FR1 to FR2 and FR5 schedules of reinforcement. A further 10 saline-treated mice underwent the identical procedure, but received saline instead of amphetamine. Salinetreated mice were included in all parts of the acquisition phase, and 5 of 10 underwent abstinence and a saline challenge. Figure $1 B-E$ demonstrates the different measures recorded during the acquisition phase.

The number of active lever presses by the amphetamine self-administering mice increased from 45 to 76 during the first $3 \mathrm{~d}$ of FR1 and then plateaued at 60-70 presses for the remaining $7 \mathrm{~d}$ of FR1 (Fig. 1B). Thereafter, the number of active lever presses increased to $\sim 120$ at FR2 and to $\sim 240$ at FR5. This increase in the number of active presses required to receive the same number of infusions demonstrates the motivation of this group to receive amphetamine.

The active and inactive lever pressing of saline-treated and nonresponding mice was minimal (Fig. 1C). Likewise, amphetamine self-administering mice did not often press the inactive lever, but their active lever presses increased with the fixed ratio of reinforcers (saline-treated vs amphetamine self-administering active lever presses over time; $F_{(15,120)}=26.55, p<0.0001^{a}$, two-way ANOVA; Fig. $1 B$ ). The percentage ratio of active to total (active + inactive) lever presses assessed the ability to discriminate the effect of pressing the active from inactive lever. The amphetamine self-administering mice achieved an average of $90 \pm 3,95 \pm 1$, and $95 \pm 1 \%$ active/total lever presses during FR1, FR2, and FR5, respectively (Fig. 1D). This was greater than the active/total lever ratio in salinetreated mice $\left(F_{(1,7)}=149, p<0.0001^{\mathrm{b}}\right.$, two-way ANOVA) who achieved $55 \pm 3,65 \pm 6$, and $75 \pm 3 \%$ during $F R 1, F R 2$, and FR5. The amphetamine self-administering mice obtained a greater number of drug reinforcers than salinetreated mice $\left(F_{(15,120)}=3.837, p<0.0001^{c}\right.$, two-way ANOVA) and consistently reached 50 , the maximum allowed, during the $2 \mathrm{~h}$ session of each schedule (Fig. 1E).

We assessed the effect of abstinence on drug-seeking behavior. After $7 \mathrm{~d}$ of forced abstinence, we injected the amphetamine self-administering mice with either amphet- amine alone (1 mg/kg, i.p.) or with amphetamine $(1 \mathrm{mg} / \mathrm{kg}$, i.p.) and nicotine $(0.25 \mathrm{mg} / \mathrm{kg}$, i.p.). We then placed the mice in the same operant chamber as used during the acquisition phase for $30 \mathrm{~min}$. This amphetamine challenge resulted in a slight incubation effect when compared with the first 30 min period of the final FR5 session (76 44 vs $63 \pm 4$ active lever presses during the incubation vs FR5 session, respectively; $p=0.01^{d}, t=3.7, d f=6$, paired $t$ test). Nicotine coadministration with amphetamine reduced both the number of active lever presses $\left(-44 \pm 14 \% ; p=0.02^{\mathrm{e}}, t=3.04, \mathrm{df}=5\right.$, paired $t$ test $)$ and the number of reinforcing cues obtained $\left(-37 \pm 9 \% ; p=0.02^{f}\right.$, $t=3.5, \mathrm{df}=5$, paired $t$ test; Fig. $1 F-l)$, resulting in a similar profile of drug-seeking responses as seen in salinetreated mice challenged with a saline injection. Nicotine treatment did not alter lever discrimination, as neither the number of inactive lever presses $\left(p=0.07^{9}, t=2.2, \mathrm{df}=6\right.$, paired $t$ test) nor the percentage ratio of active/total lever presses changed $\left(p=0.15^{\mathrm{h}}, t=1.7, \mathrm{df}=5\right.$, paired $t$ test; Fig. $1 G, H)$.

\section{The tonic firing of Chls is lower in amphetamine self-administering mice}

Psychostimulants enhance DA availability and induce long-lasting plasticity in Chl activity and ACh availability (Bickerdike and Abercrombie, 1997, 1999; Bamford et al., 2008; Witten et al., 2010; Wang et al., 2013a), yet their effect on Chl firing is poorly understood. To determine whether amphetamine self-administration modifies Chl activity ex vivo, we measured their spontaneous firing using cell-attached recordings in acute striatal slices from amphetamine self-administering and saline-treated mice. The baseline firing frequency of Chls from amphetamine self-administering mice $(2.25 \pm 0.03 \mathrm{~Hz}$; range $1.05-4.5$ $\mathrm{Hz}$; $n=15$ cells) was $37 \%$ lower than Chls from salinetreated mice $(3.58 \pm 0.58 \mathrm{~Hz}$; range $1.05-9.06 \mathrm{~Hz} ; n=14$ cells; $p=0.03^{i}$, Student's $t$ test; Fig. $2 A$ ).

Through their widespread dendritic and axonal fields, Chls modulate corticostriatal excitability through changes in the frequency of their tonic firing (Wilson et al., 1990). We developed computer algorithms to examine the power and relative distribution of individual firing frequencies in Chls from saline-treated and amphetamine selfadministering mice (Tables 1-6). The Welch's power spectral density estimate of Chl activity from salinetreated mice revealed a unimodal distribution, with a single local maximum of $3.68 \pm 0.4 \mathrm{~Hz}$ centered on the average frequency of $3.58 \pm 0.58 \mathrm{~Hz}$ (Fig. 2B). Most $(\sim 90 \%)$ individual Chls from amphetamine self-ad- 

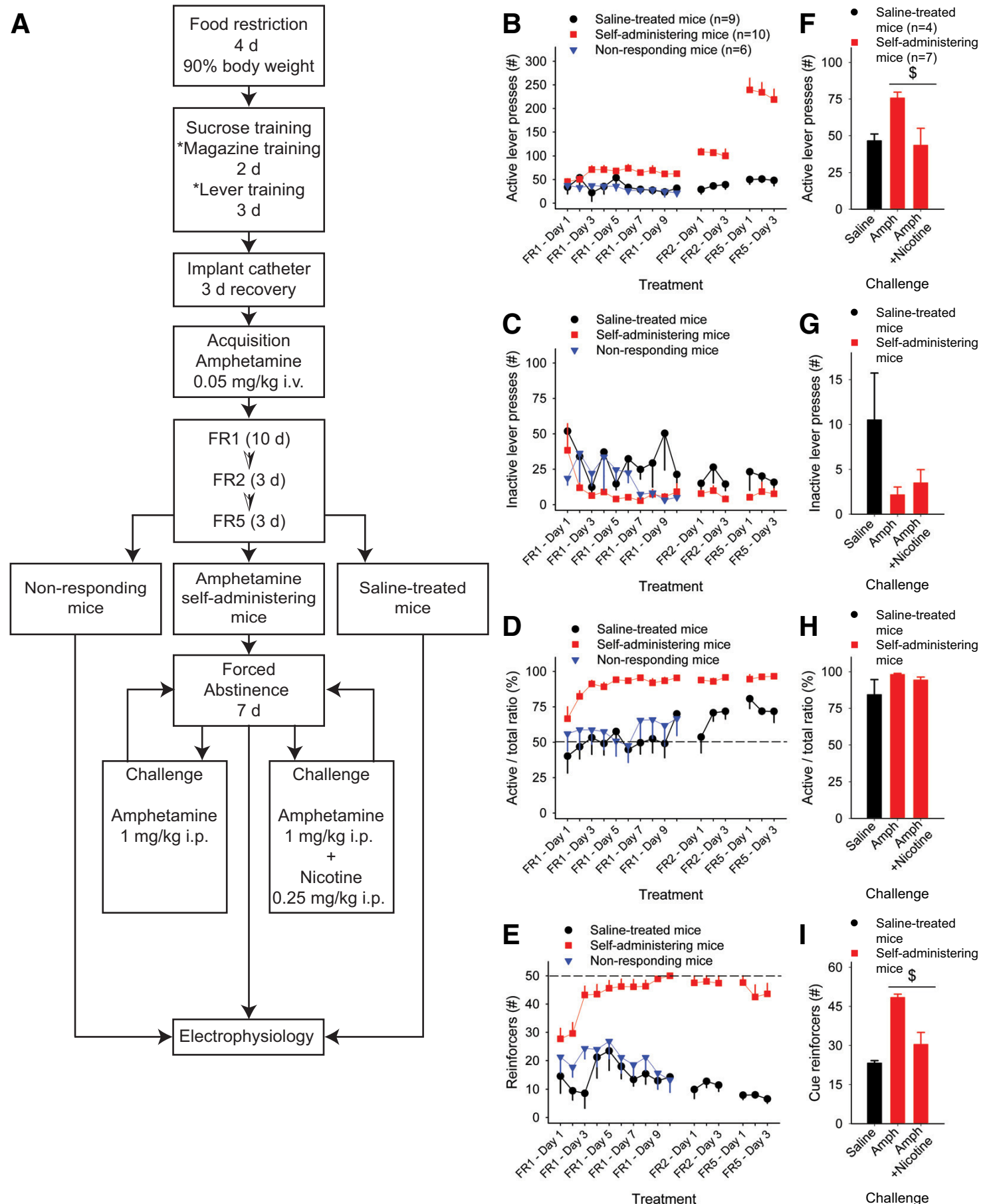

Figure 1. Mice self-administer amphetamine. A, Acquisition of amphetamine self-administration: Following sucrose pretraining, mice were trained to self-administer amphetamine under increasing schedules of reinforcement. After $10 \mathrm{~d}$ on FR1, mice that had not achieved stable responding ( $<20$ reinforcers during the last $3 \mathrm{~d}$ of FR1) were designated as nonresponding mice and were excluded from the remainder of the behavioral study. Thereafter the saline-treated mice and amphetamine self-administering mice underwent a further $6 \mathrm{~d}$ on FR2 and FR5 schedules of reinforcement. Following this acquisition phase, the amphetamine self-administering mice underwent $7 \mathrm{~d}$ of abstinence. This was followed by an amphetamine challenge in the same operant boxes and protocol as used during intravenous self-administration to assess the incubation of drug seeking behaviors. The effect of nicotine on this amphetamine challenge was also assessed. $\boldsymbol{B}$, In comparison with saline-treated mice, amphetamine self-administering mice increased the number of active lever presses. $\boldsymbol{C}$, The number of inactive lever presses was similar across all groups. $\boldsymbol{D}$, Compared with saline-treated mice, the amphetamine self-administering mice showed drug-lever association, as assessed by the ratio of active to total (inactive + active) lever presses (\%). E, During FR1, FR2, and FR5 schedules of reinforcement, amphetamine self-administering mice achieved a greater number of reinforcers than mice treated with saline, often reaching 50 , the maximum allowed during the $2 \mathrm{~h}$ session. $\boldsymbol{F}$, Following forced abstinence, nicotine reduced the total number of active lever presses observed after an amphetamine challenge (G) without 
continued

altering the inactive lever presses. $\boldsymbol{H}$, There was no effect of nicotine on lever discrimination, as shown by the ratio of active/total lever presses. $\boldsymbol{I}$, The administration of nicotine with amphetamine reduced the number of reward-associated cues. The effect of a saline injection on saline-treated mice is shown for comparison with amphetamine self-administering mice. For all panels, ${ }^{\$} p<0.05$, paired $t$ test.

ministering mice also demonstrated a unimodal frequency distribution, but their averaged contributions appeared bimodal, with the uppermost peak frequency centered on the average frequency of Chls from saline-treated mice, whereas the second maxima was centered on lower frequencies $\sim 1 \mathrm{~Hz}$ (Fig. 2B-D). The peak frequencies identified by the power spectral density estimate approximated the frequency distributions derived from their ISIs and showed that Chl spiking in amphetamine selfadministering mice was lower than saline-treated mice due to an increased distribution of low-frequency activity between 0.5 and $1.5 \mathrm{~Hz}$ (Fig. 2C,D).

\section{An amphetamine challenge increases tonic Chl firing in amphetamine self-administering mice}

To determine whether an amphetamine challenge modified Chls activity ex vivo, amphetamine $(10 \mu \mathrm{M})$ was bath-applied in a concentration that elevates striatal DA concentrations to $\sim 3 \mu \mathrm{M}$ (Bamford et al., 2004b), via a reversal of the DA transporter (Sulzer, 2011). Amphetamine reduced the firing frequency of Chls from salinetreated mice by $15 \pm 4 \%(2.64 \pm 0.53 \mathrm{~Hz}$ in vehicle vs $2.24 \pm 0.28 \mathrm{~Hz}$ with amphetamine; $n=7$ cells; $p=0.006^{j}$, paired $t$ test), but increased the firing rate of Chls from amphetamine self-administering mice by $58 \pm 34 \%$ $(1.82 \pm 0.27 \mathrm{~Hz}$ vs $2.65 \pm 0.39 \mathrm{~Hz}$ with amphetamine; $n=6$ cells; $p=0.04^{\mathrm{k}}$, paired $t$ test; Fig. $\left.2 \mathrm{E}-\mathrm{G}\right)$. Spectral analysis showed that amphetamine reduced the average peak frequency in Chls from saline-treated mice by augmenting low-frequency activity between $0.5 \mathrm{~Hz}$ and $1.5 \mathrm{~Hz}$ (Fig. $2 \mathrm{H})$. In Chls from amphetamine self-administering mice, an amphetamine challenge increased activity by diminishing the contribution of those same frequencies (Fig. 2l). Treatment with amphetamine did not reorganize the bimodal frequency distribution of Chl activity in amphetamine self-administering mice, but modified the skewed, fat-tailed firing frequency to better approximate the spectra of Chls from saline-treated mice (Fig. 2E, F, and J).

\section{Nicotine opposes the change in tonic $\mathrm{Chl}$ firing caused by an amphetamine challenge}

Nicotine attenuated amphetamine-induced drug-seeking behaviors (Fig. 1), and we determined whether nicotine

Table 8. Sucrose pre-training

\begin{tabular}{llll}
\hline & Day 1 & Day 2 & Day 3 \\
Left Lever & $21 \pm 3$ & $20 \pm 3$ & $27 \pm 5$ \\
Right Lever & $43 \pm 6$ & $37 \pm 4$ & $41 \pm 5 *$ \\
Time & $40 \pm 5$ & $28 \pm 3$ & $20 \pm 1^{\# \#}$
\end{tabular}

The lever preference (left or right) and time taken to obtain 30 reinforcers during 3 consecutive days of sucrose pretraining. $* p<0.05$ versus day 3 , left lever, ${ }^{\# \#} p<0.01$ versus time to obtain 30 reinforcers on day 1 .
(100 nM) ex vivo, in a concentration that approximates serum levels in smokers (Dani and Harris, 2005), modifies the effect of an amphetamine challenge on tonic Chl firing. When administered with amphetamine in vitro, nicotine blocked amphetamine inhibition of Chl activity in saline-treated mice $(2.64 \pm 0.53 \mathrm{~Hz}$ in vehicle vs $2.61 \pm 0.31 \mathrm{~Hz}$ with amphetamine and nicotine; $p=0.3^{\mathrm{p}}$, paired $t$ test) by enhancing frequencies between 2 and 3 $\mathrm{Hz}$ (Fig. 2E-H). Conversely, in Chls from amphetamine self-administering mice, nicotine suppressed amphetamine-mediated excitation $(1.82 \pm 0.27 \mathrm{~Hz}$ in vehicle vs $2.16 \pm 0.51 \mathrm{~Hz}$ with amphetamine and nicotine; $p=0.3^{q}$, paired $t$ test) by diminishing these same frequencies (Fig. $2 E-G, I)$. Nicotine modified higher frequencies and blocked the change in tonic firing caused by an amphetamine challenge.

\section{Amphetamine self-administration reduces burst firing in Chls}

Reward-reporting stimuli increase the activity of dopaminergic neurons and correlate with a change in Chl activity throughout the striatum (Aosaki et al., 1994). These conditioned responses modify the tonic activity of Chls by producing burst, pause, and rebound burst-firing patterns of various lengths that modify downstream network activity (Graybiel et al., 1994; Fig. 3A). Thus, minute, as well as volume-transmitted changes in ACh availability at nicotinic receptors may encourage gaiting at corticostriatal synapses. Electrophysiological studies have shown that although tonic activity may remain stable, changes in the burst and pause activity of DA neurons may play a role in degenerative disease (Lobb, 2014; Lobb and Jaeger, 2015) and could be altered by psychostimulant exposure. Indeed, Chls show distinct region-specific responses to cocaine (Benhamou et al., 2014), but alterations in Chl burst or pause activity that accompany amphetamine self-administration are unclear.

We used the RGS method to detect and quantify how amphetamine self-administration modifies unique burst and pause patterns in individual Chls. The RGS method has been successful in identifying changes in bursting patterns of DA neurons (Branch et al., 2013; Lobb and Jaeger, 2015), as it exhibits a robust adaptability to varying firing rates through two steps: normalization of local ISI distributions and iterative addition of normalized ISIs, based on the $\mathrm{p}$ value obtained from global Gaussian statistics of the whole spike train, to burst and pause strings. (Ko et al., 2012). RGS thresholds for burst and pause activity were determined in Chls from salinetreated ( $n=13$ cells) and amphetamine self-administering mice ( $n=12$ cells) using Gaussian probability distribution of the ISIs for each cell (see Materials and Methods; 

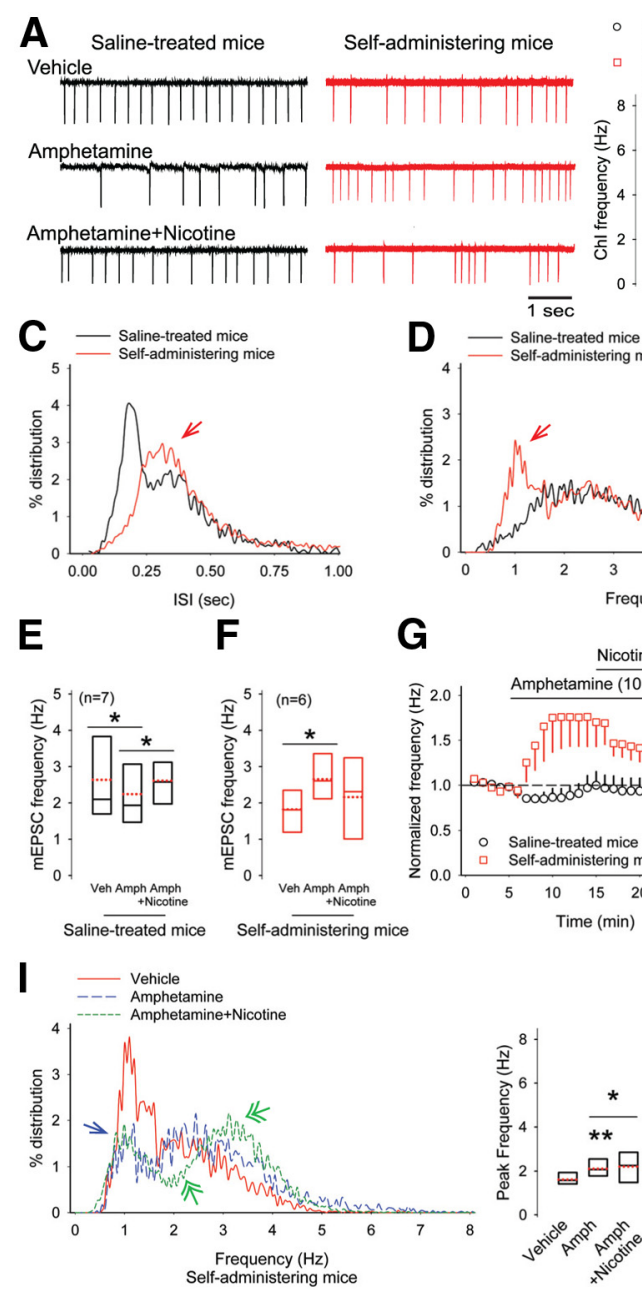

G
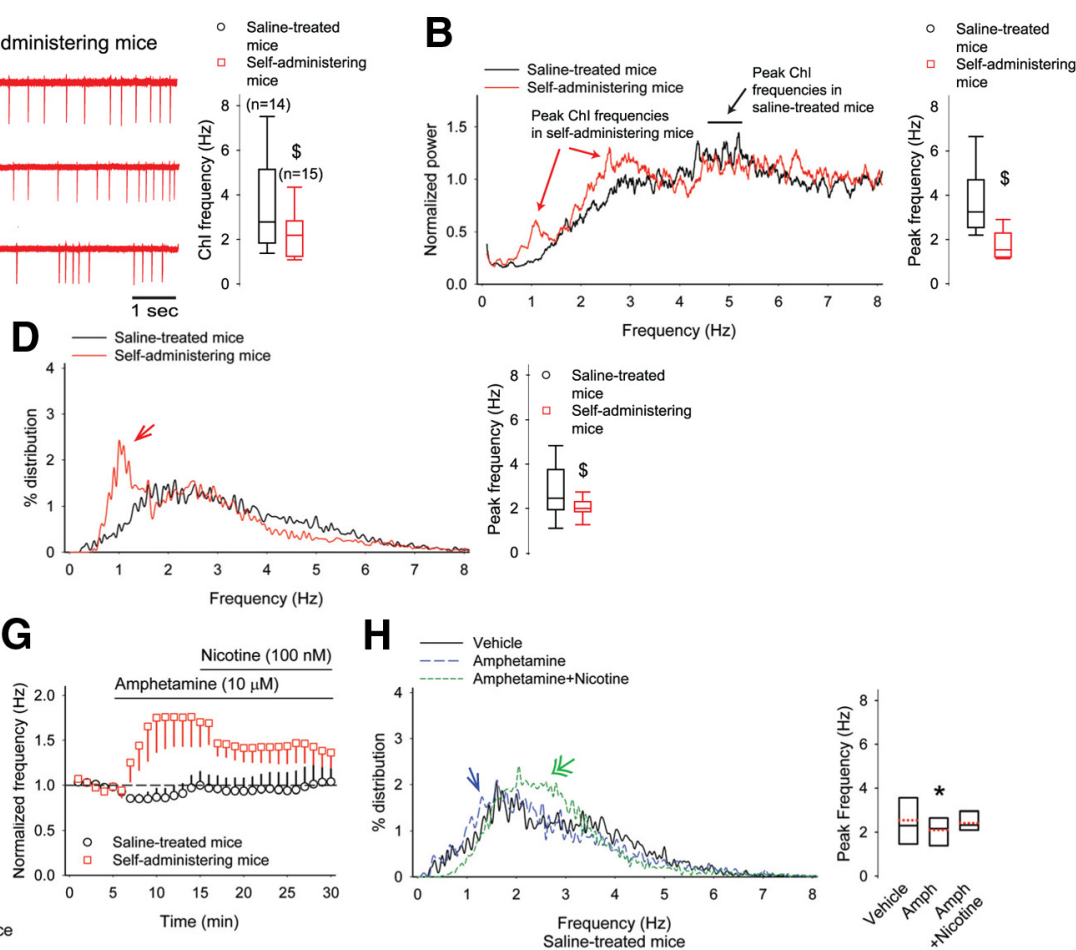

J

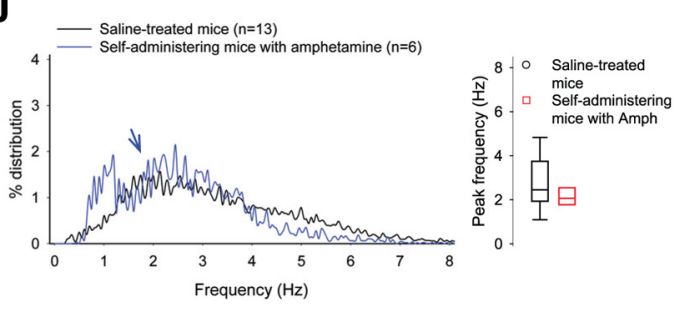

Figure 2. Amphetamine self-administration modifies Chl firing. $\boldsymbol{A}$, Representative traces of cell-attached recordings in Chls from saline-treated and amphetamine self-administering mice (left). The average baseline firing frequency (right) was lower in Chls from amphetamine self-administering mice; This is shown in box-and-whisker plots where the median is shown as a solid line, the mean value is dotted red, the ends of the box indicate the $25^{\text {th }}$ and 75 th percentiles, and the bars indicate the $10^{\text {th }}$ and $90^{\text {th }}$ percentiles. For all panels, ${ }^{\$} p<0.05$, Student's $t$ test; $* p<0.05$ and $* * p<0.01$, paired $t$ test. $\boldsymbol{B}$, The normalized power distribution (left) and the average peak frequency (right) show prominent low-frequency activity in Chls from amphetamine self-administering mice. $\boldsymbol{C}$, The ISI distribution for Chls from saline-treated and amphetamine self-administering mice (arrow). $\boldsymbol{D}$, Frequency distributions (left) and their average peaks (right) show the prominent low-frequency distribution (1/ISI) of Chl firing from amphetamine self-administering mice (arrow). $\boldsymbol{E}$, Mean \pm SE frequencies of Chls from saline-treated and $(\boldsymbol{F})$ amphetamine self-administering mice in response to amphetamine (Amph) or amphetamine with nicotine. G, Normalized firing frequencies over time for the experiments shown in $\boldsymbol{E}$ and $\boldsymbol{F}$. $\boldsymbol{H}$, The frequency distribution (left) and the average peak frequency (right) of Chls from saline-treated mice. Amphetamine produced a small increase in activity at $0.5 \mathrm{~Hz}$ (arrow). Nicotine blocked the inhibition caused by amphetamine and increased activity at $2.5 \mathrm{~Hz}$ (double arrow). I, Frequency distribution (left) and the average peak frequency (right) of Chls from amphetamine self-administering mice show that amphetamine reduced 1-2 Hz activity (arrow). The addition of nicotine moderated the potentiating effect of amphetamine by reducing activity between 2 and $3 \mathrm{~Hz}$, while increasing 3-4 Hz activity (double arrows). $\boldsymbol{J}$, When exposed to amphetamine, the bimodal frequency distribution (left) and average peak frequency (right) of Chls from amphetamine self-administering mice converged with the unimodal frequency distribution of Chls from saline-treated mice.

Fig. 3B). To determine whether amphetamine selfadministration modified the cycle and extent of burst activity, we expanded our burst-firing analysis to measure any change in the burstiness of the cell, defined by its intraburst frequency, burst length, and the percentage of time spent bursting. We also measured discrete pauses (single pauses in activity without intervening spikes), pause strings (contiguous discrete pauses with intermit- tent low-frequency spikes), intrapause frequency, pause length, and the percentage of time spent pausing.

Compared to saline-treated mice, Chls from amphetamine self-administering mice had a lower frequency of discrete bursts $(1.65 \pm 0.19$ bursts/min vs $1.12 \pm 0.15$ bursts/min for amphetamine self-administering mice; $p=0.03^{r}$, Student's $t$ test) and a reduction in their burstiness; the average burst length $(612 \pm 63 \mathrm{~ms}$ vs $447 \pm 42 \mathrm{~ms}$ 
A
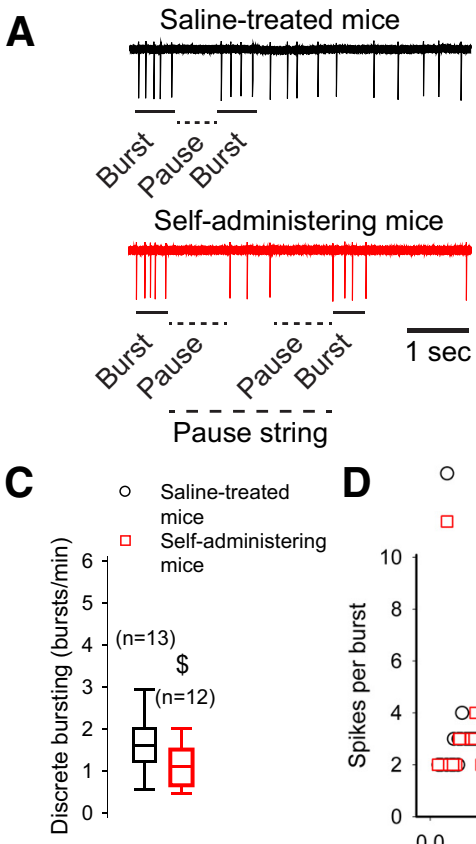

B

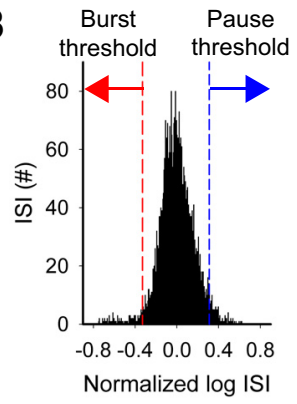

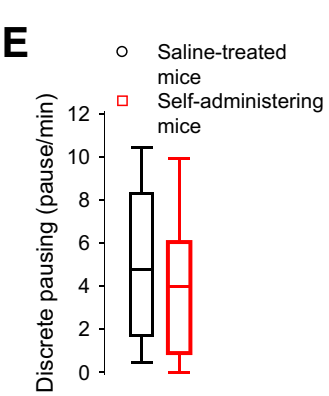

G

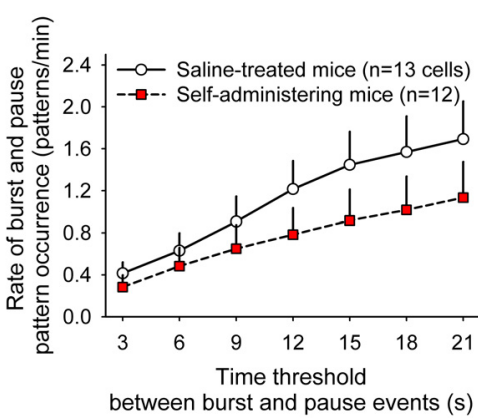

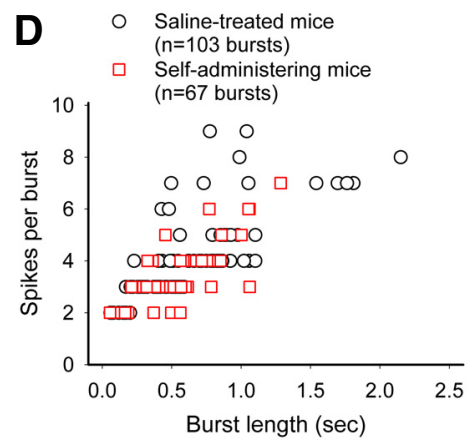
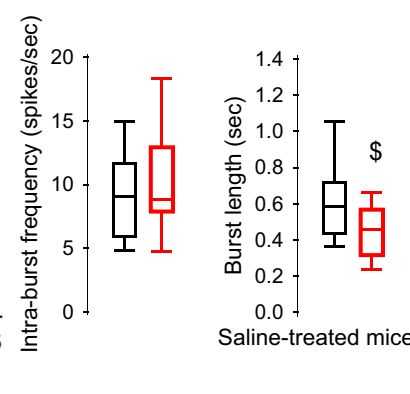

Saline-treated mice
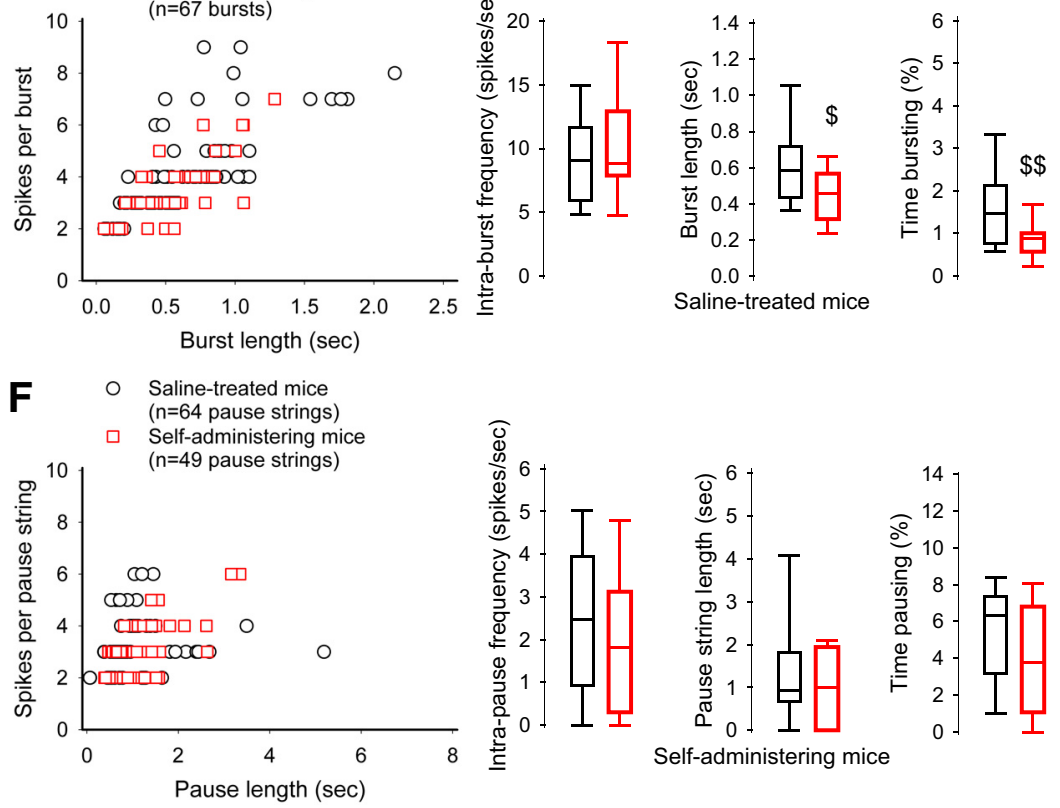

H

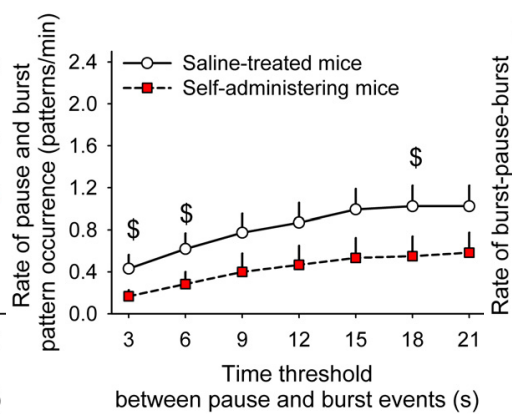

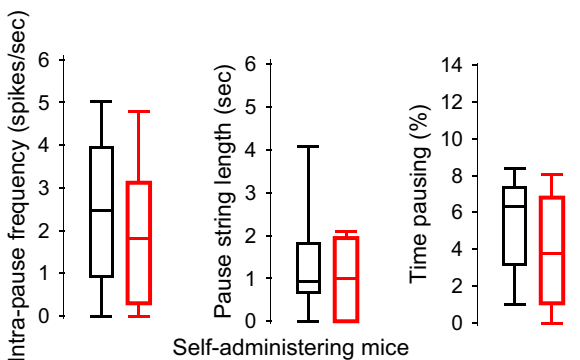

\section{I}

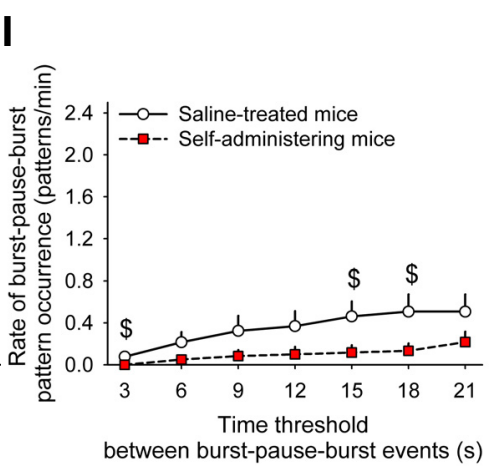

Figure 3. Amphetamine self-administration alters burst firing. $\boldsymbol{A}$, The representative traces from a cell-attached recording of Chls from saline-treated and amphetamine self-administering mice show burst, pause, and pause-string activity. The pause response of Chls begins with an initial depolarizing phase followed by a pause in spike firing and ensuing rebound excitation. In this example, the Chl from a self-administering mouse lacks rebound excitation. $\boldsymbol{B}$, The representative normalized $\log _{10}$ ISI distribution demonstrates the RGS method for determining burst and pause thresholds for each Chl. The $\log _{10}$ ISI values of burst $(-0.324)$ and pause thresholds (0.311) for this cell correspond to the top 0.5 percentile and bottom 0.5 percentile. $\mathbf{C}$, The average frequency (bursts $/ \mathrm{min}$ ) of discrete bursts was lower in Chls from amphetamine self-administering mice. For all panels, $\$ p<0.05, \$ \$ p<0.01$, Student's t test. $\boldsymbol{D}$, The histogram (left) compares the length of each burst with the frequency of spikes contained within that burst. The average intraburst frequency (spikes/s), average burst length (s), and the average percentage of time spent bursting determines the cell's burstiness. Compared to saline-treated mice, Chls from amphetamine self-administering mice had a similar intraburst frequency, because the bursts contained a lower number of spikes and were of shorter duration. $\boldsymbol{E}$, The average frequency (pauses $/ \mathrm{min}$ ) of discrete pause activity. $\boldsymbol{F}$, The histogram (left) compares the length of each pause string with the frequency of spikes contained within that pause string. The average intrapause string frequency (spikes/s), average pause string length (s), and the average percentage of time used by pause strings was similar in Chls from saline-treated and amphetamine self-administering mice. $\boldsymbol{G}$, The minimum time thresholds 
continued

that connect burst and pause events are compared with rate of burst-pause, $(\boldsymbol{H})$ pause-burst, and $(\boldsymbol{I})$ burst-pause-burst occurrence.

for amphetamine self-administering mice; $p=0.02^{\mathrm{s}}$, Student's $t$ test) and the percentage of time spent bursting $(1.57 \pm 0.26 \%$ vs $0.83 \pm 0.13 \%$ for amphetamine selfadministering mice; $p=0.01^{\mathrm{t}}$, Student's $t$ test) decreased, whereas the intraburst frequency remained constant $(8.99 \pm 0.1$ spikes/s vs $10.1 \pm 0.13$ spikes/s for amphetamine self-administering mice; Fig. $3 C, D$ ). There was no change in discrete pauses or pause strings (Fig. 3E,F). Thus, amphetamine self-administration reduced both tonic firing and bursting and uncoupled burst and pause activity in Chls (Fig. 3G-l).

\section{Amphetamine and nicotine modify burst and pause activity in Chls}

Nicotine opposes the change in tonic Chl firing caused by an amphetamine challenge. We therefore determined if a nicotine challenge would modify the burst and pause activity in Chls from saline-treated and amphetamine selfadministering mice. In Chls from saline-treated mice $(n=7$ cells), amphetamine in vitro reduced the frequency of discrete bursts $(1.55 \pm 0.31$ vs $0.94 \pm 0.17$ bursts $/ \mathrm{min}$ without or with amphetamine; $p=0.02^{\mathrm{u}}$, paired $t$ test), but did not modify pausing (Fig. $4 A-D$ ). When combined with amphetamine, nicotine blocked the reduction in discrete bursts $(1.55 \pm 0.31$ bursts $/ \mathrm{min}$ vs $1.26 \pm 0.28$ bursts $/ \mathrm{min}$ with amphetamine and nicotine) and had no effect on pausing.

In Chls from amphetamine self-administering mice, an amphetamine challenge in vitro had no effect on burst activity. Instead, amphetamine increased the frequency of discrete pauses $(2.53 \pm 0.99$ pauses/min vs $5.62 \pm 1.02$ pauses/min with amphetamine; $p=0.04^{\mathrm{v}}$, paired $t$ test) and enhanced the pause strings by increasing the intrapause frequency $(1.19 \pm 0.42$ spikes/s vs $1.96 \pm 0.27$ spikes/s with amphetamine; $p=0.03^{\mathrm{w}}$, paired $t$ test), as well as the percentage of time spent pausing $(3.79 \pm 1.14 \%$ vs $7.54 \pm 1.02 \%$ with amphetamine; $p=0.04^{\mathrm{x}}$, paired $t$ test; Fig. $\left.4 G, H\right)$. When added to amphetamine, nicotine increased the burst length and blocked the rise in discrete pausing and pause strings. Therefore, an amphetamine challenge reduced tonic firing and bursting in Chls from saline-treated mice and reversed the depression in the Chl activity of amphetamine self-administering mice by increasing tonic firing. In summary, nicotine attenuated drug-seeking behaviors and opposed the changes in Chl activity that occurred following an amphetamine challenge.

\section{Nicotine reduces tonic, burst, and pause activity of Chls}

Next, we examined nicotine's modulation of Chl activity in the absence of amphetamine. Bath-applied nicotine, at a concentration that desensitizes high-affinity $\alpha 4 \beta 2 *$-type nicotinic receptors (Lester and Dani, 1995; Wooltorton et al., 2003), decreased the firing frequency of Chls from both saline-treated mice $(-41 \pm 8 \%$; $3.76 \pm 0.67 \mathrm{~Hz}$ vs
$2.08 \pm 0.26 \mathrm{~Hz}$ with nicotine; $n=6$ cells; $p=0.03^{y}$, paired $t$ test) and amphetamine self-administering mice $(-39 \pm 18 \%$; $2.88 \pm 0.52 \mathrm{~Hz}$ vs $1.57 \pm 0.22 \mathrm{~Hz}$ with nicotine; $n=6$ cells; $p=0.04^{z}$, paired $t$ test; Fig. $5 A, B$ ). Nicotine reduced tonic firing by increasing low-frequency activity and by reducing higher frequencies (Fig. 5C,D). Nicotine converted the spectra of Chls from amphetamine self-administering mice to a unimodal distribution that was characteristic of Chls from saline-treated mice (Fig. 5E).

Nicotine in vitro reduced the frequency of discrete bursts $(1.77 \pm 0.26$ bursts $/ \mathrm{min}$ vs $0.7 \pm 0.09$ bursts $/ \mathrm{min}$ with nicotine; $p=0.01^{\text {aa }}$, paired $t$ test; Fig. $5 F$ ) and the burstiness of Chls from saline-treated mice. The intraburst frequency and burst length remained constant, whereas the percentage of time spent bursting decreased $\left(1.42 \pm 0.22 \%\right.$ vs $0.73 \pm 0.09 \%$ with nicotine; $p=0.01^{\mathrm{ab}}$, paired $t$ test; Fig. $5 G$ ). Nicotine preserved the coupling between burst and pause activity (Aosaki et al., 1994), as the reduction in bursting was accompanied by a drop in discrete pauses $(5.73 \pm 1.33$ pauses/min vs $4.59 \pm 1.06$ pauses/min with nicotine; $p=0.04^{\mathrm{ac}}$, paired $t$ test; Fig. $5 H, I)$.

Similar to Chls from saline-treated mice, nicotine in vitro reduced the frequency of discrete bursts $(1.4 \pm 0.23$ bursts $/ \mathrm{min}$ vs $0.34 \pm 0.12$ bursts $/ \mathrm{min}$ with nicotine; $p=0.0008^{\text {ad }}$, paired $t$ test; Fig. $5 \mathrm{~J}$ ) and the burstiness of Chls from amphetamine self-administering mice. The interburst frequency and burst length remained constant, whereas the percentage of time spent bursting decreased $\left(0.92 \pm 0.23 \%\right.$ vs $0.42 \pm 0.19 \%$ with nicotine; $p=0.01^{\text {ae }}$, paired $t$ test; Fig. $5 K$ ). The reduction in bursts accompanied a decrease in discrete pauses $(5.37 \pm 1.52$ spikes/s vs $2.42 \pm 0.72$ spikes/s with nicotine; $p=0.02^{\text {af }}$, paired $t$ test; Fig. $5 L$ ) and an increase in pause strings: The intra-pause frequency decreased $(3.3 \pm 058$ pauses/min vs $1.19 \pm 0.19$ pauses/min with nicotine; $p=0.02^{\mathrm{ag}}$, paired $t$ test), whereas the pause string length increased $(0.92 \pm 0.26 \mathrm{~s}$ vs $3.8 \pm 0.92 \mathrm{~s}$ with nicotine; $p=0.02^{\text {ah }}$, paired $t$ test). There was no change in percentage of time spent pausing, suggesting that the discrete pauses coalesced into pause strings with reduced intra-pause activity (Fig. 5M). Thus, nicotine reduced tonic, burst, and pause activity in both amphetamine naive and self-administering mice, perhaps by its interactions with $\alpha 4 \beta 2 *-$ or $\alpha 7 *$-type nicotinic autoreceptors located on Chls (Azam et al., 2003).

\section{Amphetamine self-administration promotes a CPD in corticostriatal activity}

Chls modulate corticostriatal activity through pre- and postsynaptic muscarinic receptors (Calabresi et al., 2000; Witten et al., 2010), but their control over corticostriatal activity derived through presynaptic nicotinic receptors remains unclear. We used whole-cell recordings in acute striatal slices to measure mEPSCs in MSNs from salinetreated, amphetamine self-administering, and nonresponding mice. The baseline frequency of mEPSCs 
A

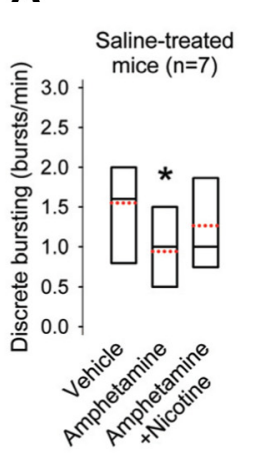

C

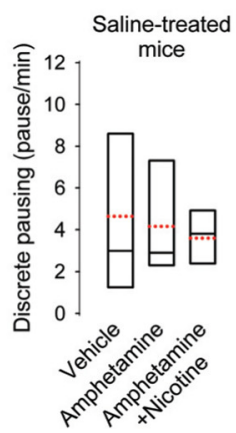

E

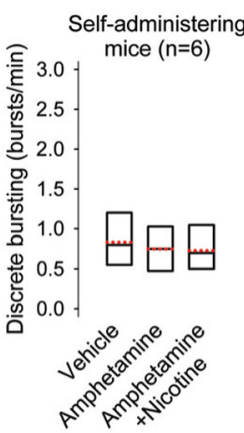

G

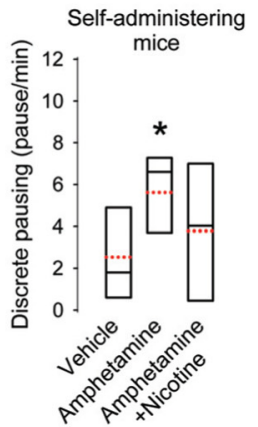

B $\bigcirc$ Vehicle $(n=53$ bursts $)$

$\checkmark$ Amphetamine ( $n=21$ bursts)

Amphetamine
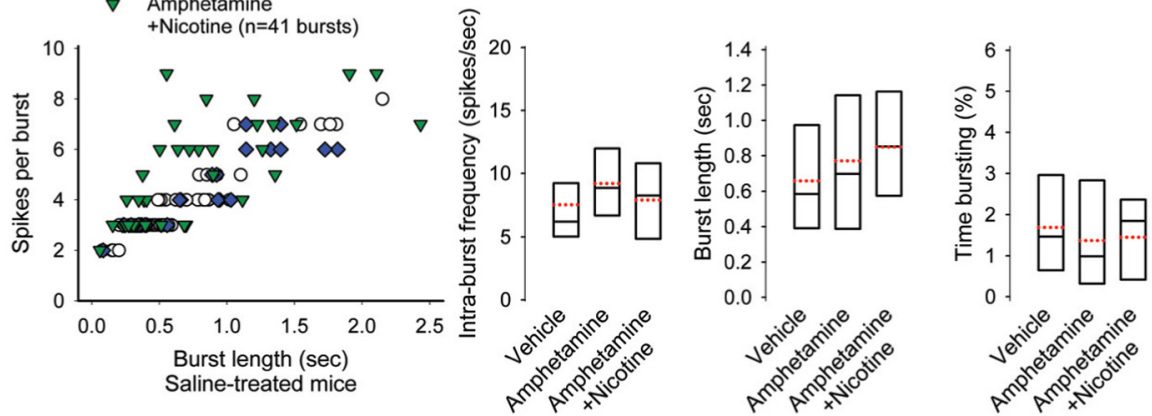

D $\bigcirc \quad$ Vehicle ( $n=37$ pause strings)

$\diamond \quad$ Amphetamine ( $n=46$ pause strings) Amphetamine
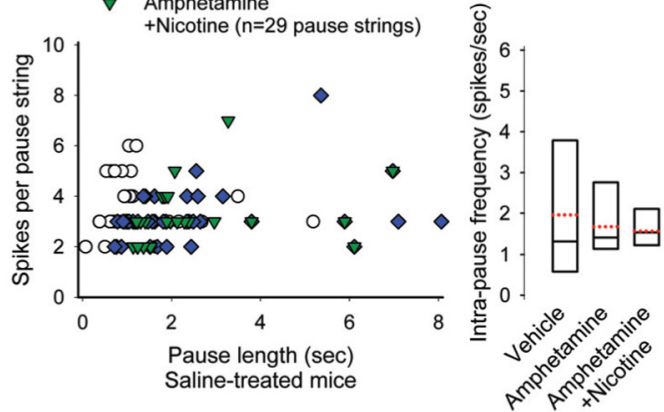

Saline-treated mice
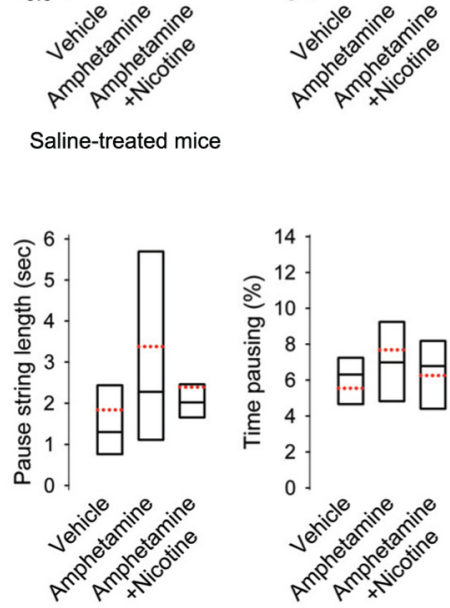

Saline-treated mice
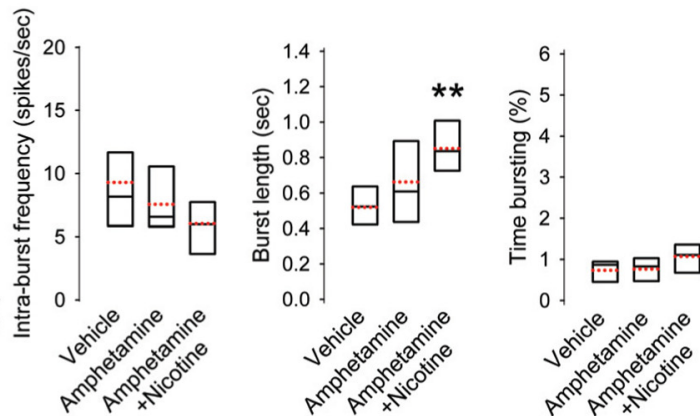

Self-administering mice
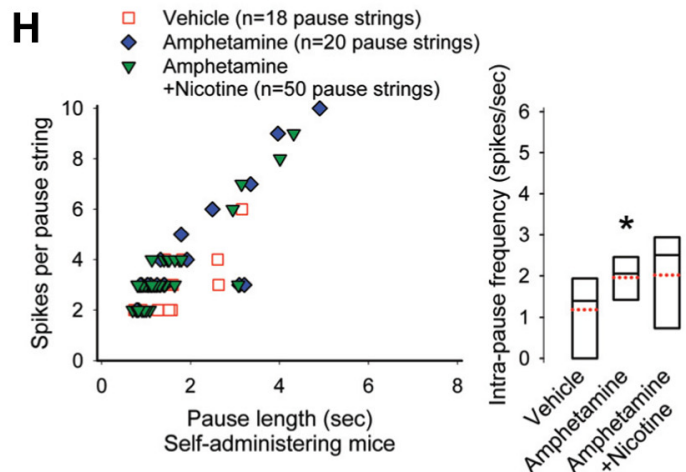

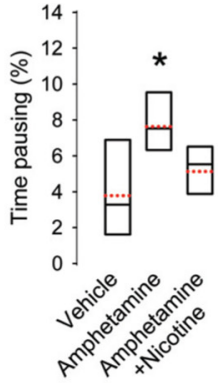

Self-administering mice

Figure 4. Nicotine and amphetamine modify burst and pause activity. $\boldsymbol{A}$, Nicotine blocked the reduction of discrete burst activity by amphetamine in Chls from saline-treated mice. For all panels, $* p<0.05, * * p<0.01$, paired $t$ test. $\boldsymbol{B}$, The burstiness of Chls from saline-treated mice was unaffected by amphetamine or the coadministration of nicotine. $\boldsymbol{C}$, Amphetamine with nicotine or without did not change discrete pausing or $(\boldsymbol{D})$ pause strings in Chls from saline-treated mice. $\boldsymbol{E}$, In Chls from amphetamine self-administering mice, amphetamine or coadministered nicotine did not modify discrete bursting $(\boldsymbol{F})$ but nicotine increased the length of bursting. $\boldsymbol{G}$, Nicotine blocked the increase in discrete pausing by amphetamine in Chls from amphetamine self-administering mice. $\boldsymbol{H}$, In Chls from amphetamine self-administering mice, an amphetamine challenge produced a nicotine-dependent enhancement of pause strings by 
continued

boosting the intra-pause frequency and the percentage of time spent pausing.

in MSNs from amphetamine self-administering mice $(3.45 \pm 0.42 \mathrm{~Hz})$ was lower than mEPSCs in MSNs from saline-treated mice $\left(4.92 \pm 0.59 \mathrm{~Hz} ; p=0.04^{\text {ai }}\right.$, Student's $t$ test; Fig. 6A), consistent with a depression in corticostriatal activity. The baseline frequency of mEPSCs in MSNs from nonresponding mice $(13.59 \pm 3.82 \mathrm{~Hz})$ was much higher than saline-treated $\left(p=0.003^{\text {aj }}\right.$, Student's $t$ test $)$ or amphetamine self-administering mice $\left(p=0.0003^{a k}\right.$, Student's $t$ test). Differences in mEPSCs between these groups of mice mainly affected low-amplitude currents and there were no differences in the mEPSC amplitude distribution (Fig. 6B), suggesting that corticostriatal plasticity was presynaptic (Van der Kloot, 1991). The depression of mEPSC in MSNs from amphetamine selfadministering mice was secondary to an increase in lowfrequency activity distributed between 0.5 and $2 \mathrm{~Hz}$, whereas the prominence of mEPSCs in MSNs from nonresponding mice was due to the persistence of frequencies $>7 \mathrm{~Hz}$ (Fig. 6C).

\section{An amphetamine challenge promotes PPP in self-administering mice}

Having established that amphetamine self-administration depresses corticostriatal activity, we then determined how an amphetamine $(10 \mu \mathrm{M})$ challenge in vitro would modify this plasticity. In saline-treated mice, amphetamine reduced mEPSC frequency by $20 \pm 8 \%(4.42 \pm 1.1$ $\mathrm{Hz}$ in vehicle vs $3.58 \pm 1.03 \mathrm{~Hz}$ with amphetamine; $n=8$ cells; $p=0.04^{\text {al }}$, paired $t$ test; Fig. $6 D$ ), consistent with D2R-mediated depression of corticostriatal activity (FloresHernández et al., 1997; Bamford et al., 2004b). In the presence of amphetamine, nicotine (100 nM) further reduced the frequency of mEPSCs $(-8 \pm 2 \%$; $3.28 \pm 0.96 \mathrm{~Hz}$ in amphetamine and nicotine; $p=0.04^{\mathrm{am}}$, paired $t$ test compared with amphetamine alone; $p=0.01^{\text {an }}$, compared with vehicle, paired $t$ test). Both amphetamine and amphetamine with nicotine in vitro reduced low-amplitude currents, but not the mEPSC amplitude distribution (Fig. $6 E)$. The frequency spectra showed that both amphetamine and amphetamine with nicotine reduced mEPSC frequencies by increasing low-frequency activity between 0.5 and $1.5 \mathrm{~Hz}$ (Fig. 6F).

In amphetamine self-administering mice, amphetamine in vitro paradoxically increased mEPSC frequency by $21 \pm 5 \%(4.09 \pm 0.8 \mathrm{~Hz}$ vs $4.64 \pm 0.8 \mathrm{~Hz}$ with amphetamine; $n=8$ cells; $p=0.004^{\text {ao }}$, paired $t$ test; Fig. $6 G$ ), thereby enhancing mEPSC frequency to the same level seen in MSNs from saline-treated mice without amphetamine $(4.42 \pm 1.1 \mathrm{~Hz})$. Nicotine in vitro blocked amphetaminegenerated PPP as it reduced mEPSC frequency in amphetamine self-administering mice $(-20 \pm 5 \% ; 3.8 \pm 0.8$ $\mathrm{Hz}$ in amphetamine and nicotine; $p=0.006^{\mathrm{ap}}$, compared with amphetamine alone, paired $t$ test) by depressing low-amplitude currents (Fig. 6G,H). Amphetamine in vitro increased the mEPSC frequency by reducing lowfrequency events, whereas nicotine in vitro blocked PPP by enhancing these same frequencies (Fig. 6/). Similar to responses in Chls (Fig. 2J), treatment with amphetamine stabilized mEPSCs in amphetamine self-administering mice, as their event frequencies approximated mEPSCs from saline-treated mice (Fig. 6J).

The baseline mEPSC frequency in MSNs from nonresponding mice was much higher than that from either amphetamine naive mice or self-administering mice. Amphetamine in vitro significantly depressed mEPSCs by $-54 \pm 13 \%(13.6 \pm 4.18 \mathrm{~Hz}$ in vehicle vs $4.41 \pm 1.62 \mathrm{~Hz}$ in amphetamine; $n=6$ cells; $p=0.003^{\mathrm{aq}}$, paired $t$ test; Fig. $6 K)$. When combined with amphetamine, nicotine in vitro produced a further reduction in mEPSCs $(-31 \pm 8 \%$; $2.41 \pm 0.92$ in amphetamine and nicotine; $p=0.02^{\text {ar }}$, compared with amphetamine alone, paired $t$ test). Amphetamine and nicotine in vitro reduced mEPSC frequency by reducing small amplitude currents and amplifying lowfrequency events (Fig. $6 L, M$ ).

\section{Nicotine modulates corticostriatal activity through $\alpha 4 \beta 2 *-$ and $\alpha 7 *$-type nicotinic receptors}

We determined whether the parallel alterations in Chl spiking and corticostriatal activity that followed amphetamine self-administration were promoted through $\alpha 7 *$ - as well as $\alpha 4 \beta 2 *$-type nicotinic receptors acting at glutamatergic synapses in the dorsal striatum (McGehee et al., 1995; Marchi et al., 2002; Pakkanen et al., 2005). Nicotine in vitro reduced the frequency of mEPSCs in MSNs from saline-treated mice by $13 \pm 5 \%(5.29 \pm 0.8 \mathrm{~Hz}$ vs $4.67 \pm 0.71 \mathrm{~Hz}$ with nicotine; $n=8$ cells; $p=0.04^{\text {as }}$, paired $t$ test), primarily by decreasing small amplitude currents and by magnifying low-frequency events (Fig. 7A-C). In comparison, nicotine in vitro increased the frequency of mEPSCs in MSNs from amphetamine self-administering mice (33 $\pm 7 \%$; $2.81 \pm 0.3 \mathrm{~Hz}$ vs $3.4 \pm 0.56 \mathrm{~Hz}$ with nicotine; $n=8$ cells; $p=0.03^{\text {at }}$, paired $t$ test) by modulating these same currents and frequencies (Fig. 7D-F). Nicotine did not alter the cumulative amplitude distribution of mEPSC in MSNs from saline-treated or amphetamine self-administering mice, suggesting modulation at presynaptic sites (Fig. 7B,E, inset). Amphetamine self-administration reduced the baseline frequency of mEPSCs in MSNs $(5.29 \pm 0.8 \mathrm{~Hz}$ for saline-treated vs 2.81 $\pm 0.3 \mathrm{~Hz}$ for amphetamine self-administering mice; $p=0.007^{\mathrm{au}}$, Student's $t$ test) and nicotine blocked this depression by increasing the frequency of mEPSCs $\left(4.42 \pm 1.1 \mathrm{~Hz} ; p=0.2^{\mathrm{av}}\right.$, compared with mEPSCs from saline-treated mice, Student's $t$ test; Fig. 7G). Therefore, nicotine in vitro blocked CPD and PPP in amphetamine self-administering mice and helped stabilize the frequency distribution of mEPSCs in these cells (Fig. $7 H$ ).

We used saline-treated mice to test whether nicotine modulation at corticostriatal terminals acts through $\alpha 4 \beta 2 *-$ and $\alpha 7 *$-type nicotinic receptors. The mEPSC frequency increased by $46 \pm 18 \%$ when the $\alpha 4 \beta 2 *$-type receptor antagonist dihydro-beta-erythroidine $(\mathrm{DH} \beta \mathrm{E} ; 40$ 
A

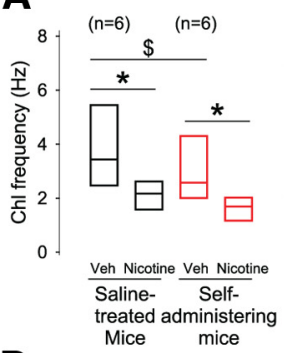

D

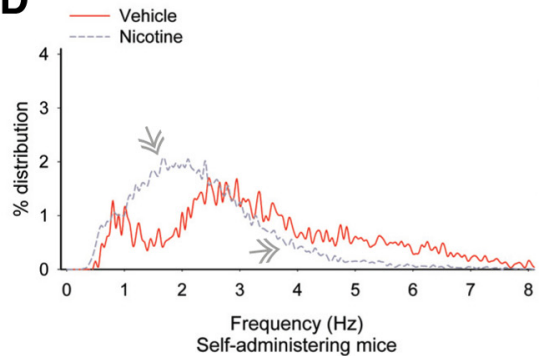

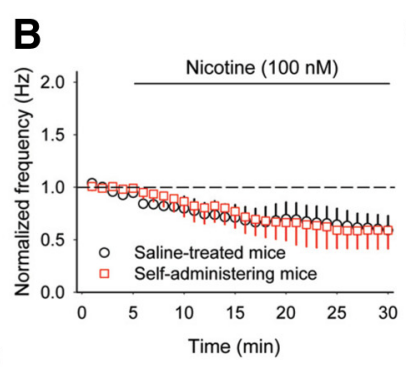

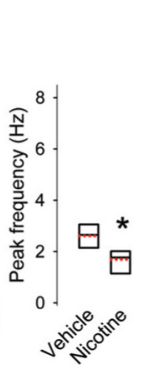

C - Velicle

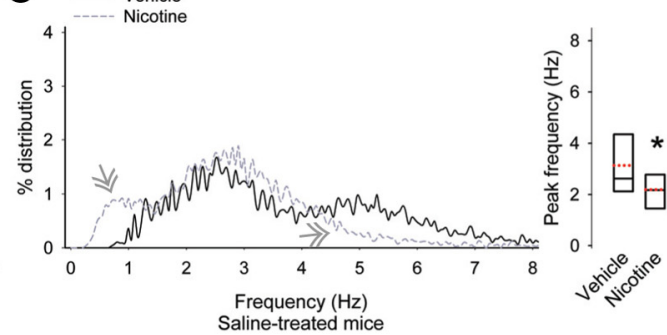

E

- Saline-treated mice $(n=13)$

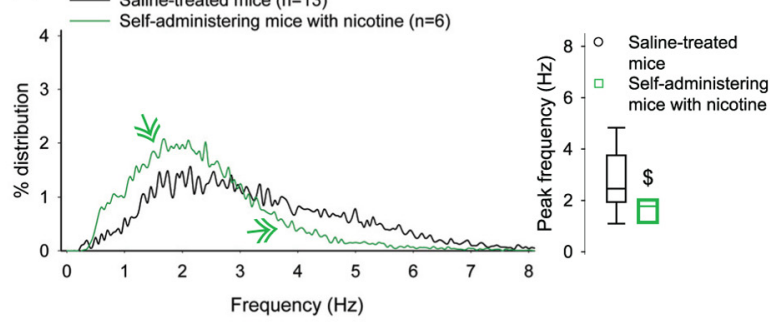

$\mathbf{F}$

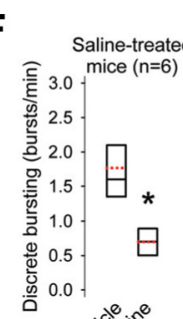

H

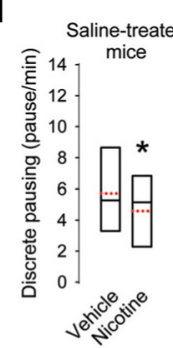

J

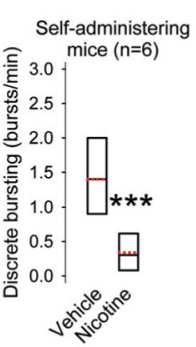

$\mathbf{L}$

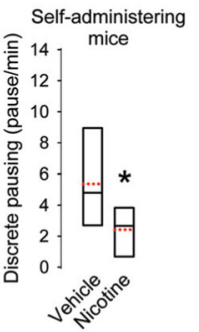

G $\bigcirc$ Vehicle ( $n=50$ bursts)
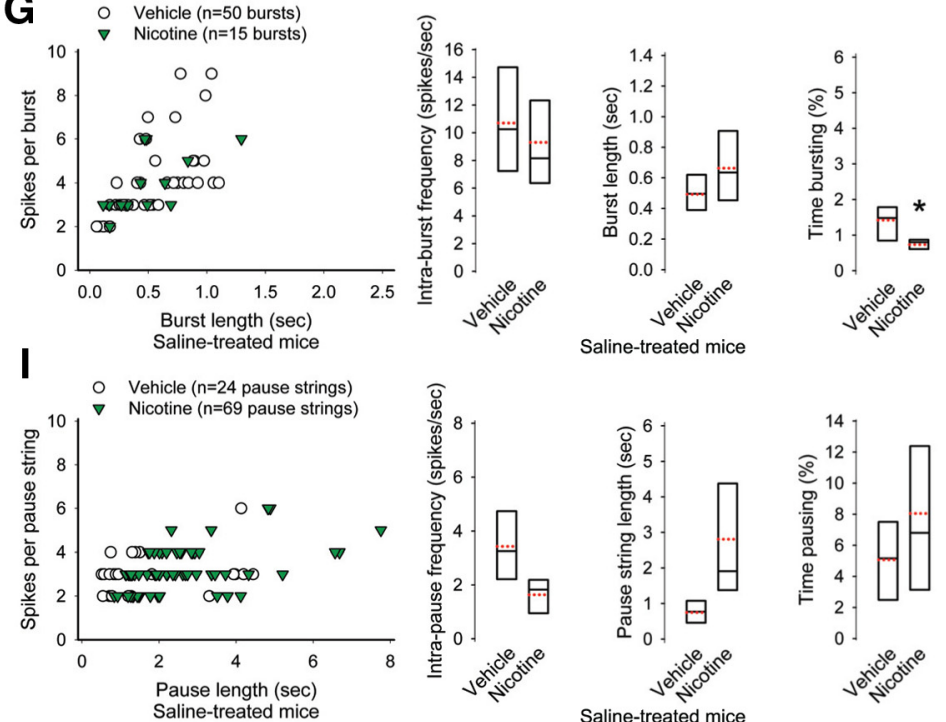

K $\bigcirc \quad$ Vehicle ( $n=42$ bursts)
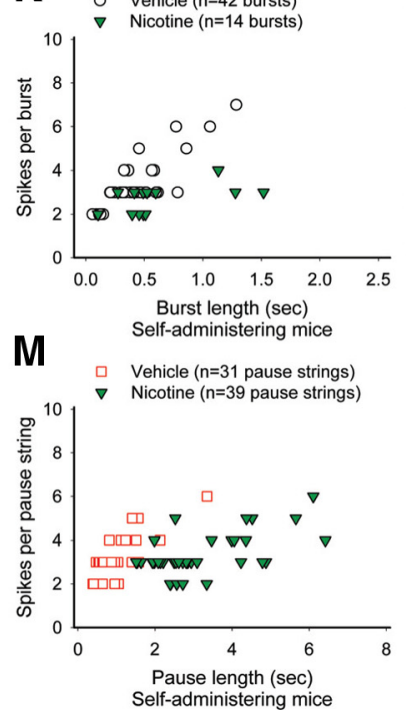
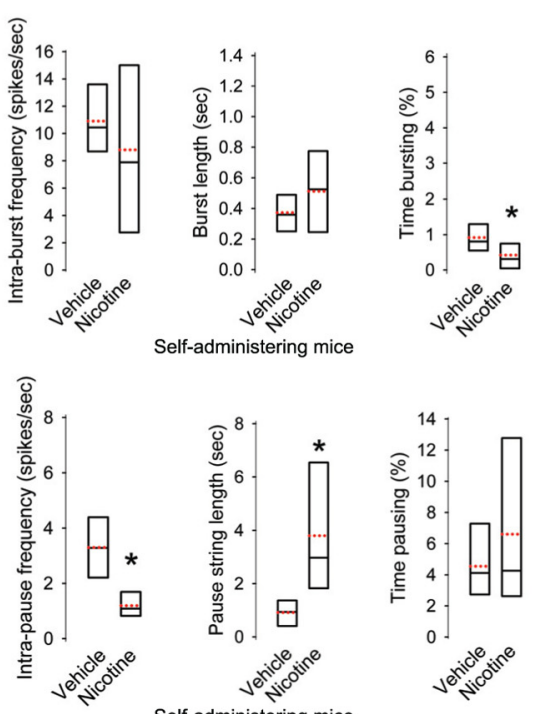

Figure 5. Nicotine inhibits $\mathrm{Chl}$ activity. $\boldsymbol{A}$, Nicotine reduced the mean frequencies of Chls from saline-treated and amphetamine 
continued

self-administering mice. For all panels, ${ }^{\$} p<0.05$, Student's $t$ test and $* p<0.05$, $* * * p<0.001$, paired $t$ test. $\boldsymbol{B}$, Normalized-firing frequencies over time for the experiments shown in $\boldsymbol{A}$. $\boldsymbol{C}$, In Chls from saline-treated mice, the spectra (left) show that nicotine (double arrows) increased low frequencies, whereas reducing higher frequencies and the average peak frequency (right). Nicotine shifted the unipolar distribution of Chls from saline-treated mice toward the bimodal distribution of average frequencies in amphetamine self-administering mice. $\boldsymbol{D}$, In Chls from amphetamine self-administering mice, nicotine increased low frequencies, reduced high frequencies, and suppressed the average peak frequency. $\boldsymbol{E}$, Nicotine shifted the bimodal distribution of average frequencies in amphetamine self-administering mice toward the unipolar distribution of Chls from saline-treated mice. $\boldsymbol{F}$, In Chls from saline-treated mice, nicotine suppressed discrete bursting, $(\boldsymbol{G})$ the percentage of time spent bursting, and $(\boldsymbol{H})$ discrete pausing, but $(\boldsymbol{I})$ did not alter pause strings. $\boldsymbol{J}$, In Chls from amphetamine self-administering mice, nicotine suppressed discrete bursting, $(\boldsymbol{K})$ the percentage of time spent bursting, and $(\boldsymbol{L})$ discrete pausing. $\mathbf{M}$, Amphetamine self-administration modified pause strings; the intra-pause spike frequency decreased whereas the length of the pause string increased.

nM) was added to nicotine $(1.37 \pm 0.21 \mathrm{~Hz}$ vs $1.93 \pm 0.31$ $\mathrm{Hz}$ with nicotine and $\mathrm{DH} \beta \mathrm{E} ; n=5$ cells; $p=0.04^{\text {aw }}$, paired $t$ test; Fig. $7 I, J)$, consistent with $\alpha 4 \beta 2 *$-type receptor desensitization at this concentration of nicotine (Lester and Dani, 1995; Wooltorton et al., 2003). When the $\alpha 7 *$-type nicotinic receptor antagonist methyllycaconitine (MLA; 40 $\mathrm{nM}$ ) was applied with nicotine, the mEPSC frequency was inhibited $(-29 \pm 6 \%$; $2.98 \pm 0.54 \mathrm{~Hz}$ vs $2 \pm 0.24 \mathrm{~Hz}$ with nicotine and MCT; $n=8$ cells; $p=0.04^{\text {ax }}$, paired $t$ test; Fig. $7 K, L)$, beyond that seen with nicotine alone $(-13 \pm 5 \%$; $p=0.04$, Student's $t$ test). This suggests that nicotine can boost corticostriatal activity through low-affinity $\alpha 7 *$-type nicotinic receptors, which desensitize with much higher levels of nicotine (>500 nм; Lester and Dani, 1995; Wooltorton et al., 2003). These data show that nicotine can block CPD at corticostriatal terminals and that alterations in Chl activity and ACh availability following repeated amphetamine likely modify corticostriatal activity through $\alpha 7 *$-type, as well as $\alpha 4 \beta 2 *$-type nicotinic receptors.

\section{Nicotine modifies behaviors and corticostriatal activity in noncontingent amphetamine-treated mice} Behavioral sensitization characterizes the progressive and enduring enhancement found in many amphetamineinduced behaviors (Robinson and Camp, 1987). More specifically, locomotor sensitization depends on psychostimulant-induced plasticity of ACh-releasing Chls in the dorsal striatum that promote long-lasting changes in corticostriatal activity (Bamford et al., 2008; Witten et al., 2010; Wang et al., 2013a). In contrast to noncontingent amphetamine-treated mice, mice self-administering amphetamine (contingent amphetamine-administration) had a $57 \%$ larger reduction in baseline Chl activity in withdrawal (24\% vs $37 \%$ for amphetamine self-administering mice) but a 34\% smaller increase in activity following an amphetamine challenge in vitro $(88 \pm 27 \%$ vs $57 \pm 34 \%$ for amphetamine self-administering mice; data not shown in figures). Similarly, the baseline frequency of mEPSC in MSNs was depressed following amphetamine self-administration, but was unchanged following noncontingent treatment. Further, an amphetamine challenge in vitro produced a much smaller increase in mEPSC frequency in amphetamine selfadministering mice $(107 \pm 21 \%$ vs $21 \pm 11 \%$ for amphetamine self-administering mice; data not shown in figures). Therefore, the contingent administration of amphetamine produced a greater depression in Chl firing and corticostria- tal activity, but a lower rebound following an amphetamine challenge.

\section{Nicotine modifies the incubation of locomotor sensitization and corticostriatal activity}

To assess whether nicotine might alter the expression of locomotor sensitization, as well as incubation of drugseeking behaviors, we treated mice with repeated amphetamine and challenged them with amphetamine and nicotinic receptor ligands in withdrawal. Mice received saline for $2 \mathrm{~d}$ and amphetamine (2 $\mathrm{mg} / \mathrm{kg} / \mathrm{d}$, i.p.) for $4 \mathrm{~d}$. Following a $5 \mathrm{~d}$ withdrawal, we challenged mice with amphetamine (2 mg/kg, i.p.; Fig. 8A). Mice increased their locomotor ambulations following each amphetamine treatment $\left[F_{(5,18)}=11.6, p<0.001^{\text {ay }}\right.$, repeated-measures (rm)ANOVA; Fig. 8B]. Compared to locomotor ambulations following their first $\left(F_{(17,102)}=5.19, p<0.001^{\text {az }}\right.$, two-way rmANOVA) and fourth day of amphetamine treatment $\left(F_{(17,102)}=3.71, p<0.001^{\text {az }}\right.$, two-way rm-ANOVA), ambulations increased when mice were challenged with amphetamine in withdrawal (Fig. 8C).

To test whether nicotine modified locomotor ambulations in withdrawal, mice received either low- $(0.1 \mathrm{mg} / \mathrm{kg}$, i.p.) or high- dose (1 $\mathrm{mg} / \mathrm{kg}$, i.p.) nicotine on withdrawal day 5. Neither dose of nicotine had an effect on locomotion in saline-treated mice $\left(p=0.9^{\mathrm{ba}}\right.$, two-way, rm-ANOVA; Fig. 8D). In amphetamine-treated mice challenged with amphetamine, low-dose nicotine had no effect on locomotor ambulations $\left(F_{(17,102)}=0.1, p=1^{\mathrm{bb}}\right.$, two-way rmANOVA), whereas the higher dose of nicotine reduced locomotor ambulations $\left(F_{(17,102)}=3.19, p=0.01^{\mathrm{bc}}\right.$, twoway rm-ANOVA; Fig. 8E). Ambulations following highdose nicotine were similar to those following the fourth dose of amphetamine, indicating that nicotine suppressed the expression of locomotor sensitization. Locomotor testing following an amphetamine challenge in nonsensitized, saline-exposed mice showed that nicotine (1 $\mathrm{mg} / \mathrm{kg}$ ) did not block the acute stimulating effect of amphetamine on locomotion $\left(p=0.9^{\text {bd }}\right.$, two-way rm-ANOVA; Fig. $8 F)$. These same saline and nicotine $(1 \mathrm{mg} / \mathrm{kg})$ challenges in amphetamine-treated mice revealed similar ambulations compared with saline-treated mice challenged with saline ( $p=0.9^{\text {be }}$, two-way rm-ANOVA; Fig. 8G). This indicates that amphetamine-experienced mice lack conditioned locomotor activity elicited by placement into the amphetamine-associated chamber and show that nico- 
A

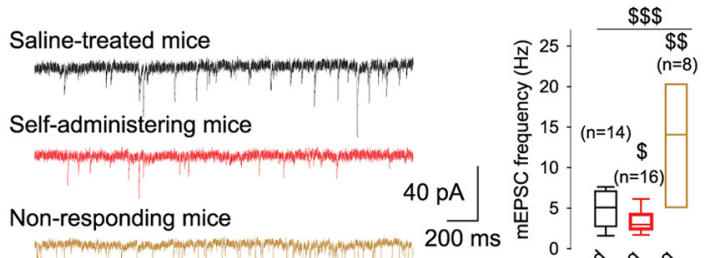

B $\quad \sim$ saline-treated mice
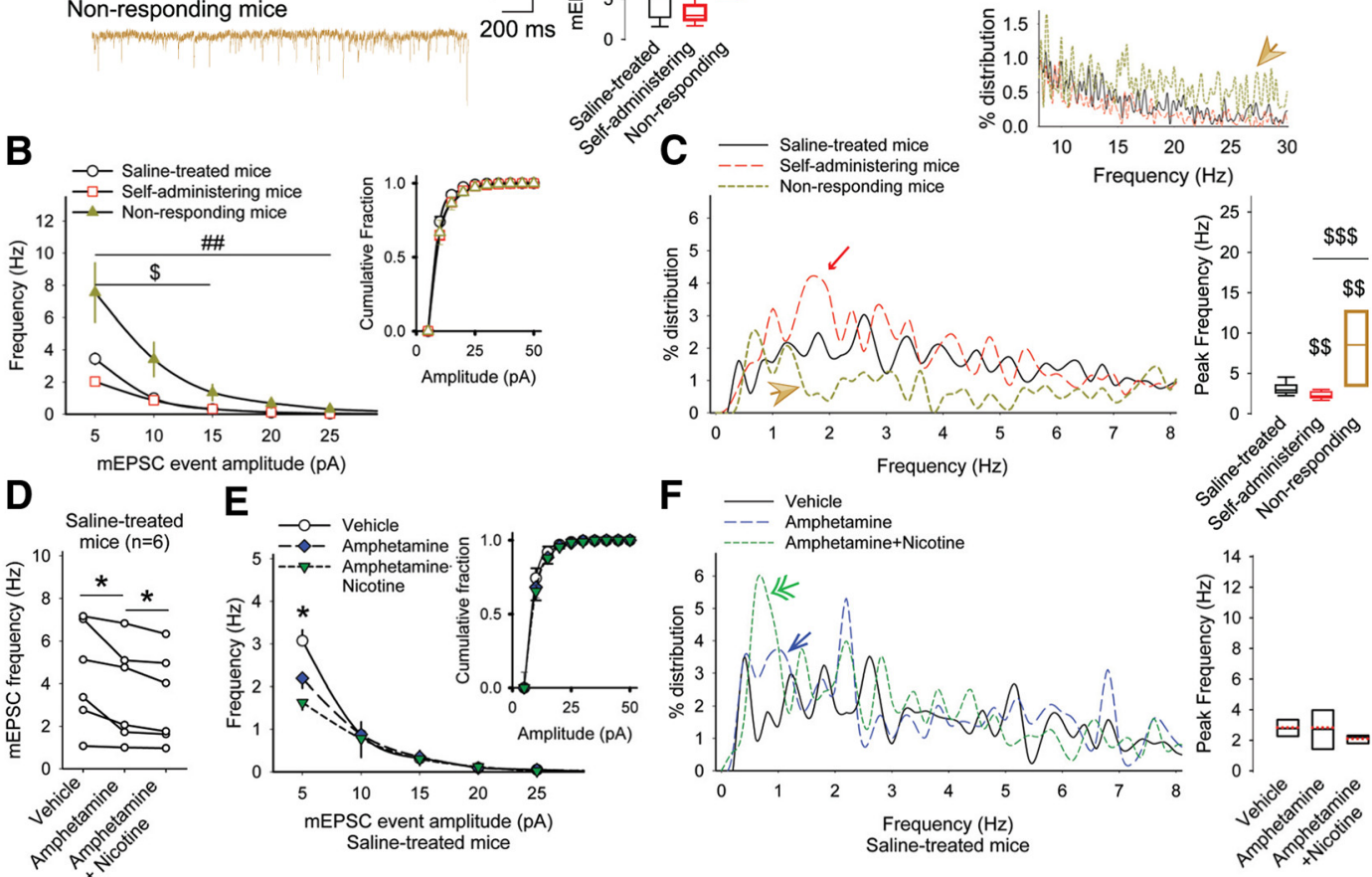

F $-\begin{aligned} & \text { Vehicle } \\ & --- \\ & \text { Amphetamin }\end{aligned}$

requency $(\mathrm{Hz})$
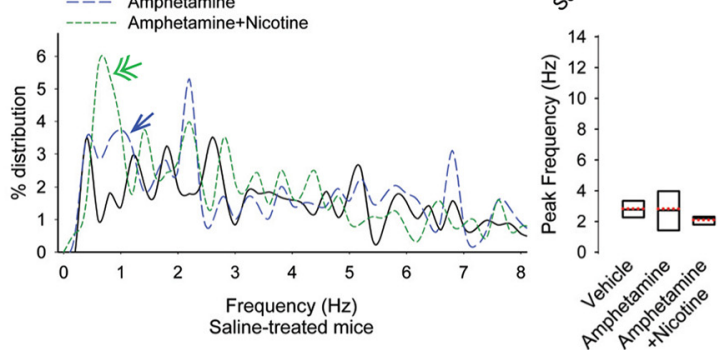

\section{G}

\section{H}
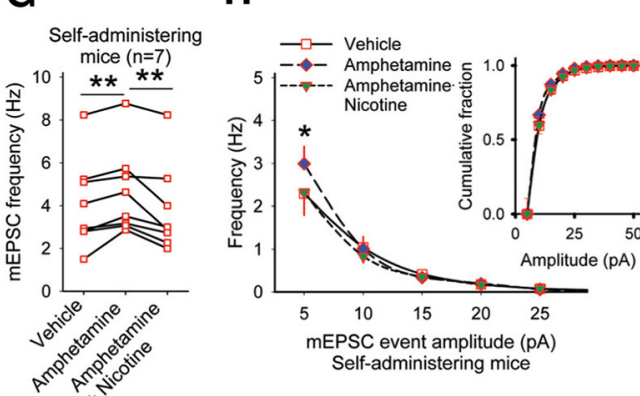

\section{I}

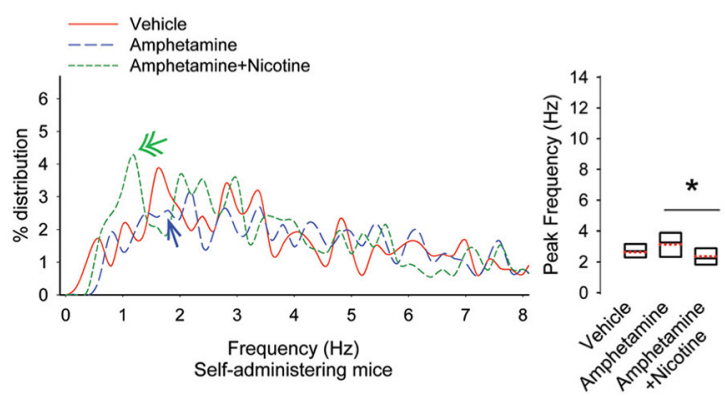

J E Saline-treated mice
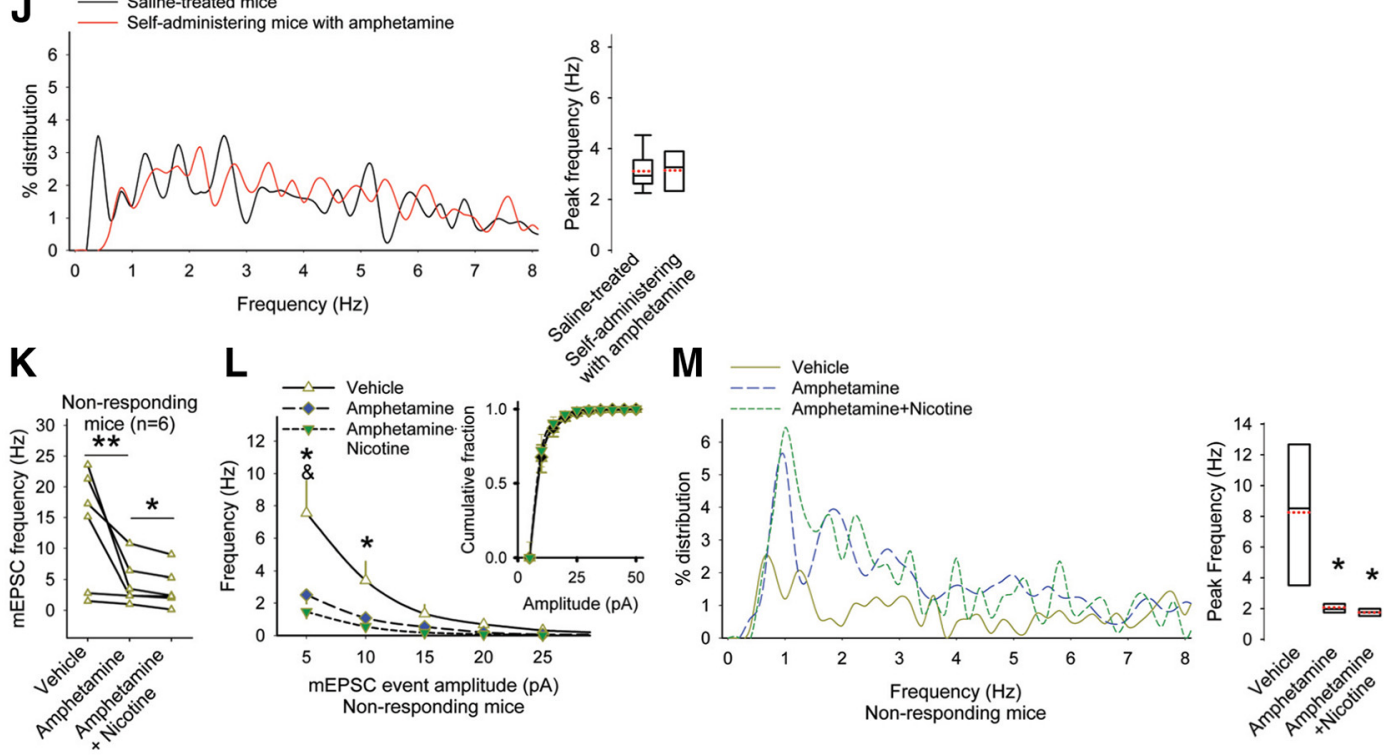
Figure 6. Nicotine blocks PPP. A, Representative traces (left) and plots (right) show that the frequency of mEPSC in MSNs from saline-treated mice was greater than amphetamine self-administering mice but far less than those in nonresponding mice. ${ }^{\$} p<0.05$, $\$ \$ p<0.01,{ }^{\$ \$} p<0.001$, Student's $t$ test. $\boldsymbol{B}$, Compared with saline-treated mice, amphetamine self-administration reduced the frequency of low-amplitude mEPSCs, while the frequency of mEPSCs was broadly higher in nonresponding mice. ${ }^{\$} p<0.05$, saline-treated versus amphetamine self-administering mice; ${ }^{\# \#} p<0.01$, saline-treated versus nonresponding mice; Bonferroni $t$ test. Inset, The cumulative mEPSC amplitude distribution was unchanged across groups. $\boldsymbol{C}$, Frequency distributions (left) and the average peak frequency (right) show a prominent low-frequency distribution of mEPSCs from amphetamine self-administering mice (small arrow) and more broadly distributed firing frequencies in MSNs from nonresponding mice (arrowhead; inset). ${ }^{\$ \$ p}<0.01,{ }^{\$ \$} p<0.001$, Student's $t$ test. $\boldsymbol{D}$, Responses of individual MSNs from saline-treated mice show that amphetamine, and the addition of nicotine, reduced the frequency of mEPSCs. $* p<0.05$, paired $t$ test. $\boldsymbol{E}$. Amphetamine with nicotine or without decreased the frequency of low-amplitude mEPSCs. $* p<0.05$, Bonferroni $t$ test, amphetamine compared with either vehicle or amphetamine with nicotine. Inset, The mEPSC amplitude distribution was unchanged. $\boldsymbol{F}$, Frequency distributions (left) and the average peak frequency (right) of mEPSCs from saline-treated mice shows that both amphetamine (arrow) and amphetamine with nicotine (double arrow) increased low-frequency events. G, In MSNs from amphetamine self-administering mice, nicotine blocked the increase in mEPSCs that followed amphetamine. $* p<0.05$, paired $t$ test. $\boldsymbol{H}$. Amphetamine augmented the frequency of low-amplitude mEPSCs, but had no effect on their amplitude distribution (inset). $* p<0.05$, Bonferroni $t$ test, amphetamine compared with either saline or amphetamine with nicotine. $\boldsymbol{I}$, The distribution (left) and the average peak frequency (right) of mEPSCs from amphetamine self-administering mice show that amphetamine reduces $1-2 \mathrm{~Hz}$ activity (arrow). The addition of nicotine moderated the effect of amphetamine by increasing 1-2 $\mathrm{Hz}$ activity (double arrows). $* p<0.05$, paired $t$ test. $\boldsymbol{J}$, The distribution (left) and average peak frequency (right) show that mEPSCs $\mathrm{s}$ from saline-treated mice were similar to those from amphetamine self-administering mice exposed to amphetamine. $\boldsymbol{K}$, Both amphetamine and amphetamine with nicotine reduced the mEPSC frequency in MSNs from nonresponding mice. $* p<0.05$, $* * p<0.01$, paired $t$ test. $\boldsymbol{L}$, Amphetamine and nicotine reduced low-amplitude mEPSCs, but had no effect on their amplitude distribution (inset). $* p<0.05$, amphetamine compared with either vehicle or amphetamine with nicotine; ${ }^{\&} p<0.01$, vehicle compared with either amphetamine or amphetamine with nicotine; Bonferroni $t$ test. $\boldsymbol{M}$, The frequency distribution (left) and average peak frequency (right) of mEPSCs from nonresponding mice show that amphetamine with (double arrow) or without nicotine (arrow) increases low-frequency events. $* p<0.05$, paired $t$ test.

tine did not modify locomotor activity in the absence of amphetamine.

It was previously shown that withdrawal from repeated injections of amphetamine produced CPD and PPP following reinstatement (Wang et al., 2013a). In another group of similarly treated mice, we performed electrophysiological recordings to determine whether nicotine in vitro modifies corticostriatal activity in withdrawal. eEPSCs in MSNs were obtained in response to $50 \mathrm{~ms}$ pairedpulses delivered to the motor cortex. In MSNs from saline-treated mice, puff-applied nicotine decreased the amplitude of the first current of the pair by $19 \pm 5 \%$ $(-99 \pm 11 \mathrm{pA}$ vs $-78 \pm 10 \mathrm{pA}$ with nicotine; $n=12$ cells; $p=0.02^{\text {bf }}$, paired $t$ test) and increased the PPR by $34 \pm 12 \% \quad(1.18 \pm 0.06$ vs $1.56 \pm 0.15$ with nicotine; $p=0.009^{\mathrm{bg}}$, paired $t$ test; Fig. $8 H$ ), indicating a reduction in corticostriatal excitation. In MSNs from amphetaminetreated mice, nicotine increased the amplitude of the first current by $30 \pm 6 \%(-66 \pm 6 \mathrm{pA}$ vs $-83 \pm 5 \mathrm{pA}$ with nicotine; $n=10$ cells; $p<0.001^{\text {bh }}$, paired $t$ test) and decreased the PPR by $23 \pm 3 \%(1.25 \pm 0.11$ vs $0.95 \pm 0.07$ with nicotine; $p=0.013^{\mathrm{bi}}$, paired $t$ test; Fig. $8 /$ ). Compared with MSNs from saline-treated mice ( $n=12$ cells), the amplitude of the first pulse of the pair was lower in MSNs from amphetamine-treated mice in withdrawal $(n=10$ cells; $-99 \pm 11 \mathrm{pA}$ for saline-treated vs $-66 \pm 6 \mathrm{pA}$ in withdrawal; $p=0.02^{\mathrm{bj}}$, Student's $t$ test; Fig. 8 , compare $\mathrm{H}, \mathrm{I}$ ). By increasing the amplitude of the first eEPSC, nicotine blocked the synaptic depression in withdrawal $(-99 \pm 11$ $\mathrm{pA}$ for saline-treated in vehicle vs $-83 \pm 5 \mathrm{pA}$ for withdrawal with nicotine; $p=0.2^{\mathrm{bk}}$, Student's $t$ test). Therefore, alterations in ACh availability extend to models of noncontingent amphetamine-treated mice because nicotine suppressed the expression of locomotor sensitization and although nicotine in vitro reduced eEPSCs in saline- treated mice, it blocked synaptic depression in withdrawal by enhancing corticostriatal activity.

\section{Discussion}

The transition from psychostimulant use to dependence involves changes in corticostriatal activity in consequence of intermittent DA release (Kalivas, 2009; Sulzer, 2011). Repeated exposure to amphetamine, which releases DA (Bamford et al., 2004b), promotes long-lasting and parallel changes in drug-primed rewarding, locomotor sensitization, Chl firing, and corticostriatal activity. This suggests that Chls in the striatum participate in addictive behaviors and contribute to normal motor and cognitive function by promoting allostasis and sensitized responses (Ahmed and Koob, 2005). Our data show that the rewarding properties of amphetamine and the potentiation of locomotor sensitization are dependent on ACh because nicotine attenuated both responding to an amphetamine challenge after abstinence and sensitized locomotor responses to an amphetamine challenge in withdrawal.

Preclinical and clinical evidence suggests that cigarette smoking and nicotinic receptors participate in psychostimulant addiction (Rahman, 2013; Mello et al., 2014; Verrico et al., 2014). Contingent models of drug-seeking behavior in rodents have shown an interaction between nicotine and methamphetamine incubation (Shepard et al., 2004; Hiranita et al., 2006; Neugebauer et al., 2010; Pipkin et al., 2014). However, this interaction is complex and altered by diverse factors such as age, dose, drug pairing, and frequency of use. No studies have investigated the effect of acute nicotine on amphetamine incubation in mice. Using a standard self-administration protocol based on fixed schedules of reinforcement, we demonstrate that mice acquire amphetamine selfadministration behaviors and develop the motivation to ob- 
A

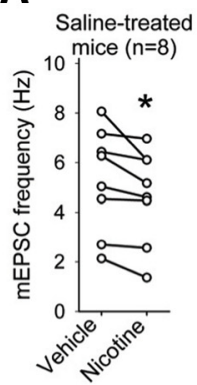

D

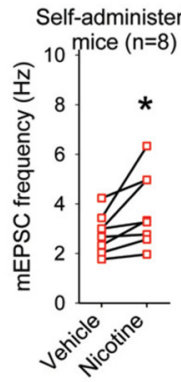

B

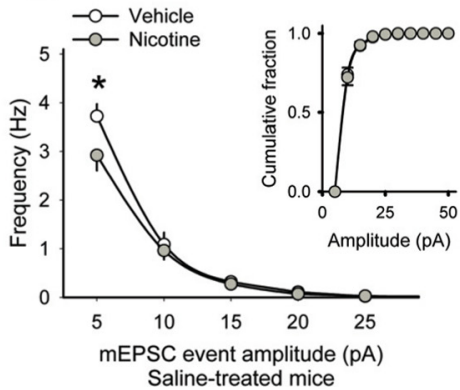

E

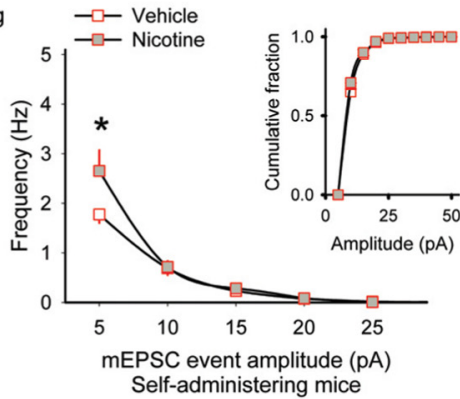

C

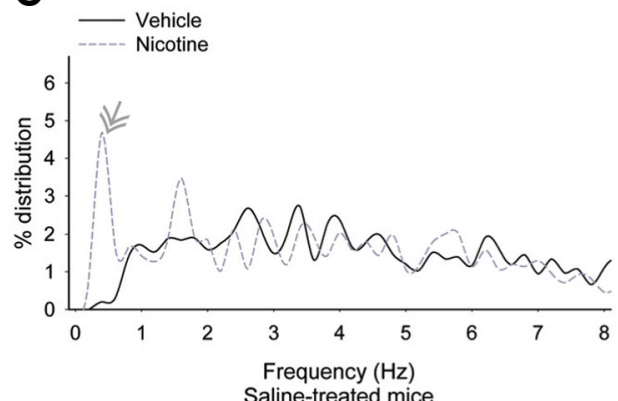

F

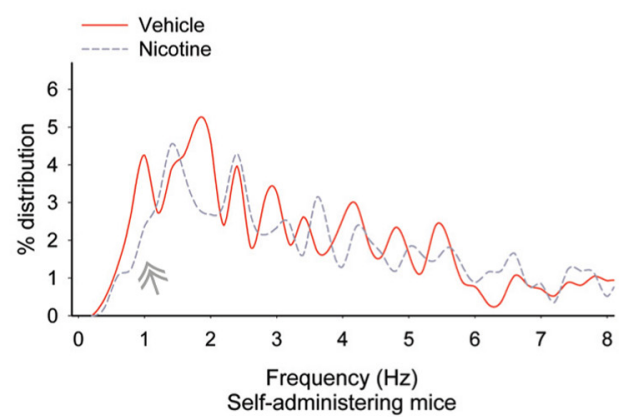

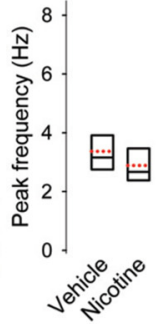

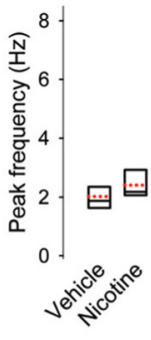

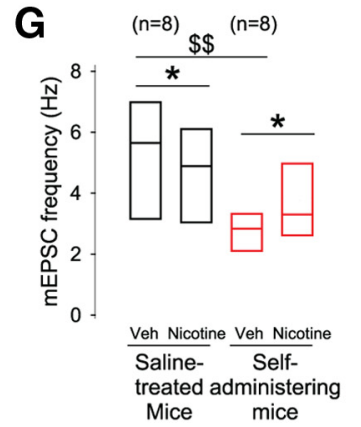

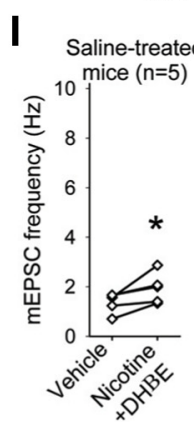

H - Saline-treated mice

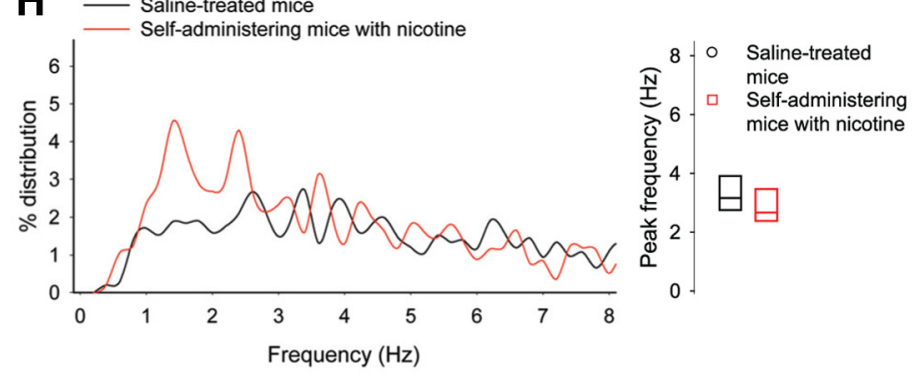

J $\stackrel{-\infty-\text { Venide }}{ }$

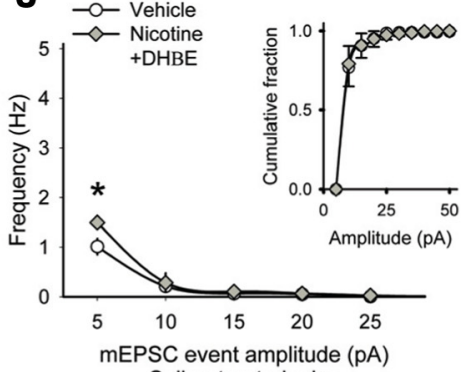

K Saline-treated

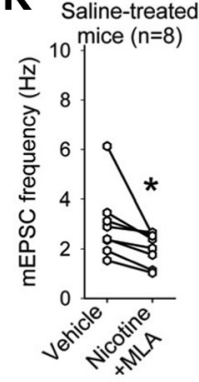

L $-\circ-$ Vehicle

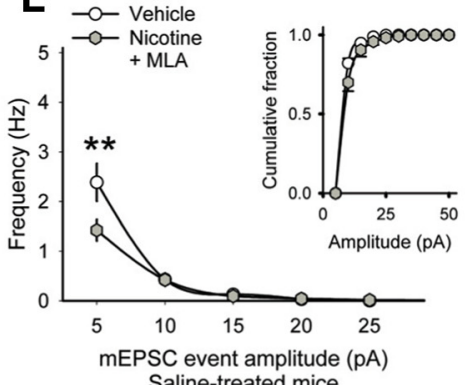

Figure 7. Nicotine in vitro blocks CPD through $\alpha 7 *$ - and $\alpha 4 \beta 2 *$-type nicotinic receptors. $\boldsymbol{A}$, Responses of individual MSNs show that nicotine inhibited corticostriatal activity in saline-treated mice by $(\boldsymbol{B})$ reducing high-frequency, low-amplitude mEPSCs, but had no effect on their amplitude distribution (inset). For $\boldsymbol{B}, \boldsymbol{E}, \boldsymbol{J}, * p<0.05$, Bonferroni $t$ test; for all other panels, $* p<0.05$, paired t test and $\$ \$ p<0.01$, Student's t test. $\boldsymbol{C}$, The frequency distribution (left) and the average peak frequency (right) of mEPSCs. Nicotine increased low-frequency mEPSCs in saline-treated mice. $\boldsymbol{D}$, Nicotine increased the frequency of mEPSCs in MSNs from amphetamine self-administering mice by $(\boldsymbol{E})$ augmenting high-frequency, low-amplitude mEPSCs, while having no effect on their amplitude distribution (inset). $\boldsymbol{F}$, The frequency distribution (left) and average peak frequency (right) of mEPSCs. Nicotine reduced low-frequency mEPSCs in amphetamine self-administering mice. G, Mean \pm SE frequencies of mEPSCs from saline-treated and amphetamine self-administering mice in response to nicotine. $\boldsymbol{H}$, The frequency distribution (left) and average peak frequencies (right) compares mEPSCs in MSNs from saline-treated mice with those from amphetamine self-administering mice exposed to nicotine in vitro. $\boldsymbol{I}$, The $\alpha 4 \beta 2 *$-type receptor antagonist $\mathrm{DH} \beta \mathrm{E}$ blocked the synaptic depression generated by nicotine and $(\boldsymbol{J})$ increased high-frequency, low-amplitude synaptic events. $\boldsymbol{K}$, The $\alpha 7 *$-type nicotinic receptor antagonist MLA reduced $(\boldsymbol{L})$ high-frequency, low-amplitude mEPSCs. $\boldsymbol{J}, \boldsymbol{L}$, Insets show similar mEPSC amplitude distributions. 
A
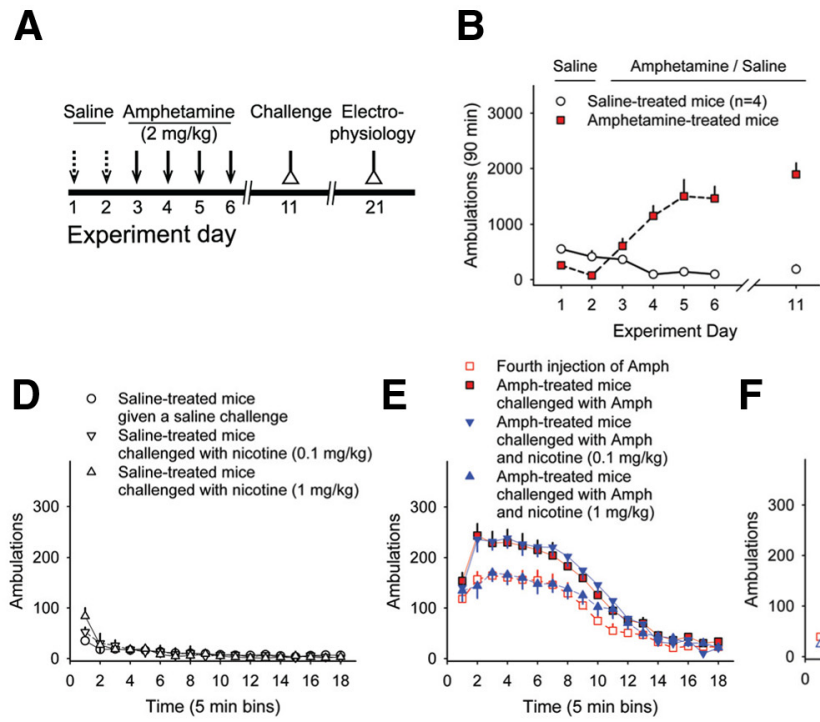

$\mathbf{F}$
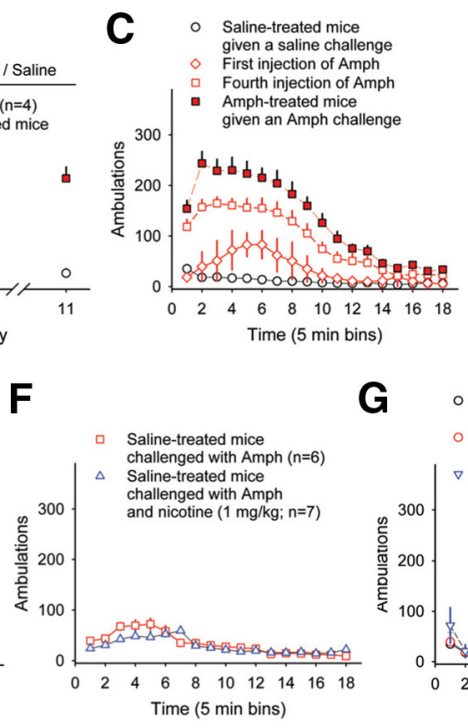
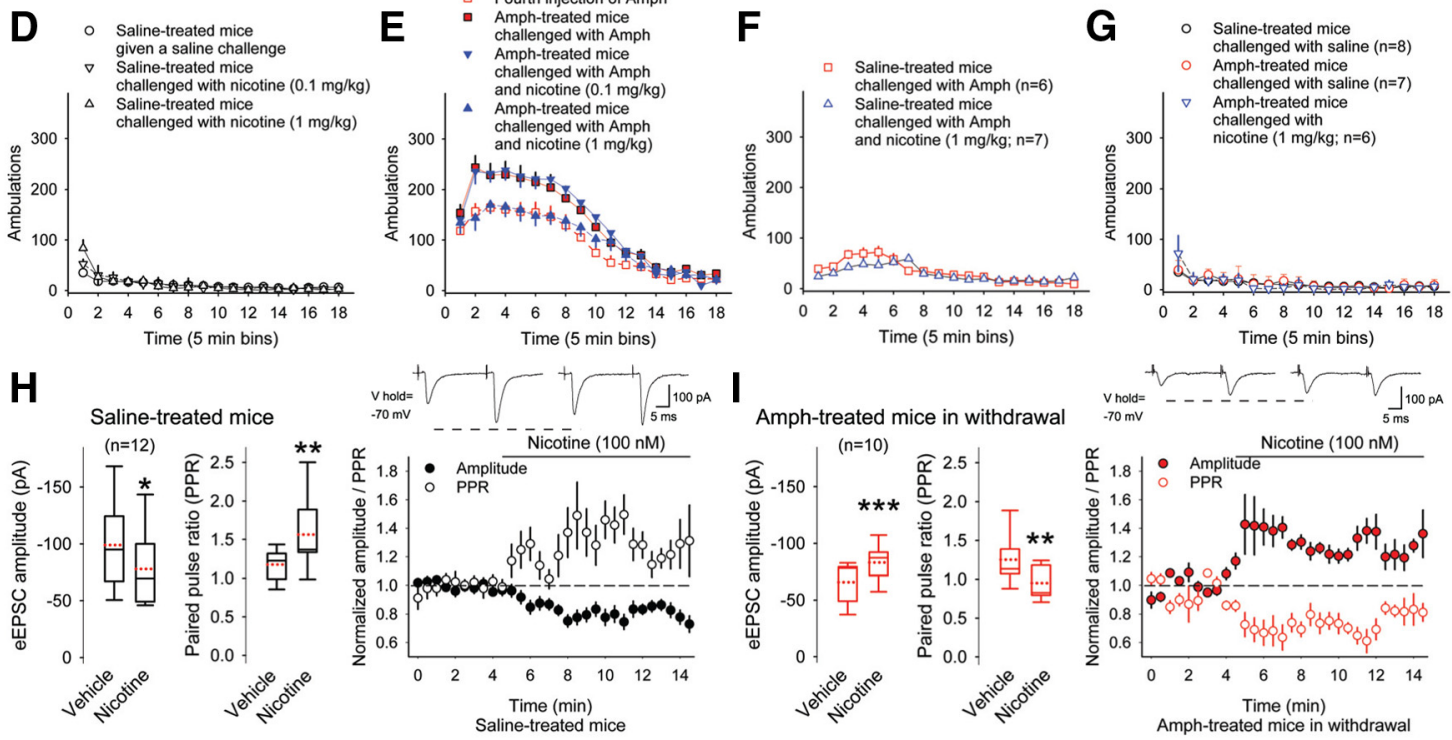

Figure 8. Nicotine modifies locomotor sensitization and corticostriatal activity. A, Protocol for testing the effect of amphetamine and nicotine on locomotor sensitization. The amphetamine treatment group received saline injections for the first $2 \mathrm{~d}$, whereas the saline treatment group received saline on all days. B. Average locomotor ambulations over 90 min in mice treated with either saline or amphetamine. C, Interval locomotor ambulations over $90 \mathrm{~min}$; compare the ambulations following the first injection of amphetamine with those following an amphetamine challenge in withdrawal. Also shown are ambulations in saline-treated mice following a saline challenge. $\boldsymbol{D}$, Interval locomotor ambulations over $90 \mathrm{~min}$ in saline-treated mice that follow an injection of low-dose nicotine, high-dose nicotine, or saline. $\boldsymbol{E}$, Interval locomotor ambulations over $90 \mathrm{~min}$ in amphetamine-treated mice. Ambulations that follow the first injection of amphetamine are compared with ambulations that follow an amphetamine challenge in withdrawal, with and without simultaneous treatment with nicotine in vivo. Low-dose nicotine had little effect on ambulations, whereas the higher dose of nicotine reduced ambulations to those observed during the last daily treatment of amphetamine. $\boldsymbol{F}$, Interval locomotor ambulations over $90 \mathrm{~min}$ in saline-treated mice following an amphetamine challenge, with and without high-dose nicotine. $\mathbf{G}$, Interval locomotor ambulations over $90 \mathrm{~min}$ in amphetamine-treated mice following a challenge with saline or high-dose nicotine are compared to ambulations in saline-treated mice challenged with saline. $\boldsymbol{H}$, In MSNs from saline-treated mice, nicotine in vitro decreased the amplitude of the first eEPSC and increased the PPR. For all panels, $* p<0.05, * * p<0.01$, $* * * p<0.001$, paired $t$ test. $\boldsymbol{I}$, In MSNs from amphetamine-treated mice, nicotine increased the amplitude of the first eEPSC and decreased the PPR.

tain this drug. As this experiment is technically challenging, we then used a within-subject design (Ma et al., 2013), to assess the effect of nicotine on amphetamine-seeking behaviors following abstinence. When combined with the electrophysiological analysis of MSNs and Chls, amphetamine self-administration provides a valuable tool to explore the striatal circuit- and Chl-adaptations induced by contingent drug exposure (Fig. 9).

Chls in the dorsal striatum respond to conditioned sensory stimuli that signal reward delivery and elicit behavioral reactions (Aosaki et al., 1994). Measures of Chl frequencies ex vivo revealed a reduction in tonic $\mathrm{Chl}$ activity from amphetamine self-administering mice. Although having no effect on pausing, an amphetamine challenge following abstinence decreased the frequency of discrete bursts and burstiness, thereby dissociating or uncoupling burst activity from pausing in the absence of DA-releasing stimuli. Nicotine reduced tonic firing, discrete bursts, burstiness, and discrete pauses in Chls from both saline-treated and amphetamine self-administering mice. When nicotine suppressed already low tonic firing in amphetamine self-administering mice, the discrete pauses coalesced into pause strings. As Chls are widely distributed throughout the striatum, the uncoupling of burst and pause activity could serve to modulate the activity of surrounding neurons and mediate rewarding behaviors.

The literature on where these forms of plasticity and their related behaviors occur is unclear. However, much evidence indicates that the circuitry underlying am- 
A

\section{Drug-naive condition}

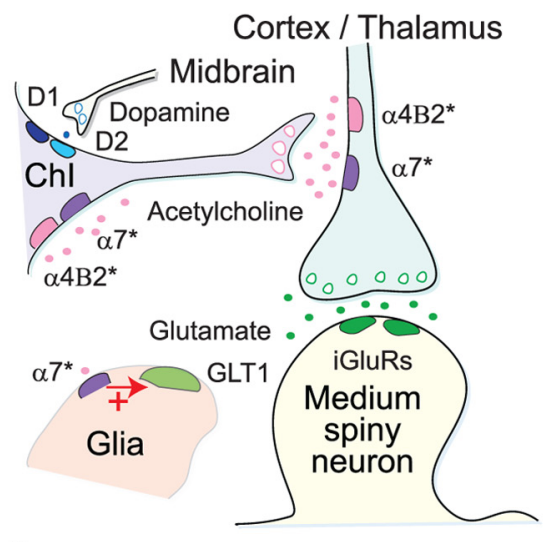

C
B

\section{Synaptic depression during abstinance}

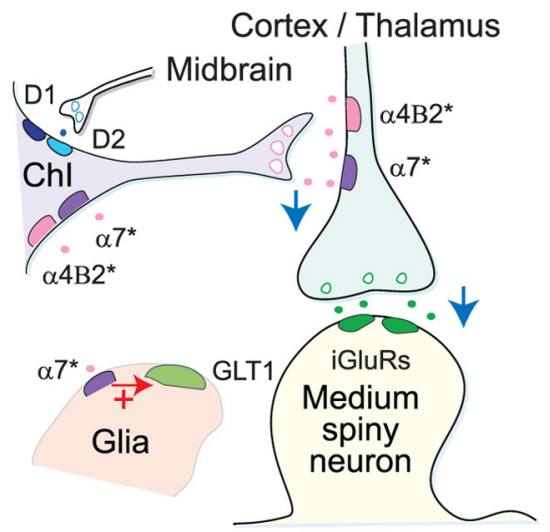

D

Drug cue with nicotine

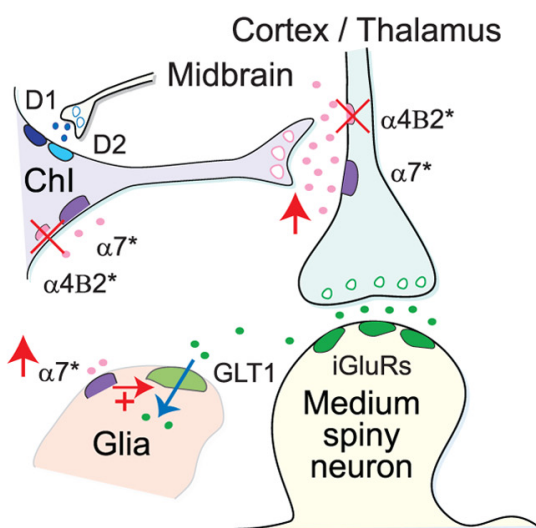

Figure 9. Proposed mechanism for nicotinic modulation of striatal synaptic plasticity following amphetamine self-administration. $\boldsymbol{A}$, The simplified striatal circuit is composed of MSNs, Chls, and glia. Glutamate released from cortical and thalamic afferents excites MSNs through ionotropic glutamate receptors (iGluRs). In the drug naive condition, ACh efflux from Chls binds to excitatory $\alpha 4 \beta 2 *-$ and $\alpha 7 *$-type nicotinic receptors and modulates $\mathrm{Chl}$ firing and glutamate release from corticostriatal terminals (Bamford et al., 2008; Wang et al., 2013a). The glial glutamate transporter (GLT1) limits the access of synaptic glutamate to the extracellular space (Kalivas, 2009). B, Synaptic depression develops during abstinence from repeated amphetamine. Repeated DA release by amphetamine stimulates inhibitory D2-class receptors on Chls (Yan et al., 1997; Wang et al., 2013a). The reduction in tonic excitation at $\alpha 4 \beta 2 *-$ and $\alpha 7$ *-type nicotinic receptors depresses corticostriatal activity. Low tonic levels of ACh are supported during drug withdrawal by nicotinic autoreceptors that lower the set point of Chl firing (Wang et al., 2013a). C, A drug cue promotes transient synaptic potentiation. Because of the lowered set point of Chl activity, DA released by a drug cue stimulates ACh efflux via excitatory D1-class receptors on Chls (Yan and Surmeier, 1997; Wang et al., 2013a). The increase in ACh boosts glutamate release, causing PPP. $\boldsymbol{D}$, Nicotine prevents PPP. The concentration of nicotine achieved in smokers (100 nM) desensitizes excitatory $\alpha 4 \beta 2 *-t y p e$ nicotinic receptors (Dani and Harris, 2005). The lack of nicotinic receptor excitation reduces Chl spiking and corticostriatal activity in the drug naive condition and during abstinence. The drug cue enhances ACh tone but desensitization prevents PPP in response to drug reinstatement. Activation of $\alpha 7 *$-type nicotinic receptors expressed on astrocytes (Pirttimaki et al., 2013) recruit AMPA receptors to glutamatergic terminals (Wang et al., 2013b), have a protective effect on oxidative stress (Liu et al., 2015), and increase activity of GLT1 to clear glutamate from the extracellular space (Kalivas, 2009).

phetamine-induced locomotion is mediated by NAc, whereas stereotypies are mediated by dorsal striatum (Asher and Aghajanian, 1974; Pijnenburg et al., 1976; Segal, 1976; Castall et al., 1977). Furthermore, the development of sensitization is associated with prefrontal cortex and VTA, whereas expression is associated with the prefrontal cortex and the NAc (McFarland and Kalivas, 2001; Kalivas, 2009). The data presented here suggests that the potentiation of locomotor sensitization is also associated with long-term plasticity in the dorsal striatum. The role of Chls in the dorsal striatum has been associated with cue-dependent behaviors and the expression of locomotor responses to repeated amphetamine (Wang et al., 2013a), thus agreeing with the results of our selfadministration studies. Repeated psychostimulant use produces similar forms of glutamatergic plasticity in the 
ventral (Kalivas, 2009) and dorsal striatum (Bamford et al., 2008), suggesting that both structures play a role in the behavioral potentiation seen in locomotor sensitization and self-administration.

Psychostimulant-released DA reduces Chl firing through D2-class DA receptors on Chls (Yan et al., 1997), and the firing rate of Chls remained suppressed following amphetamine self-administration. Data support the hypothesis that a lasting inhibition of Chl activity in withdrawal occurs through a reduction in tonic excitation at autoregulatory receptors, because nicotine reduced spontaneous firing and concentered the spectral signatures in Chls from both saline-treated and amphetamine self-administering mice. Therefore, a decrease in tonic excitation at nicotinic autoreceptors on Chls (Azam et al., 2003) in amphetamine self-administering mice may maintain the depression of $\mathrm{Chl}$ firing in withdrawal.

The differential action of excitatory D1- and inhibitory D2-class DA receptors located on Chls establish a set point for Chl activity (Abercrombie and DeBoer, 1997; Wang et al., 2013a). An amphetamine challenge reduced tonic firing and discrete bursting in Chls from amphetamine naive mice, but increased the already low tonic firing in Chls from amphetamine self-administering mice. Amphetamine regulates $\mathrm{Chl}$ activity through DA receptors on Chls, where the reduction in tonic firing in salinetreated mice occurs through D2 receptors, whereas the excitation during amphetamine withdrawal are generated through heightened responses mediated through D1 receptors (Wang et al., 2013a). Thus, repeated DA release during acquisition followed by abstinence may create a shift in the activity set point of Chls and reverse their response to an amphetamine challenge or to cues paired with the drug. Nicotine suppressed these two divergent DA-dependent changes in Chl activity, suggesting that nicotinic autoreceptors participate in DA-dependent plasticity. Although amphetamine modulated Chl firing at frequencies centered on $1 \mathrm{~Hz}$, nicotine shifted Chl activity toward a pre-existing spectral baseline by modulating frequencies centered on $3 \mathrm{~Hz}$. Nicotine may oppose DAdependent changes in Chl activity by stabilizing membrane potentials required for GABA receptor modulation of Chls (DeBoer and Westerink, 1994) or hyperpolarization-activated cation channels that encode their autonomous firing (Bennett et al., 2000).

Data indicate that Chl firing (and ACh availability) promotes parallel changes in corticostriatal activity. Similar to responses in Chls, amphetamine in vitro reduced corticostriatal activity in saline-treated mice and repeated amphetamine promoted CPD in withdrawal. Nicotine blocked both CPD and amphetamine-induced PPP, signifying that nicotinic receptors are both necessary and sufficient to promote long-lasting corticostriatal plasticity. PPP was absent in nonresponding mice even though they were exposed to small doses of amphetamine in vivo. Although the responses to amphetamine and nicotine were similar to saline-treated mice, nonresponding mice had a much higher frequency of mEPSCs at baseline and consequently, amphetamine produced a robust depression in activity. Future investigations of both the behav- ioral responding to different doses of amphetamine and cellular adaptations will be required to understand the basis of these observations.

Nicotine reduced amphetamine-seeking behaviors and the expression of locomotor sensitization. Although nicotinic receptors are located throughout the brain, nicotine may modify $\mathrm{Chl}$ and corticostriatal activity through $\alpha 4 \beta 2 *-$ and $\alpha 7 *$-type nicotinic receptors that are located on Chls (Azam et al., 2003) and presynaptic corticostriatal terminals (Marchi et al., 2002; Pakkanen et al., 2005). The level of nicotine (100 nM) has been shown to desensitize $\alpha 4 \beta 2 *$-type nicotinic receptors (Lester and Dani, 1995; Wooltorton et al., 2003) and may therefore act to lessen Chl excitation and corticostriatal activity. In saline-treated mice, nicotine reduced corticostriatal excitation caused by synaptic ACh, likely by desensitizing and internalizing excitatory $\alpha 4 \beta 2 *$ receptors (Zhou et al., 2002; Pakkanen et al., 2005). In amphetamine self-administering mice, the decrease in ACh availability may promote CPD by reducing excitation at both $\alpha 4 \beta 2 *-$ and $\alpha 7 *$-type nicotinic receptors, whereas the increase in Chl activity following an amphetamine challenge supports PPP. Nicotine may therefore supplement the low availability of ACh to increase corticostriatal activity, but desensitizes the $\alpha 4 \beta 2 *-$ type nicotinic receptor and prevents PPP when given in combination with amphetamine. Thus, nicotine may offset corticostriatal plasticity by preventing the change in $\mathrm{ACh}$ availability that occurs during the incubation of drugseeking behavior. However, the modulation of $\mathrm{Chl}$ and corticostriatal activity by ACh and nicotine is likely complex and involves a host of nicotine receptor subtypes with different sensitivities and levels of expression.

Increasing evidence suggests that $\mathrm{Chl}$ firing and ACh availability promote an imbalance in glutamate release from corticostriatal terminals (Bamford et al., 2008; Wang et al., 2013a) to produce motor and neuropsychological symptoms of drug dependence (Robinson and Camp, 1987; Kalivas, 2009). Although psychostimulant-releasing DA reduces $\mathrm{Chl}$ and corticostriatal activity in amphetamine naive mice, the increase in DA and ACh availability following a drug challenge in sensitized mice promotes a PPP of corticostriatal activity that correlates with the increase in locomotor activity and promotes sensitization by specifically activating D1R-expressing MSNs (Gass and Olive, 2008; Wang et al., 2013a). Together, CPD and PPP provide a mechanism by which a drug challenge promotes locomotor sensitization and allostasis (Ahmed and Koob, 2005). The much higher basal level of corticostriatal activity in nonresponding mice may provide some protection against PPP, because an amphetamine challenge reduced the frequency of mEPSCs to that found in saline-treated mice.

These data extend to observations of cocaine-induced glutamatergic neuroadaptations, where drug withdrawal and reinstatement accompany a reversible reduction in extracellular (Kalivas, 2009) and synaptic glutamate (Kozell and Meshul, 2003). Sensitization models of incentive salience (Robinson and Camp, 1987) suggest that a supra-physiological glutamatergic drive promotes compulsive drug-seeking in addicts by decreasing the value of 
natural rewards (Kalivas, 2009). While demonstrating that CPD and PPP play key roles in sensitization, these experiments show that alterations in ACh may overlap with the plasticity and learning associated with self-administration and incubation. Thus, DA modulation of ACh release may provide a set point for glutamate availability (Ahmed and Koob, 2005) that extends to the escalation of drug intake (Hansen and Mark, 2007).

Chls appear to support motor coordination, cognitive flexibility, and locomotion through ACh interactions with striatal projection neurons (Bamford et al., 2008; Witten et al., 2010; Wang et al., 2013a). Because DA provokes state changes in corticostriatal activity, our findings may explain how salient experiences encode behaviors and automatic movements. Changes in ACh and glutamate availability are promoted by repeated DA release. Our findings are consistent with human trials, which demonstrate that nicotinic receptors and changes in glutamate transmission participate in the pathogenesis of many neuropsychological disorders (Mihailescu and Drucker-Colín , 2000; Gass and Olive, 2008), including Parkinson's disease where nicotinic receptor ligands prevent the disruption of striatal and cholinergic activity following DA depletion (Quik, 2004). Similarly, therapeutic approaches using nicotinic receptor ligands that prevent PPP may facilitate the extinction of drug seeking behavior. If provided during the process of sensitization, these drugs would prevent CPD and disrupt the reinforcing effects of drugs in addicts (Gass and Olive, 2008; Reissner and Kalivas, 2010). Together, these observations suggest the need for additional circuit-level and behavioral experiments in conjunction with epidemiological studies to determine whether pharmacological targeting of nicotinic receptors can modify the development of drug seeking and reduce relapse.

\section{References}

Abercrombie ED, DeBoer P (1997) Substantia nigra D1 receptors and stimulation of striatal cholinergic interneurons by dopamine: a proposed circuit mechanism. J Neurosci 17:8498-8505. Medline

Ahmed SH, Koob GF (2005) Transition to drug addiction: a negative reinforcement model based on an allostatic decrease in reward function. Psychopharmacology (Berl) 180:473-490. CrossRef Medline

Aosaki T, Tsubokawa H, Ishida A, Watanabe K, Graybiel AM, Kimura M (1994) Responses of tonically active neurons in the primate's striatum undergo systematic changes during behavioral sensorimotor conditioning. J Neurosci 14:3969-3984. Medline

Asher IM, Aghajanian GK (1974) 6-Hydroxydopamine lesions of olfactory tubercles and caudate nuclei: effect on amphetamineinduced stereotyped behavior in rats. Brain Res 82:1-12. Medline

Azam L, Winzer-Serhan U, Leslie FM (2003) Co-expression of alpha7 and beta2 nicotinic acetylcholine receptor subunit mRNAs within rat brain cholinergic neurons. Neuroscience 119:965-977. Medline

Bair W, Koch C, Newsome W, Britten K (1994) Power spectrum analysis of bursting cells in area MT in the behaving monkey. $J$ Neurosci 14:2870-2892. Medline

Bamford NS, Robinson S, Palmiter RD, Joyce JA, Moore C, Meshul CK (2004a) Dopamine modulates release from corticostriatal terminals. J Neurosci 24:9541-9552. CrossRef Medline

Bamford NS, Zhang H, Schmitz Y, Wu NP, Cepeda C, Levine MS, Schmauss C, Zakharenko SS, Zablow L, Sulzer D (2004b) Heterosynaptic dopamine neurotransmission selects sets of corticostriatal terminals. Neuron 42:653-663. Medline
Bamford NS, Zhang H, Joyce JA, Scarlis CA, Hanan W, Wu NP, André VM, Cohen R, Cepeda C, Levine MS, Harleton E, Sulzer D (2008) Repeated exposure to methamphetamine causes longlasting presynaptic corticostriatal depression that is renormalized with drug readministration. Neuron 58:89-103. CrossRef Medline

Benhamou L, Kehat O, Cohen D (2014) Firing pattern characteristics of tonically active neurons in rat striatum: context dependent or species divergent? J Neurosci 34:2299-2304. CrossRef Medline

Bennett BD, Wilson CJ (1999) Spontaneous activity of neostriatal cholinergic interneurons in vitro. J Neurosci 19:5586-5596. Medline

Bennett BD, Callaway JC, Wilson CJ (2000) Intrinsic membrane properties underlying spontaneous tonic firing in neostriatal cholinergic interneurons. J Neurosci 20:8493-8503. Medline

Bertran-Gonzalez J, Laurent V, Chieng BC, Christie MJ, Balleine BW (2013) Learning-related translocation of $\delta$-opioid receptors on ventral striatal cholinergic interneurons mediates choice between goal-directed actions. J Neurosci 33:16060-16071. CrossRef Medline

Bickerdike MJ, Abercrombie ED (1997) Striatal acetylcholine release correlates with behavioral sensitization in rats withdrawn from chronic amphetamine. J Pharmacol Exp Ther 282:818-826. Medline

Bickerdike MJ, Abercrombie ED (1999) Enhanced acetylcholine release in striatum after chronic amphetamine is NMDA-dependent. Neuroreport 10:77-80. Medline

Bradfield LA, Bertran-Gonzalez J, Chieng B, Balleine BW (2013) The thalamostriatal pathway and cholinergic control of goal-directed action: interlacing new with existing learning in the striatum. Neuron 79:153-166. CrossRef Medline

Branch SY, Goertz RB, Sharpe AL, Pierce J, Roy S, Ko D, Paladini CA, Beckstead MJ (2013) Food restriction increases glutamate receptor-mediated burst firing of dopamine neurons. J Neurosci 33:13861-13872. CrossRef Medline

Calabresi P, Centonze D, Gubellini P, Pisani A, Bernardi G (2000) Acetylcholine-mediated modulation of striatal function. Trends Neurosci 23:120-126. Medline

Castall B, Marsden CD, Naylor RJ, Pycock CJ (1977) Stereotyped behaviour patterns and hyperactivity induced by amphetamine and apomorphine after discrete 6-hydroxydopamine lesions of extrapyramidal and mesolimbic nuclei. Brain Res 123:89-111. Medline

Chuhma N, Mingote S, Moore H, Rayport S (2014) Dopamine neurons control striatal cholinergic neurons via regionally heterogeneous dopamine and glutamate signaling. Neuron 81:901-912. CrossRef Medline

Chuhma N, Zhang H, Masson J, Zhuang X, Sulzer D, Hen R, Rayport $S$ (2004) Dopamine neurons mediate a fast excitatory signal via their glutamatergic synapses. J Neurosci 24:972-981. CrossRef Medline

Cui Y, Ostlund SB, James AS, Park CS, Ge W, Roberts KW, Mittal N, Murphy NP, Cepeda C, Kieffer BL, Levine MS, Jentsch JD, Walwyn WM, Sun YE, Evans CJ, Maidment NT, Yang XW (2014) Targeted expression of $\mu$-opioid receptors in a subset of striatal direct-pathway neurons restores opiate reward. Nat Neurosci 17: 254-261. CrossRef

Dani JA, Harris RA (2005) Nicotine addiction and comorbidity with alcohol abuse and mental illness. Nat Neurosci 8:1465-1470. CrossRef Medline

DeBoer P, Westerink BH (1994) GABAergic modulation of striatal cholinergic interneurons: an in vivo microdialysis study. J Neurochem 62:70-75. Medline

Everitt BJ, Robbins TW (2005) Neural systems of reinforcement for drug addiction: from actions to habits to compulsion. Nat Neurosci 8:1481-1489. CrossRef Medline

Everitt BJ, Robbins TW (2015) Drug addiction: updating actions to habits to compulsions ten years on. Annu Rev Psychol 67:23-50. CrossRef Medline 
Flores-Hernández J, Galarraga E, Bargas J (1997) Dopamine selects glutamatergic inputs to neostriatal neurons. Synapse 25:185-195. CrossRef Medline

Gass JT, Olive MF (2008) Glutamatergic substrates of drug addiction and alcoholism. Biochem Pharmacol 75:218-265. CrossRef Medline

Gonzales KK, Smith Y (2015) Cholinergic interneurons in the dorsal and ventral striatum: anatomical and functional considerations in normal and diseased conditions. Ann N Y Acad Sci 1349:1-45. CrossRef Medline

Graybiel AM, Aosaki T, Flaherty AW, Kimura M (1994) The basal ganglia and adaptive motor control. Science 265:1826-1831. Medline

Hansen ST, Mark GP (2007) The nicotinic acetylcholine receptor antagonist mecamylamine prevents escalation of cocaine selfadministration in rats with extended daily access. Psychopharmacology (Berl) 194:53-61. CrossRef Medline

Hiranita T, Nawata Y, Sakimura K, Anggadiredja K, Yamamoto T (2006) Suppression of methamphetamine-seeking behavior by nicotinic agonists. Proc Natl Acad Sci U S A 103:8523-8527. CrossRef Medline

Jokinen H, Ollila J, Aumala O (2000) On windowing effects in estimating averaged periodograms of noisy signals. Measurement 28:197-207. CrossRef

Joshi PR, Wu NP, André VM, Cummings DM, Cepeda C, Joyce JA, Carroll JB, Leavitt BR, Hayden MR, Levine MS, Bamford NS (2009) Age-dependent alterations of corticostriatal activity in the YAC128 mouse model of Huntington disease. J Neurosci 29:2414-2427. CrossRef Medline

Kalivas PW (2009) The glutamate homeostasis hypothesis of addiction. Nat Rev Neurosci 10:561-572. CrossRef Medline

Ko D, Wilson CJ, Lobb CJ, Paladini CA (2012) Detection of bursts and pauses in spike trains. J Neurosci Methods 211:145-158. CrossRef Medline

Kozell B, Meshul K (2003) Alterations in nerve terminal glutamate immunoreactivity in the nucleus accumbens and ventral tegmental area following single and repeated doses of cocaine. Psychopharmacology (Berl) 165:337-345. CrossRef Medline

Legéndy CR, Salcman M (1985) Bursts and recurrences of bursts in the spike trains of spontaneously active striate cortex neurons. J Neurophysiol 53:926-939. Medline

Lester RA, Dani JA (1995) Acetylcholine receptor desensitization induced by nicotine in rat medial habenula neurons. J Neurophysiol 74:195-206. Medline

Li H, Bu Q, Chen B, Shao X, Hu Z, Deng P, Lv L, Deng Y, Zhu R, Li Y, Zhang B, Hou J, Du C, Zhao Q, Fu D, Zhao Y, Cen X (2014) Mechanisms of metabonomic for a gateway drug: nicotine priming enhances behavioral response to cocaine with modification in energy metabolism and neurotransmitter level. PLoS One 9:e87040. CrossRef Medline

Liu Y, Zeng X, Hui Y, Zhu C, Wu J, Taylor DH, Ji J, Fan W, Huang Z, $\mathrm{Hu} \mathrm{J}$ (2015) Activation of $\alpha 7$ nicotinic acetylcholine receptors protects astrocytes against oxidative stress-induced apoptosis: implications for Parkinson's disease. Neuropharmacology 91:8796. CrossRef Medline

Lobb C (2014) Abnormal bursting as a pathophysiological mechanism in Parkinson's disease. Basal Ganglia 3:187-195. CrossRef Medline

Lobb CJ, Jaeger D (2015) Bursting activity of substantia nigra pars reticulata neurons in mouse parkinsonism in awake and anesthetized states. Neurobiol Dis 75:177-185. CrossRef Medline

Ma YY, Henley SM, Toll J, Jentsch D, Evans CJ, Levine MS, Cepeda C (2013) Drug-primed reinstatement of cocaine seeking in mice: increased excitability of medium-sized spiny neurons in the nucleus accumbens. ASN Neuro 5:257-271.

Marchi M, Risso F, Viola C, Cavazzani P, Raiteri M (2002) Direct evidence that release-stimulating alpha7* nicotinic cholinergic receptors are localized on human and rat brain glutamatergic axon terminals. J Neurochem 80:1071-1078. Medline
Maurice N, Mercer J, Chan CS, Hernandez-Lopez S, Held J, Tkatch T, Surmeier DJ (2004) D2 dopamine receptor-mediated modulation of voltage-dependent $\mathrm{Na}+$ channels reduces autonomous activity in striatal cholinergic interneurons. J Neurosci 24:1028910301. CrossRef Medline

McFarland K, Kalivas PW (2001) The circuitry mediating cocaineinduced reinstatement of drug-seeking behavior. J Neurosci 21: 8655-8663. Medline

McFarland K, Lapish CC, Kalivas PW (2003) Prefrontal glutamate release into the core of the nucleus accumbens mediates cocaineinduced reinstatement of drug-seeking behavior. J Neurosci 23: 3531-3537. Medline

McGehee DS, Heath MJ, Gelber S, Devay P, Role LW (1995) Nicotine enhancement of fast excitatory synaptic transmission in CNS by presynaptic receptors. Science 269:1692-1696. Medline

Mello NK, Fivel PA, Kohut SJ, Carroll FI (2014) Effects of chronic varenicline treatment on nicotine, cocaine, and concurrent nicotine + cocaine self-administration. Neuropsychopharmacology 39:1222-1231. CrossRef Medline

Mihailescu S, Drucker-Colín R (2000) Nicotine, brain nicotinic receptors, and neuropsychiatric disorders. Arch Med Res 31:131-144. Medline

Nelson CL, Milovanovic M, Wetter JB, Ford KA, Wolf ME (2009) Behavioral sensitization to amphetamine is not accompanied by changes in glutamate receptor surface expression in the rat nucleus accumbens. J Neurochem 109:35-51. CrossRef

Neugebauer NM, Harrod SB, Bardo MT (2010) Nicotine elicits methamphetamine-seeking in rats previously administered nicotine. Drug Alcohol Depend 106:72-78. CrossRef Medline

Pakkanen JS, Jokitalo E, Tuominen RK (2005) Up-regulation of beta2 and alpha7 subunit containing nicotinic acetylcholine receptors in mouse striatum at cellular level. Eur J Neurosci 21:2681-2691. CrossRef Medline

Pierce RC, Bell K, Duffy P, Kalivas PW (1996) Repeated cocaine augments excitatory amino acid transmission in the nucleus accumbens only in rats having developed behavioral sensitization. $J$ Neurosci 16:1550-1560. Medline

Pijnenburg AJ, Honig WM, Van der Heyden JA, Van Rossum JM (1976) Effects of chemical stimulation of the mesolimbic dopamine system upon locomotor activity. Eur J Pharmacol 35:45-58. CrossRef Medline

Pipkin JA, Kaplan GJ, Plant CP, Eaton SE, Gil SM, Zavala AR, Crawford CA (2014) Nicotine exposure beginning in adolescence enhances the acquisition of methamphetamine self-administration, but not methamphetamine-primed reinstatement in male rats. Drug Alcohol Depend 142:341-344. CrossRef Medline

Pirttimaki TM, Codadu NK, Awni A, Pratik P, Nagel DA, Hill EJ, Dineley KT, Parri HR (2013) $\alpha 7$ Nicotinic receptor-mediated astrocytic gliotransmitter release: $A \beta$ effects in a preclinical Alzheimer's mouse model. PLoS One 8:e81828.

Quik M (2004) Smoking, nicotine and Parkinson's disease. Trends Neurosci 27:561-568. CrossRef Medline

Quintana A, Sanz E, Wang W, Storey GP, Güler AD, Wanat MJ, Roller BA, La Torre A, Amieux PS, McKnight GS, Bamford NS, Palmiter RD (2012) Lack of GPR88 enhances medium spiny neuron activity and alters motor- and cue-dependent behaviors. Nat Neurosci 15:1547-1555. CrossRef Medline

Rahman S (2013) Nicotinic receptors as therapeutic targets for drug addictive disorders. CNS Neurol Disord Drug Targets 12:633-640. Medline

Reissner KJ, Kalivas PW (2010) Using glutamate homeostasis as a target for treating addictive disorders. Behav Pharmacol 21:514522. CrossRef Medline

Robinson TE, Camp DM (1987) Long-lasting effects of escalating doses of d-amphetamine on brain monoamines, amphetamineinduced stereotyped behavior and spontaneous nocturnal locomotion. Pharmacol Biochem Behav 26:821-827. Medline

Segal DS (1976) Differential effects of para-chlorophenylalanine on amphetamine-induced locomotion and stereotypy. Brain Res 116: 267-276. Medline 
Shepard JD, Bossert JM, Liu SY, Shaham Y (2004) The anxiogenic drug yohimbine reinstates methamphetamine seeking in a rat model of drug relapse. Biol Psychiatry 55:1082-1089. CrossRef Medline

St-Pierre F, Marshall JD, Yang Y, Gong Y, Schnitzer MJ, Lin MZ (2014) High-fidelity optical reporting of neuronal electrical activity with an ultrafast fluorescent voltage sensor. Nat Neurosci 17:884889. CrossRef Medline

Sulzer D (2011) How addictive drugs disrupt presynaptic dopamine neurotransmission. Neuron 69:628-649. CrossRef Medline

Thomsen M, Caine SB (2005) Chronic intravenous drug selfadministration in rats and mice. Curr Protoc Neurosci Chapter9: Unit 9.20

Threlfell S, Cragg SJ (2011) Dopamine signaling in dorsal versus ventral striatum: the dynamic role of cholinergic interneurons. Front Syst Neurosci 5:11. CrossRef Medline

Van der Kloot W (1991) The regulation of quantal size. Prog Neurobiol 36:93-130. Medline

Verrico CD, Mahoney JJ 3rd, Thompson-Lake DG, Bennett RS, Newton TF, De La Garza R 2nd (2014) Safety and efficacy of varenicline to reduce positive subjective effects produced by methamphetamine in methamphetamine-dependent volunteers. Int J Neuropsychopharmacol 17:223-233. CrossRef

Wang W, Darvas M, Storey GP, Bamford IJ, Gibbs JT, Palmiter RD, Bamford NS (2013a) Acetylcholine encodes long-lasting presynaptic plasticity at glutamatergic synapses in the dorsal striatum after repeated amphetamine exposure. J Neurosci 33:1040510426. CrossRef Medline

Wang X, Lippi G, Carlson DM, Berg DK (2013b) Activation of $\alpha$-containing nicotinic receptors on astrocytes triggers AMPA receptor recruitment to glutamatergic synapses. J Neurochem 127: 632-643. CrossRef Medline

Welch PD (1967) The use of fast Fourier transform for the estimation of power spectra: a method based on time averaging over short, modified periodograms. IEEE Trans Audio Electroacoust 15:7073. CrossRef

Wickramarachi P (2003) Effects of windowing on the spectral content of a signal. Sound Vibration 37:10-13.

Wilson CJ, Chang HT, Kitai ST (1990) Firing patterns and synaptic potentials of identified giant aspiny interneurons in the rat neostriatum. J Neurosci 10:508-519. Medline

Witten IB, Lin SC, Brodsky M, Prakash R, Diester I, Anikeeva P, Gradinaru V, Ramakrishnan C, Deisseroth K (2010) Cholinergic interneurons control local circuit activity and cocaine conditioning. Science 330:1677-1681. CrossRef Medline

Wooltorton JR, Pidoplichko VI, Broide RS, Dani JA (2003) Differential desensitization and distribution of nicotinic acetylcholine receptor subtypes in midbrain dopamine areas. J Neurosci 23:3176-3185.

Yan Z, Surmeier DJ (1997) D5 dopamine receptors enhance Zn2 +sensitive $\operatorname{GABA}(A)$ currents in striatal cholinergic interneurons through a PKA/PP1 cascade. Neuron 19:1115-1126. Medline

Yan Z, Song WJ, Surmeier J (1997) D2 dopamine receptors reduce $\mathrm{N}$-type $\mathrm{Ca} 2+$ currents in rat neostriatal cholinergic interneurons through a membrane-delimited, protein-kinase-C-insensitive pathway. J Neurophysiol 77:1003-1015. Medline

Yin HH, Knowlton BJ, Balleine BW (2004) Lesions of dorsolateral striatum preserve outcome expectancy but disrupt habit formation in instrumental learning. Eur J Neurosci 19:181-189. Medline

Zhang H, Sulzer D (2004) Frequency-dependent modulation of dopamine release by nicotine. Nat Neurosci 7:581-582. CrossRef Medline

Zhou FM, Liang Y, Dani JA (2001) Endogenous nicotinic cholinergic activity regulates dopamine release in the striatum. Nat Neurosci 4:1224-1229. CrossRef Medline

Zhou FM, Wilson CJ, Dani JA (2002) Cholinergic interneuron characteristics and nicotinic properties in the striatum. J Neurobiol 53:590-605. CrossRef Medline 